\title{
TOITŪ TE MANA RANGATAHI: MARAE-BASED YOUTH COURTS - NEGOTIATING PATHWAYS FOR RANGATAHI OFFENDING
}

HAIMONA HONE HIKI-TIA-TE-RANGI WAITITI

2012 


\section{TOITŪ TE MANA RANGATAHI: MARAE-BASED \\ YOUTH COURTS: NEGOTIATING PATHWAYS FOR RANGATAHI OFFENDING}

By Haimona Hone Hiki-Tia-Te-Rangi Waititi

A thesis submitted to the Victoria

University of Wellington in fulfilment of the requirements for the degree of Masters of Science in Psychology

Victoria University of Wellington

2012 


\begin{abstract}
The Aotearoa/New Zealand Government has a disposition to spend tax payer's money on prisons. The way in which our current legal system is structured, subsequent Governments are going to have to do the same. Māori make up a disproportionate number of those in prison. Recent times have seen the establishment of an initiative aimed at reducing youth crime rates such as Restorative Justice and Marae-Based Youth Courts (MBYC). This study explores how well these new initiatives offered by the youth justice system provide for the needs of youth and community. The specific aim of this study is to analyse the MBYC from the perspective of rangatahi, lay advocates and Kaumātua (honoured elders). The purpose of this is to better understand the processes that rangatahi (Māori youth) went through when they came into contact with the criminal justice system and how cultural philosophies may better inform this process, so that improved outcomes may be achieved for these rangatahi. This research was conducted under a Kaupapa Māori methodology. A series of 3 individual interviews and 3 focus group interviews were conducted (participant total 11) with the three demographic groups. Interviews were later transcribed and analysed using thematic analysis. Four major themes were identified from the analysis. These were; Tā te ture ki te Rangatahi (law as it pertains to the rangatahi), whakamā, Te Wairuatanga o te Marae (the spirituality of the Marae) and Potentiality of the Lay Advocate Role. All four major themes had a set of subordinate themes directly related to them. It was found that the adversarial nature of the youth justice system was having a negative impact on rangatahi and was inhibiting their ability to experience the feelings of remorse and accountability that the process is designed to induce. The restorative justice parts of the system showed more promise but were also falling short of the outcomes they set for themselves. Encouraging results were seen in relation to the MBYC. However, the transplanting of the adversarial court system on to the marae warranted concerns over the domination of this institution over the marae.
\end{abstract}




\section{ACKNOWLEDGEMENTS}

He mihi maioha, he mihi aroha, he mihi matakuikui ki a koutou i whai wā ki te whakatakoto kōrero mō tēnei kaupapa. Ki te kore ko koutou, kua kore rawa tēnei kaupapa e whai kiko. Nō reira, e kore rawa ngā mihi e mutu. Heoi, ki a koutou ma ngā tangata i awhi mai i ahau ki te kimi kimi kai kōrero mō tēnei kaupapa anō nei ngā mihi ki a koutou. Kāti, ki ngā mana whēnua o Tūranga-nui-a-Kiwa, ngā maunga tipua, ngā awa e tere tere nei o te Tai Rawhiti, tae noa atu Te Poho o Rawiri Marae, nei ra te maioha mō tōu manaaki mai i tōu mokopuna.

I would firstly like to acknowledge the participants and the communities for being a part of my research. I am greatly thankful for their patients, co-operation and the sharing of their experiences during this research. I hope this research can highlight the need for change and direct our rangatahi onto the right pathways for them.

I thank my supervisor Jim (James) Liu for the continuous support and advice during this long journey. Completing this research away from the University was a huge challenge but with Jim's endless support and words of wisdom I was eventually able to get through.

I would also like to give thanks to two members of the Māori \& Psychology Research Unit at Waikato University, Linda Nikora for her initial support of my kaupapa and Mohi Rua for opening my eyes to the way of technology and how it can make your life much easier when writing a thesis.

To my fellow Psychology friends (the three musketeers), Arama Rata, Awanui Te Huia and Pania Lee: I want to say a huge thank you for all your support and feedback. Your insightful opinions have helped my development not only as an academic but more importantly as a Māori academic in the field of psychology.

Finally I would like to thank my whānau. I am grateful for all the support you have given me during this journey. Thank you to my pāpā and mother, John and Judy Waititi for supporting, loving and nurturing me. Your life experiences alone are truly inspirational and it is through your example, strength and aroha that I have learnt to approach life in a positive way. To Terri Hohneck, Kahu Waititi and Shem Murray my other whānau members who have also supported me, ngā mihi ki a koutou. 
I dedicate this thesis to Aunty Nuki and Uncle Ned who both passed away this year. Moe mai ra kōrua i roto i ngā ringa o te Atua. Mā te Atua kōrua e manaki, e tiaki. 


\section{CONTENTS}

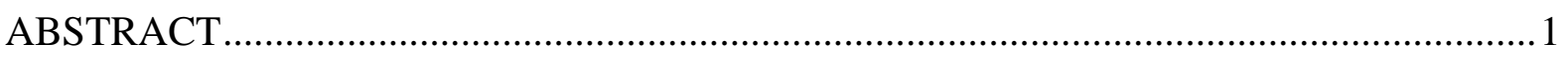

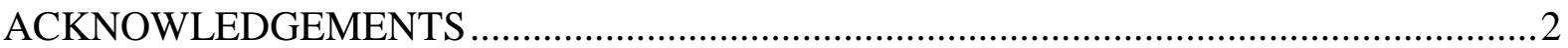

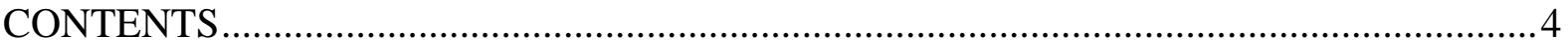

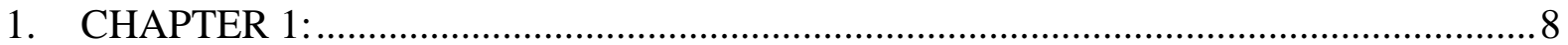

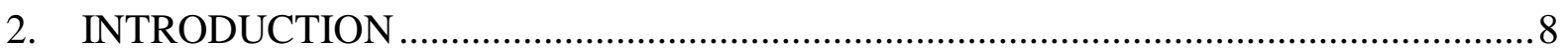

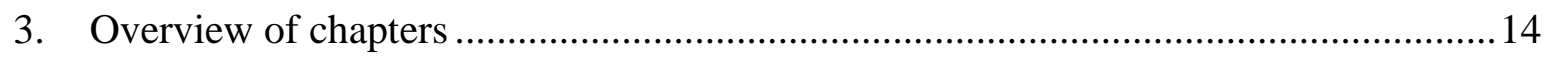

4. Chapter 2: Māori Methods of Dispute Resolution and Restorative Justice ............... 14

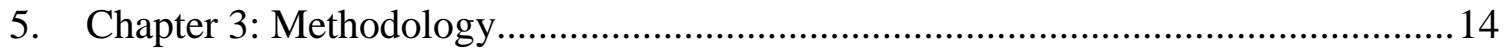

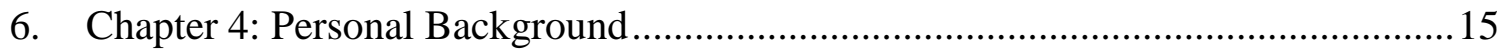

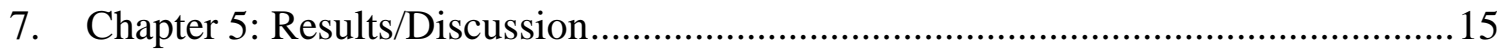

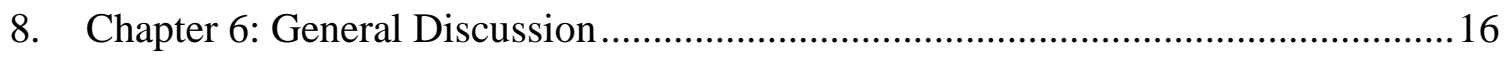

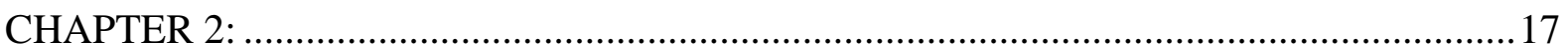

MĀORI METHODS OF DISPUTE RESOLUTION AND RESTORATIVE JUSTICE........17

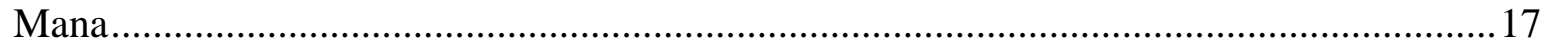

Tарu

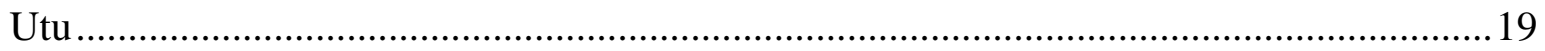

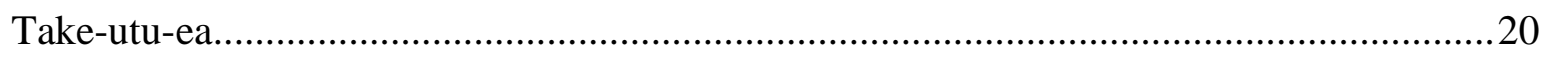

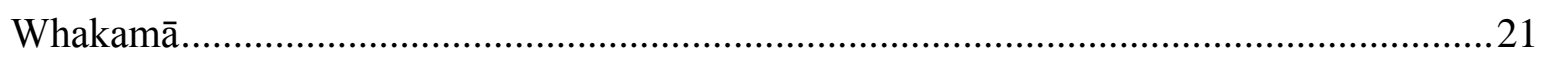

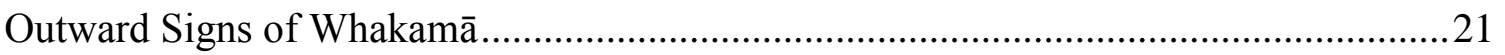

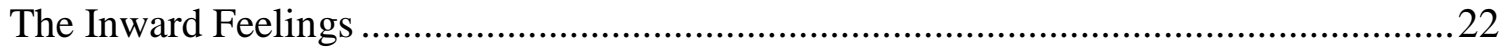

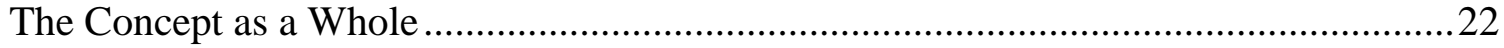

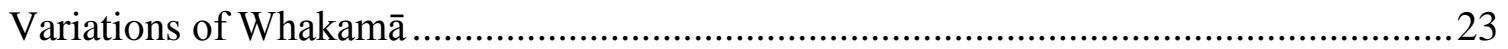

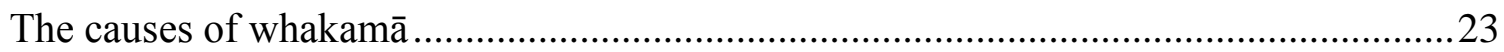

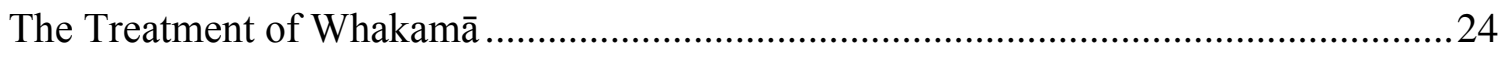

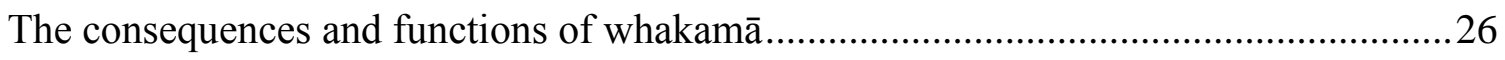

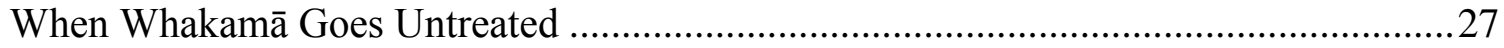

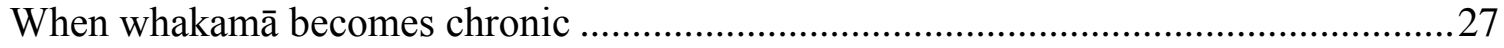

Do Young People Get Whakamā Today?.......................................................................28

Whakamā in Māori-Pākehā Relations ...................................................................... 28

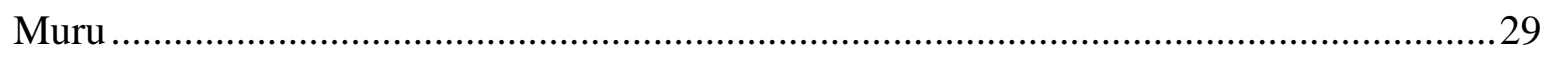

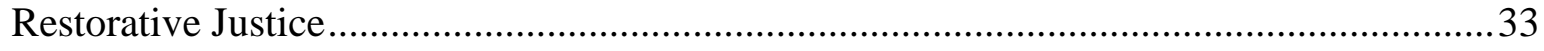


Conclusion .36

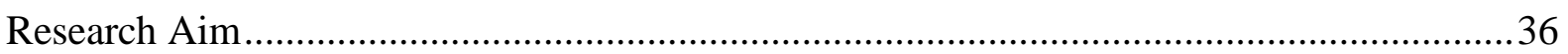

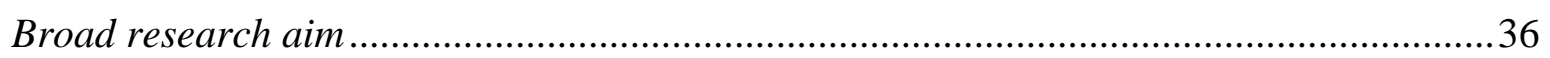

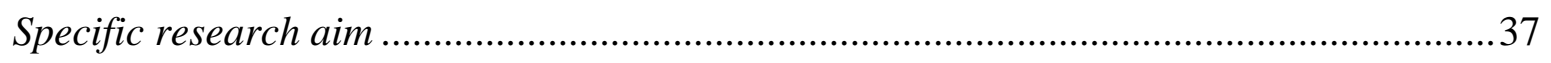

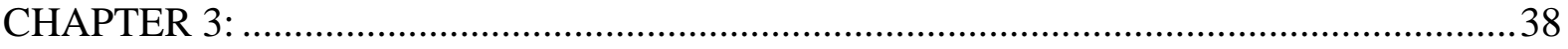

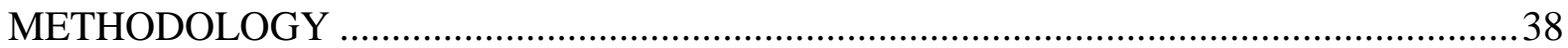

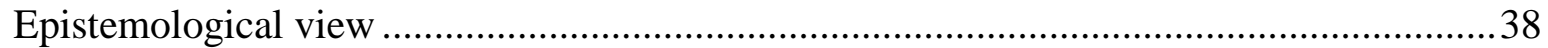

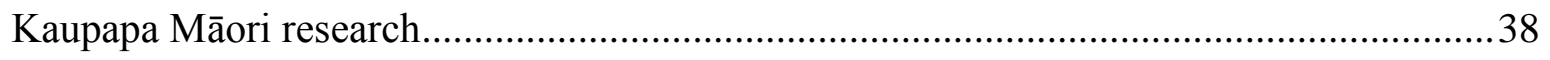

Emergence of Kaupapa Māori methodology ............................................................. 40

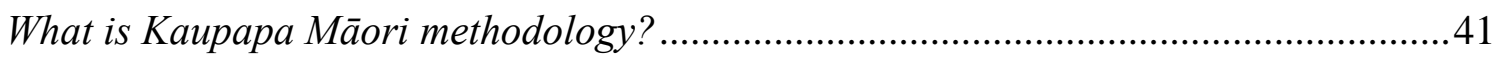

Fundamental Principles of Kaupapa Māori Methodologies ............................................42

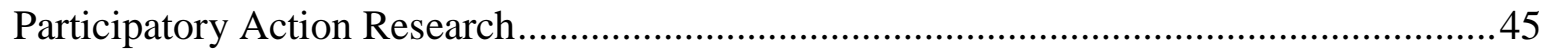

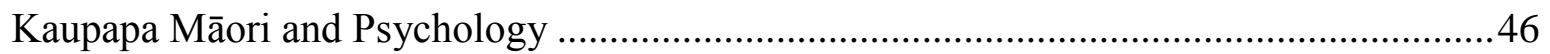

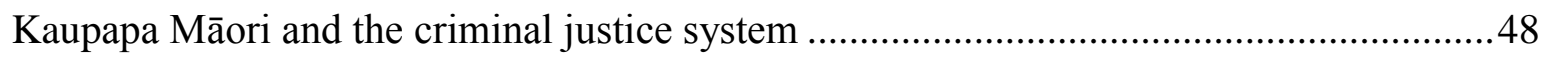

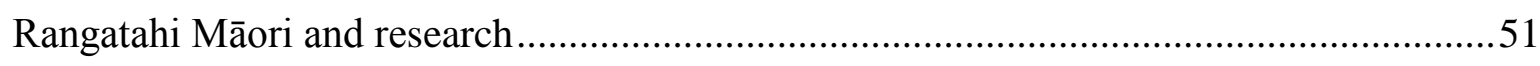

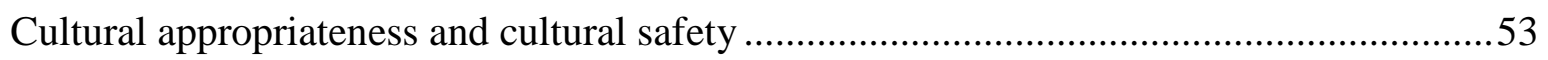

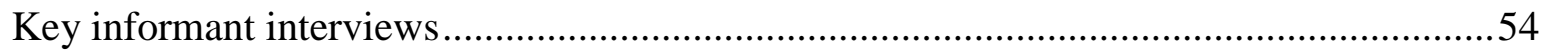

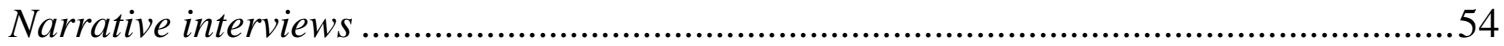

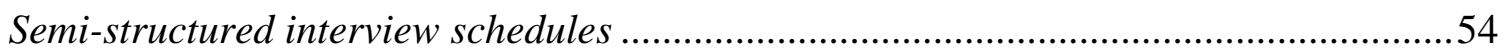

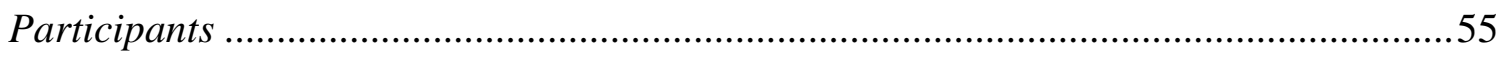

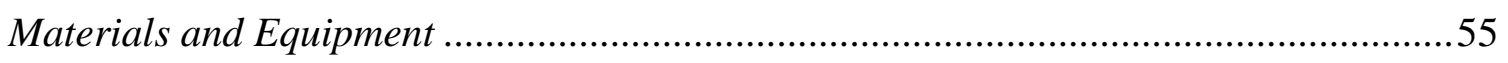

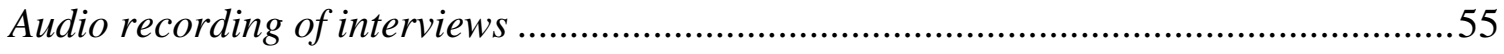

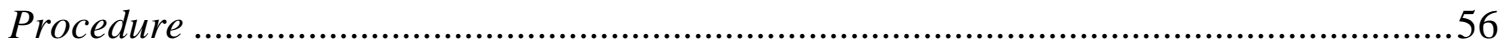

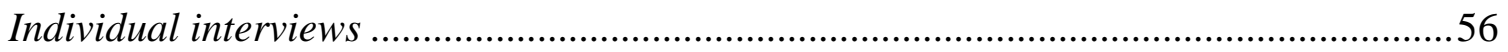

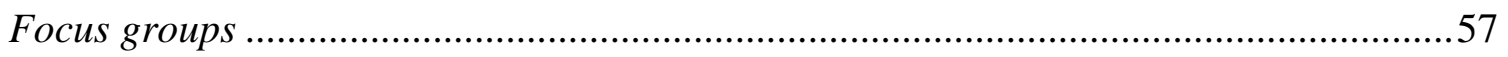

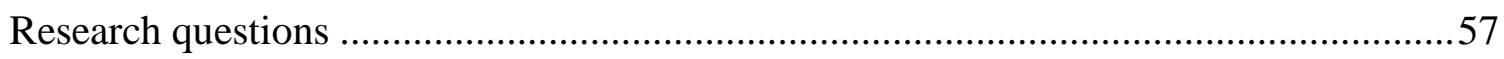

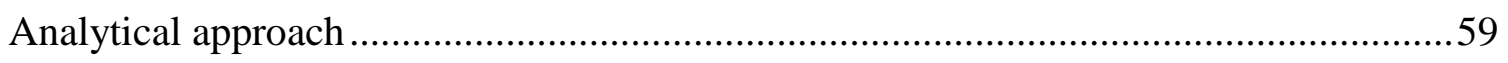

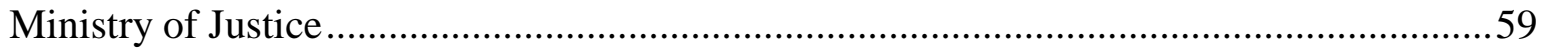

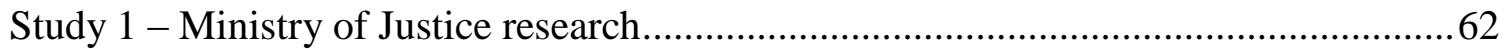

Study Two - Participant Observations: My research...................................................66

A comparison between Ministry of Justice research and my own research: Concluding

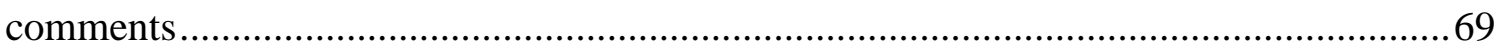

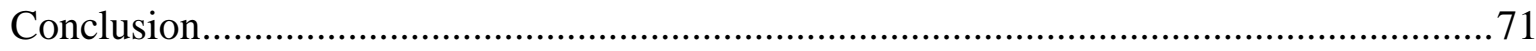

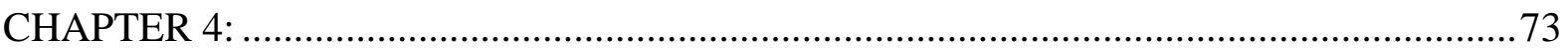




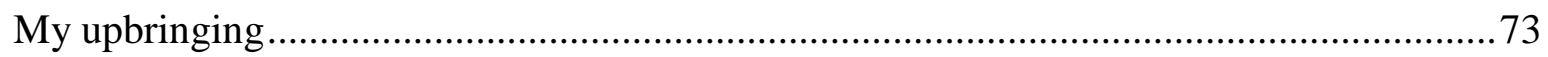

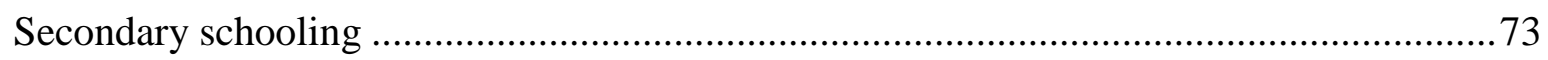

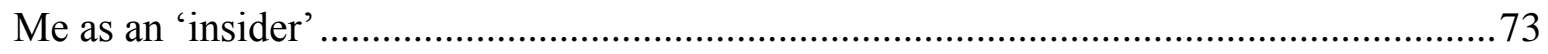

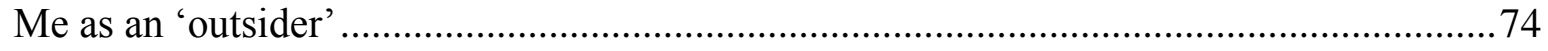

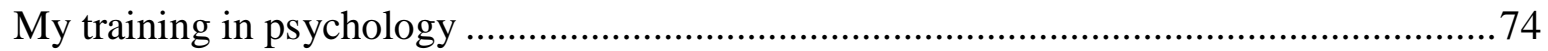

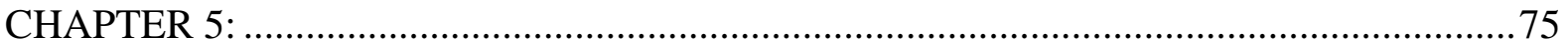

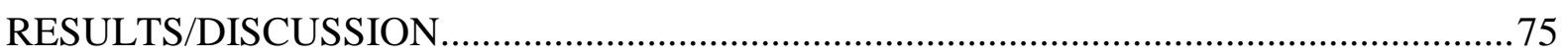

Tā te ture ki te rangatahi (Law as it pertains to the Rangatahi) ........................................ 75

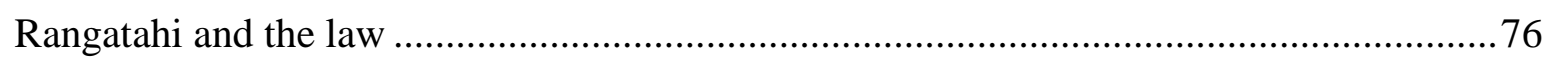

Rangatahi and the Marae-Based Youth Court (MBYC) …............................................. 77

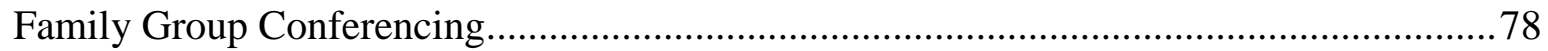

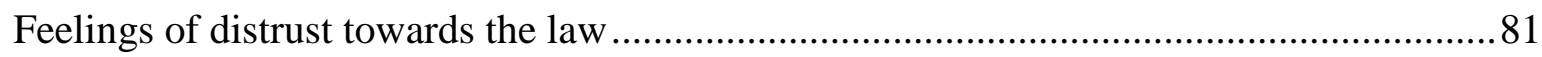

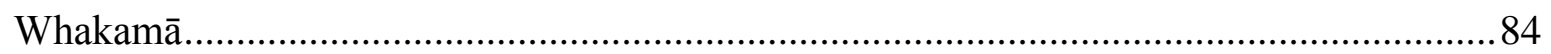

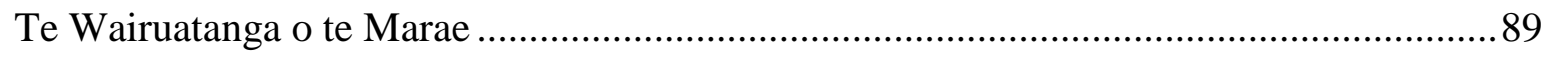

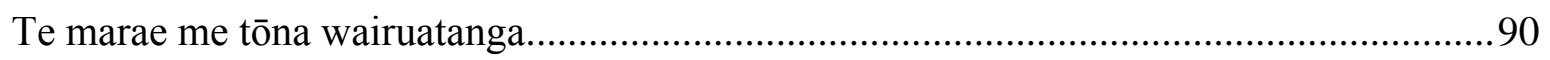

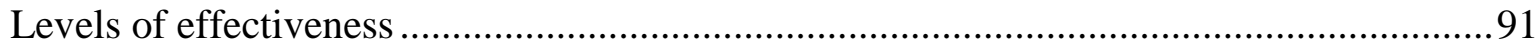

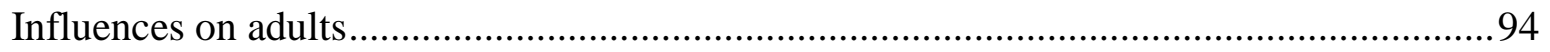

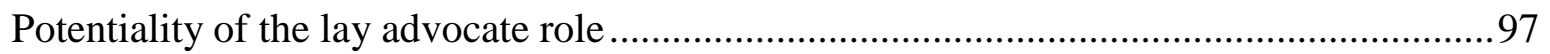

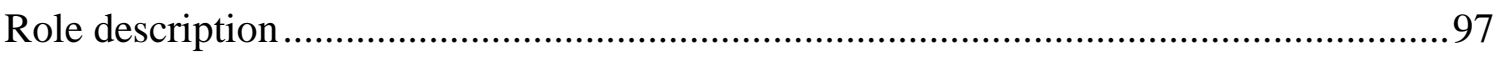

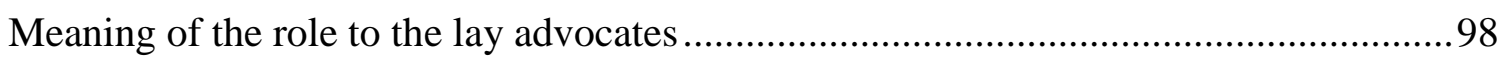

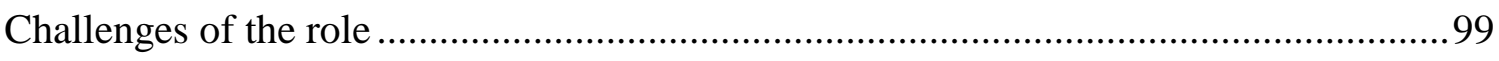

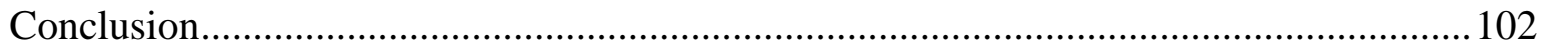

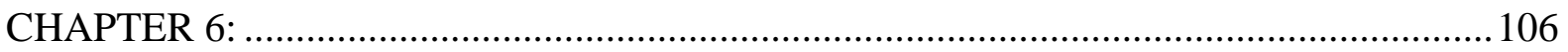

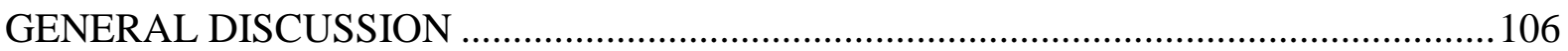

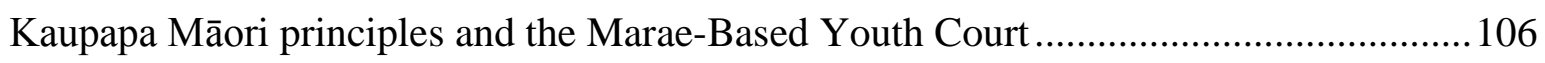

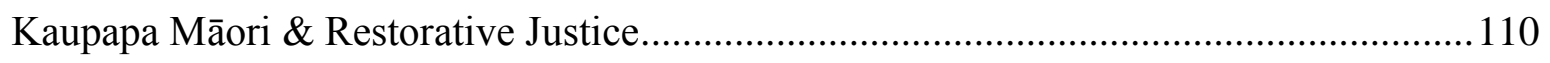

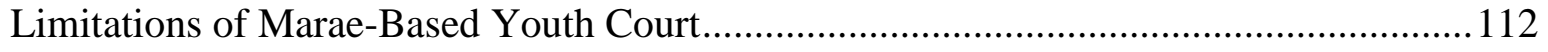

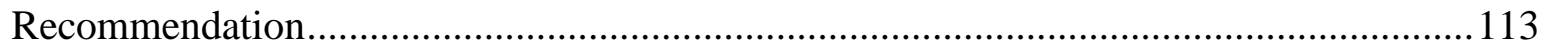

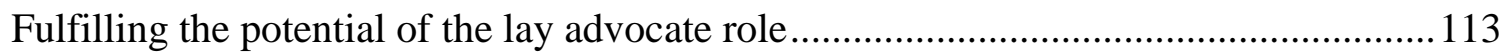

How to Combat the Notion of Marae as Court.................................................................. 114

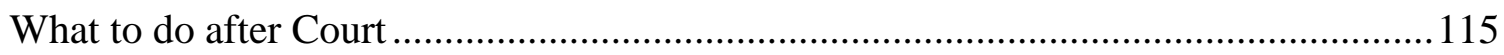

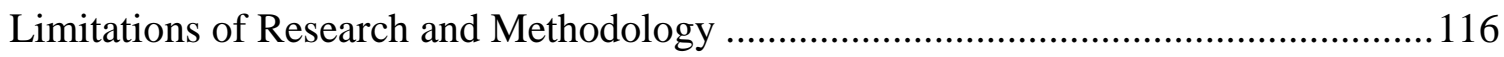




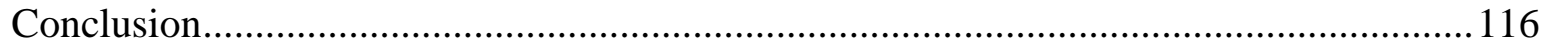

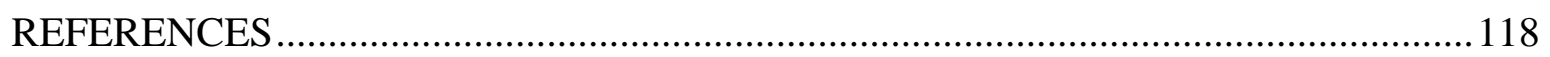

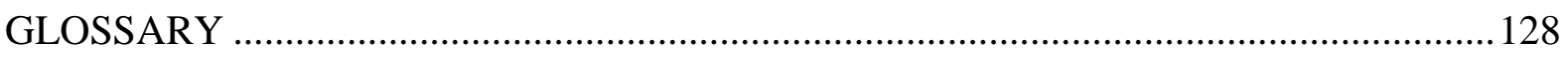

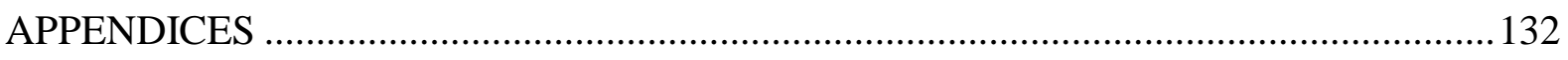

Appendix 1a: Information sheet/Interview and Focus Groups ........................................ 132

Appendix 1b: Information sheet/Interview and Focus Groups ........................................ 134

Appendix 1c: Information sheet/Interview and Focus Groups ...................................... 136

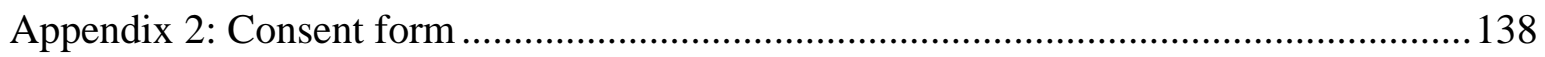

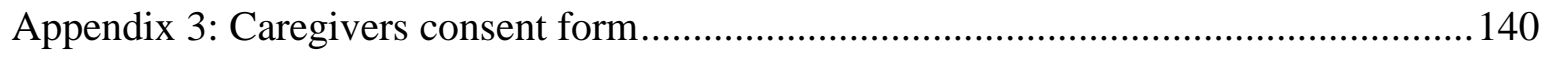

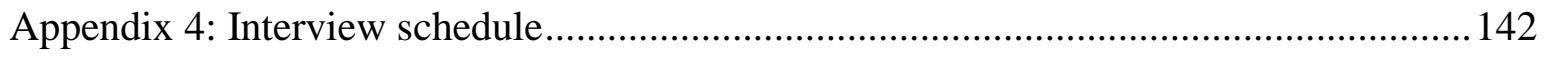

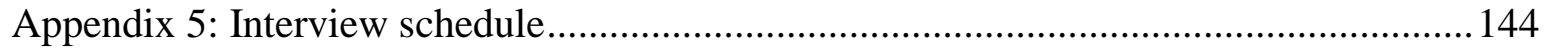

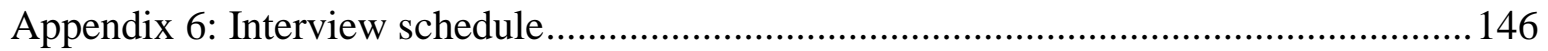




\title{
CHAPTER 1: \\ INTRODUCTION
}

\author{
"Sad Joke on a Marae"
}

Tihei Mauri ora I called

Kupe Paikea Te Kooti

Rewi and Te Rauparaha

I saw them

Grim death and wooden ghosts

Carved on the meeting house wall.

In the only Māori I knew

I called

Tihei Mauriora

Above me the tekoteko raged.

He ripped his tongue from his

mouth

And threw it at my feet.
Then I spoke.

My name is Tu the freezing worker.

Ngati D.B. is my tribe.

The pub is my Marae.

My fist is my taiaha.

Jail is my home.

Tihei Mauriora I cried.

They understood

The tekoteko and the ghosts

Though I said nothing but

Tihei Mauriora

For that's all I knew.

(Allen, 2002: p.157)

This poem by Apirana Taylor depicts a common scenario that a lot of young Māori find themselves in today. The poems speaker, Tu, is a young man alienated from his Māoritanga. He stands on a marae, he encounters the ancestral house, carved with the figures of famous adventurers, warriors and prophets. The only Māori words he can offer the ancestors are the formulaic opening for whaikōrero "Tihei Mauriora." Enraged by the situation of the contemporary Māori, in the moment of genealogical recognition the tekoteko offers the alienated and silenced $\mathrm{Tu}$ an ancestral taonga, his own tongue. It represents voice and speech and also represents defiance and the claim of victory in battle. A warrior's out-thrust tongue instils awe and defies enemies. When the tekoteko offers his tongue, he offers his voice and the warrior tradition - the power of defiance - as protection in contemporary times. When Tu formally introduces himself with his pepeha (pub is 
my marae, jail is my home...) he describes his alienation from Māori traditions and his sub-status in Aotearoa/New Zealand's dominant Pākehā culture. At this point, only the line "my fist is my taiaha" suggests defiance, and it is neither appropriate nor effective. Alienated from society, Tu has been "speaking" with his fists. His formulaic introduction is a "sad joke," a narrative cycle of numbing work, hard drinking, inevitable fighting, and incarceration. Answering his cries of "Tihei Mauri ora" - new life - the ancestral house offers Tu an alternative voice, replacing his inarticulate fists with an equally defiant but more effective tongue (explanation paraphrased from Allen, 2002).

The pertinence of this poem to this thesis is substantial. This will become apparent as this thesis continues. What this poem highlights is that a lot of Māori youth today (by no fault of their own) have become alienated from their Māoritanga. This has resulted in frustration and anger, and has manifested itself into criminal activity.

The aim of my studies over the last three years has been to work out how 'rangatahi' who have come into contact with our criminal justice system can reach their full potential as Māori New Zealanders, can avoid re-offending, and develop the tools to make a worthwhile contribution to our society. The following section will look at the statistical data on the demographics around our dramatically growing prison numbers and the current policies the Government is perusing and carrying out to cope with this situation.

To gain a better understanding of why there are a disproportionate number of Māori to Pākehā within this system we will look at aspects of the colonisation process that have contributed to this situation and explain some important philosophies from a Māori worldview to help understand the past and the present. The premise here is that an indigenous psychology based on a Māori worldview is the better place to look for causes and solutions to this problem compared with the causes and solutions the mainstream, monocultural system is offering.

Aotearoa/New Zealand is being faced with an expanding prison population, and this trend shows little sign of slowing down. Currently there are 20 prisons with a population of 8,469 (The Department of Corrections, 2010a). This is a $34 \%$ increase since 2002/03 (Department of Corrections, 2009 Annual Report). The 2008 Justice Sector Prison Population Forecast indicated that available capacity will be fully utilised in the course of the 2009/10 financial year. In the same year the 
Department of Corrections sought and obtained additional operating and capital funding for 2009/10 to undertake detailed design and planning work to ensure appropriate capacity for the forecast increase in the prison population. What resulted from this planning was a decision to increase double-bunking, the development of a new prison, an investigation into the use of modular constructions and portable type accommodation, and the replacement and expansion of capacity for one of the current prisons, to name a few (Department of Corrections, 2009 Annual Report).

This amounts to more taxpayer money being spent on the imprisonment of human beings for 'community safety'. The average annual cost of housing a prisoner is $\$ 90,977$ or $\$ 249.25$ per day. As the Associate Minister of Corrections Dr Peter Sharples says, "it would be cheaper to put them into a hotel" (The NZ Herald, 2009). Not only is housing prisoners an expensive endeavour but construction and other infrastructure requirements require huge amounts of money. The estimated costs to build and fit-out the newly proposed 960 bed Wiri men's prison is \$298 million (The Economical Impacts of the Proposed Men's Prison at Wiri Stage1 Report, 2010). The annual operational costs for the Wiri prison are estimated to be $\$ 17.6$ million just in New Zealand.

One so called cost-effective idea that has support from the Government is the public-private partnership (PPP) where the Government would build and own the prison but it would be run by a private contractor. There has been much debate over the privatisation of prisons both nationally and internationally. The current National Government justifies its support for a private prisons system based on cost effectiveness (The NZ Herald, 2010). However, those who oppose privatisation would say that going private does not necessarily convert into a cheaper prison system (Perrone \& Pratt, 2003). The previous National Government also tried a private prison and found that it was indeed cheaper to have the Government run the prisons than go private (Wagstaff, 2009). Cost is not the only contentious issue concerning private prisons. When contemplating the privatisation of prisons you inevitably make the imprisonment of human beings a business (Wagstaff, 2009). One of the main objectives of a business is to make a profit. A business will look at the most cost effective way of achieving a target. This is the proposed option for the Wiri men's prison. One would have to challenge its true cost-effectiveness as privatisation would appear to do very little to solve the problem of having a huge 
prison population by significantly reducing the number of inmates in Aotearoa/New Zealand.

The most effective way of lowering the prison population is to reduce the number incarcerations in the first place. This would save millions of tax payers' dollars and prevent what is a huge waste of human resources.

Of the 8,469 people in prison just over half are of Māori descent. Māori make up approximately $15 \%$ of New Zealand's population, yet account for $43 \%$ of convictions, $47 \%$ of violent offending convictions and $51 \%$ of those in prisons (Durie, 2007). This trend has almost become accepted as the norm, as Māori have witnessed the increase in their incarceration rates for three to four generations. Statistics show that in the 1920s Māori only made up 4\% of the national prison population, yet by the 1940s this figure reached 15\%. Between the 1950s and 1990s there was a sevenfold increase in the number of Māori sent to prisons, around four times more than non-Māori (Liu, 2007), resulting in the current situation.

Therefore, if reducing the prison population is the goal, then focusing on the reduction of Māori imprisonment would significantly increase the chances of achieving this goal. One way to accomplish this would be to identify the critical point where an intervention could be applied in this process. This may well be when a person first comes in contact with the criminal justice system. This point for many occurs during their teen years. This is also the point where youths have not yet become so-called 'hardened criminals' and are more susceptible to change. This point of intervention must be relevant and effective for the youth.

What currently exists for youth aged 14-16 is the standard Youth Court. When youth are charged with an offence they are taken to the Youth Court. If they plead guilty to the offence they are diverted to the Family Group Conference (FGC). The FGC is an opportunity for the family of the offender, the victim and the victim's family to come together to address the offending. Here, a plan of reconciliation is written up for the offending youth to complete. On completion the changes will be dropped and they will not be indicated on the youth's permanent record.

This process has had some success and has the potential to be valuable in the efforts to reduce the numbers in prisons. However, there is another culturally appropriate process that has evolved. This approach, promising new avenues for dealing with Youth Criminal Justice, involves Marae-based Youth Courts (MBYC). The MBYC was an initiative that was started by Judge Hemi Taumaunu, a local 
Gisborne youth court judge. According to the Youth Transition Services Gisborne (2008) magazine the objective behind this initiative was to reduce recidivism among youth offenders. To get this concept off the ground there would have to be collaboration with the Ministry of Justice (MoJ), Courts, Child Youth and Families, New Zealand Police and marae Trustees. The first MBYC was established and sat at Te Poho O Rāwiri Marae on the $31^{\text {st }}$ of May 2008 (Youth Transition Services, 2008).

There is great potential for these MBYCs to reduce the re-offending of rangatahi ('rangatahi' in the context of this thesis will mean 'Māori youth who come into contact with the criminal justice system' unless otherwise stipulated rangatahi is a general word to mean all Māori youth). However, to fully understand this concept and to make it successful there must be an in-depth understanding of Māori institutions and concepts of dealing with transgressions. Furthermore, the development of these concepts through time and how they have evolved is also integral.

Māori as the 'tangata whenua' of Aotearoa/New Zealand suffered similar experiences to other indigenous peoples when the wave of European colonists moved across the world in the $18^{\text {th }}$ Century. The colonists believed that they had the sovereign right to take and use lands they had 'discovered'. Since the signing of the Treaty of Waitangi in 1840, Māori have challenged the rights of the Crown to Tino Rangatiratanga (sovereignty) (Ka'ai, 2004). Despite these challenges being continuous, creative, legal and extra-legal, Ka'ai concludes that Māori have become a powerless minority in their own country (Ka'ai, 2004).

The history of colonisation and its effects on Māori has been well documented elsewhere (Walker, 1990; King, 2003; Belich, 1999; Durie, 2003; Frame, 1981; Jackson, 1988). By the mid 1850s Māori society, through no fault of its own, was seriously challenged, as all its social, political and economic structures began to erode beneath the weight of a strong, relentless coloniser. By 1896, the population had declined rapidly to 42,000 and there was a popular notion that Māori were a dying race.

Durie (2003) claims that Māori have already faced, survived and flourished after facing two main challenges to their survival. One of these challenges he terms 'the confrontation with the settlers from the west' (Durie, 2003, p. 18). While acknowledging the devastating effect this had and still has, Māori have survived and 
are beginning to flourish. Māori are still showing up in negative statistics when compared to other New Zealanders (e.g. indicators around health, education, employment, offending, and home ownership and income levels). But indicators also show that Māori are feeling much more positive about being Māori and still have a very strong sense of whānau (Durie, 2003).

The other main challenge that Māori have faced, survived and been able to flourish in spite of, according to Durie (2003) was the planned migration from the Pacific Islands to New Zealand. They learned to live in and with a very different environment. They brought with them a belief system that enabled them to make sense of their world and included processes to guide the behaviour of the group and prevent them from taking unnecessary risks.

These processes of social control were based on the concepts of tapu, noa and mana, which were also pivotal in understanding a Māori worldview. The rules to guide behaviour are called 'tikanga' and sit within this worldview which is holistic, interconnected and interdependent (Mead, 2003). This interconnected notion is reiterated by Cram (2001, p. 38):

"Māori possess an indigenous body of knowledge that seeks to define the origins of the universe and the place of humans within it. This knowledge connects humans, plants, animals, gods, and all animate and inanimate objects."

Tikanga, mātauranga Māori and the Māori view are what Nikora et al. (2006) refer to as the way in which Māori approach wellness, health and being. This way of being was a balancing act of all these forces, and unacceptable behaviour was seen as disruptive to this balance affecting both the individual and his/her whānau. To make matters right or to restore the balance was the responsibility of all the family of the transgressor. Rules were in place for achieving this which involved both the temporal and the spiritual worlds.

Māori are proven survivors and have the experience and knowledge to find solutions. To recover from the pain and suffering of the past and the trapped lifestyles of the present, Durie (2003) suggests that changes need to be made in several areas and suggests that full potential will be difficult to achieve until the power-brokers within Aotearoa/New Zealand are ready to share power.

For the purposes of this study I want to look more closely at the philosophies within the Māori worldview and the 'tikanga' that have withstood those two main 
challenges discussed above. Adaption, survival and the ability to flourish are proof that solutions will be there.

\section{- Overview of chapters}

- Chapter 2: Māori Methods of Dispute Resolution and Restorative Justice This chapter explores the traditional Māori methods of dispute resolution. It does this by examining the key concepts that are involved in dispute resolution and how they apply to different situations. This is done by reviewing the literature in this field. The concepts that are discussed are; Mana, Tapu, Utu, the process of Take-Utu-Ea, whakamā and muru. Discussion on how these concepts are relevant today is also undertaken. Following this will be a discussion on Restorative Justice and how the above concepts relate to it. Exploration will be undertaken in to the origins of Restorative Justice in Aotearoa/New Zealand, how it is used here, how it relates to Māori, the principles and objectives, its philosophy and the changes it has made to the youth justice system.

\section{- Chapter 3: Methodology}

This chapter will investigate Kaupapa Māori methodologies. This will be done by exploring the relevant literature. This chapter will examine the origins of Kaupapa Māori, its relationship with colonisation, where it emerged from and some of its key features. This chapter will also describe the fundamental principles of Kaupapa Māori which are; Tino Rangatiratanga, Taonga Tuku Iho, Ako Māori, Ki Piki Ake i ngā Raruraru o te Kainga, Whānau, Kaupapa, Tiriti o Waitangi and Ata. There will also be a focus on Participatory Action Research and how this methodology relates to that of Kaupapa Māori. Following this will be a consideration of the relationship between Kaupapa Māori and Psychology. This will look at the branch of Psychology called Indigenous Psychology and how it relates with Kaupapa Māori. This chapter will then end with a focus on Kaupapa Māori and the criminal justice system, looking specifically at the best research practises in this industry and then applying the philosophies of Kaupapa Māori to the criminal justice system.

This Methodology/Method chapter will be divided into three sections. The first, will be a description of how the research approach used was influenced by my 
personal background, my epistemological view, my consideration for rangatahi and especially by my desire to produce research that is culturally appropriate and culturally safe. The second section will examine two pieces of research that I was involved with. One of which is the main research and the other is one where I was part of a research team for the Ministry of Justice. This will compare the two research methodologies, methods and practice to show how Kaupapa Māori can produce more valuable research when Māori are involved. The third section will examine the specific methods used in this research such as; participants, materials, procedure, focus groups, individual interviews, interview questions, analytical approach and the limitations of the methodology.

\section{- $\quad$ Chapter 4: Personal Background}

In this chapter I will make explicit the ways in which my personal upbringing and experiences have shaped my position as a researcher, and how that position influences my research aims, the research process, my analysis, and the conclusions I draw.

\section{- Chapter 5: Results/Discussion}

This chapter looks to critically analyse the interviews that were done during the course of this research. This analysis produced four major themes. These themes were; Tā te Ture ki te Rangatahi (Law as Preserved by Rangatahi), Whakamā, Te Wairuatanga o te Marae (The Spirituality of the Marae), and the Potentiality of the Lay Advocate Role. Within each major theme were a set of subordinate themes that were directly related to the major themes. The first major theme, Tā te Ture ki te Rangatahi, was concerned with how the rangatahi perceived the law, how they understood it and what parts of the law influenced them the most. The second major theme, Whakamā, was concerned with the way in which whakamā manifested itself in both the MBYC and the standard Youth Court. Metge's (1986); six causes of whakamā were used to illustrate how whakamā can manifest itself positively and negatively depending on a number of factors. The third major theme, Te Wairuatanga o te Marae, was concerned with what effects the marae had on the process of the MBYC, the people running it and the rangatahi going through it. It was important to identify what exactly it was that was getting affected by the marae, 
such as; atmosphere, identity, feeling of whakamā, etc. The fourth and final major theme, Potentiality of the Lay Advocate Role, was concerned with identifying how the lay advocates viewed their role and most importantly what were the challenges that they had faced in their role.

\section{- Chapter 6: General Discussion}

This chapter looks to reflect on chapter 5. This chapter takes the Kaupapa Māori principles and compares the effectiveness of the MBYC to relate to these principles. By doing this, it also identifies the areas where the standard youth court fails rangatahi in comparison to these principles. Following this, an exploration into the relationship between Kaupapa Māori and Restorative Justice will be taken. Recommendations will then be given based on the findings of the results. These recommendations will consider the fulfilment of the lay advocate role as it pertains to the MBYC, combating the notion of the marae as a court and finally post-court options for rangatahi. Consideration into the limitations of the MBYC will also be examined. Finally, concluding comments will be made. 


\section{CHAPTER 2: \\ MĀORI METHODS OF DISPUTE RESOLUTION AND RESTORATIVE JUSTICE}

Traditional Māori society was structured upon a system of balance. Mana, Tapu and Utu are significant concepts that are involved when an individual transgresses, or disturbs this balance (Salmond, 1975). The way in which people conducted themselves in traditional Māori society was based on tikanga. Tikanga can be referred to as the governing system to maintain societal order. Tikanga is a complex concept and it is not in the scope of this thesis to explain it in its entirety. However, it must be noted that the definition of the word - Tika- refers to being right or just. Therefore, tikanga may be seen as Māori principals for determining justice (Mead, 2003). Mead (2003) also explains how Mana, Tapu and Utu are concepts that may be described as conceptual regulators of tikanga, or as providing fundamental principals or values of Māori law. Therefore it may be postulated that Mana, Tapu and Utu are the societal frameworks, or tikanga, that are involved in traditional dispute resolution.

\section{Mana}

Williams (1985) gives mana eight definitions which demonstrate the complex nature of this word; "authority, control - influence, prestige, power - effectual, binding, authoritative - having influence" to name a few. The multiplicity of definitions shows that no one English word captures the meaning of mana in its entirety, but these examples help us illustrate the concept of mana within the wider framework of a Māori worldview. Salmond (1975) goes onto explain that mana was inherited at birth, and the more senior the descent the greater the mana. From then on, people were engaged in a contest for relative mana, and according to performances in war, marriage, feasting and on the marae, mana rose and fell (Salmond, 1975). Marsden (1992) presents an even more complex definition of mana as: "lawful permission delegated by the gods to their human agents and accompanied by the endowment of spiritual power to act on their behalf and in accordance with their revealed will” (Marsden, 1992, p. 125). 


\section{Tapu}

With great mana also comes great tapu. Tapu and mana are intrinsically related to each other. (Williams, 1985) defines tapu as "under religious or superstitious restriction; a condition affecting persons, places, and things, and arising from innumerable causes...," this is a very brief definition, which fails to do justice to the entire meaning of the word. Shirres (1982) offers a comprehensive explanation of tapu and its relationship to mana. Shirres makes a distinction between two types of tapu: intrinsic and extensions. He notes, "intrinsic tapu, or the tapu inherent in all things as having been descended by the Atua and therefore all things, in their proper proportion, share in that deities' tapu" (Shirres, 1982, p. 34). This view is supported by Marsden (1975) who states that "Tapu was believed to restrict a person, place or object by being dedicated to an Atua (deity), thus removing it from the sphere of the profane and reserving it for the Atua" (Marsden, 1992, p. 52). Therefore, within this analogy tapu and mana are acquired from Atua (deities) that is passed down through whakapapa.

Shirres (1982) suggests that tapu varies in intensity depending on the occasion. For example, a wharenui is always tapu but when there is no ceremony people can be relaxed and are able to move freely. However when a ceremony begins the level of tapu on the marae increases immediately and restrictions upon human behaviour are imposed.

Best gives a practical explanation of the function of tapu and explains, "It was a series of prohibitions that acted as a means of social constraint, and reached into all spheres of traditional life" (Best, 1934, p. 155). Furthermore, tapu was a form of social control or a safety mechanism used by tohunga to restrict behaviour. For instance, if resources such as crops, animals or seafood were depleting, restrictions to harvest may be placed on them through placing a tapu on them. Likewise, access to a place (e.g. where killings had taken place) may also be restricted by making them tapu. This is why with great mana comes great tapu. Tapu is a reminder of the obligations that one has. These obligations include a responsibility to whānau, hapū, Iwi and most importantly to Atua. In instances where tapu was breached the individual was exposed to consequences of aitua (accident, misfortune). Ideologies propose 'noa' as the antithesis of 'tapu' where notions of 'pure \& unpure' (Douglas and Smith, 1975) and 'unrestricted \& restricted' 'profane \& sacred' (Salmond, 
1978) are presented. However, Shirres suggests that noa is directly opposed, not to tapu itself as suggested by Douglas et al. (1975) and Salmond (1978), but to the extension of tapu as experienced in the formal ceremony. Whereby, the restoration of balance was acquired through karakia. The obligations to maintain social order through notions of tapu may be a more powerful and effective means of restorative frameworks within criminal justice compared to the Western approaches of punishment. Therefore, a restorative model for Māori could benefit by placing more emphasis on an approach such as this. How this may be achieved needs further investigation.

\section{Utu}

Utu was one concept used to regain balance. Williams (1985) defines utu as the "return for anything; satisfaction, ransom, reward, price, reply." Once again, such is the complex nature of this word, the English language fails to capture its entire essence and only conveys a snapshot of its true breadth. Such a simplistic view is inadequate. As identified by Patterson (1992) who explains that utu is the idea of restoring balance, and can take multiple forms. To understand utu, one must understand its appropriate application in different contexts. Ka'ai and Higgins (2004) state that when the mana and tapu of an individual was challenged resulting in an incident, retribution was sought to regain and restore a balance with the initial offender. Nevertheless, balance was often momentary, as utu was constantly desired by each party until an agreement was reached between them, and the issue was considered ea (balanced). Ka'ai and Higgins (2004, p.18) explain, "More often than not, the initial hara (wrong) is so insignificant that it is overshadowed by the later events of utu" that escalates and snowballs confrontation between the two parties. Once this happens, ea can only be achieved through settlement by the chiefs of the feuding Iwi, either through warfare or tomo (arranged marriage).

Confrontation between parties can lead to positive outcomes for the two groups. For example, utu can act as a mechanism to affirm alliances with other Iwi. When one Iwi wants to start a rapport with another, it proceeds by giving some sort of gift. If the other Iwi accepts then they must utua (reciprocate) that gift with one of equal or greater worth. The gift is a symbol of the Iwi's mana so by giving a gift of less value is to undermine the mana of the other Iwi. In this manner the escalation can work favorably, with gifts such as kai (food), then moving up to prized 
possessions such as pounamu (greenstone), then maybe acts of tomo (marriage) to strengthen ties, and then ultimately accompaniment in war. The overall aim is to achieve continual interaction which strengthens relationships and is beneficial for both parties.

The notion of balance appears contradictory across these two contexts. In the first instance, balance is needed to resolve conflict. In the second instance, an imbalance is needed to strengthen ties. One may say that in order to achieve a healthy relationship in traditional Māori society an imbalance was required. These are just a few examples in which utu is observed, but utu is a part of all Māori aspects of life as, "the traditional concepts of utu pervaded the Māori social, legal, political, and economic order" (Ministry of justice, 2001, p. 67).

As in all things Māori, the prevalent appearance of these concepts of mana, tapu, and utu within one another is obvious. Their interconnectedness and ability to work side by side exhibits a well structured and effective system that served the people well. Restoring and resolving issues were easily achieved within this system with a balanced society as an outcome. It should be conceded, however, that Māori societies were integrated on a small scale, with even the largest Iwi not having extremely high numbers. Such a highly interpersonal system is probably most adaptive among smaller collectives.

\section{Take-utu-ea}

Mead (2003) refers to 'take-utu-ea' as the process of transgressions against tikanga, and finding resolution. 'Take' relates to the issue of transgression, or breach of tikanga. The responsibility to remedy a 'take' is not only the responsibility of the wrong-doer but also people aligned with this person. Before the process can proceed there must be an agreement between both parties (wrong-doer group and wronged group) that there is a 'take'. Once this 'take' is agreed upon the process of finding resolution commences.

This is the process of utu, where an appropriate utu is offered to the wronged group. This is in the form of some sort of recompense or an equivalent gesture that is given to the wronged group. The idea behind this is to gain a satisfactory outcome for all parties involved which leads onto the next stage of ea. If satisfaction can be 
obtained by all parties then ea is achieved. Ea can be described as the return of balance.

However, Mead (2003) also alludes to the fact that there are other factors that influence this process and that this is a simplistic explanation. Other influential factors include the mana of the people involved; The severity of the take and the economic status of the wrongdoer are all variables that alter this process (Mead, 2003). These concepts of take, utu, and ea are not only part of this process, but are seen in other aspects of tikanga Māori.

\section{Whakamā}

Whakamā is a concept that has been sparsely researched. Researchers have commented on it (such as James Ritchie's (1963) book, The Making of a Māori) but have not explored the concept as a whole or critically analysed its function. There is one researcher who is the exception to this and that is Joan Metge (1986). Her indepth analysis of whakamā serves as a valuable resource for Aotearoa/New Zealand. Because of the minimal amount of research that has been done on whakamā, the following discussion will be based mostly on the research of Metge (1986), unless otherwise stated.

According to the Reed Dictionary of Modern Māori (Ryan, 2005), whakamā is translated as "Shy, embarrass, feel ignominious, loss of mana". As like other Māori concepts, the English language fails to capture the breadth and width of whakamā. Metge (1986) comments that it cannot be corresponded with any other single English word but covers a range of denotation that is divided among several English words. It implies a way of thinking about interpersonal relations which is dissimilar from that articulated in and reinforced by the English language (Metge, 1986). Whakamā has been likened to an affliction, a sickness which strikes people (Metge, 1986). Furthermore, its interconnectedness with other Māori concepts is apparent.

\section{Outward Signs of Whakamā}

The outward signs of whakamā can be variations of different forms of behaviour. Metge's contributors described outward signs of whakamā as "someone who looks like a wooden post", "loss of speech, loss of action", "not speaking, being dumb, speechless", "at loss for words" (Metge, 1986, p. 26). A theme from these comments was the negation of normal activity and interaction: not moving, 
not using the sense of sight and hearing, not speaking, not making a return. They showed patterns of immobility and unresponsiveness.

Whakamā may also manifest itself in other forms of behaviour depending on certain conditions and personality types. There are various ways of cutting off visual communication which go beyond merely looking at the ground, such as turning your back. There are also small movements commonly regarded by Māori and Pākehā as indicating unease, such as restless hands and fidgeting. Behaviour of this sort involves a reduction in activity and communication rather than complete cessation. This is a mild form of whakamā.

\section{The Inward Feelings}

When a person is whakamā they experience several feelings that are closely intertwined. For example; feeling shy, embarrassed, uncertain, inadequate, incapable, afraid, hurt, depressed and ashamed. Inward feelings of whakamā cover a range far wider than that of its behavioural manifestations. The feeling of whakamā is generally negative and depressed. In most cases anger is suppressed and turned in on the self. However if a person who feels whakamā is pushed past a certain point his whakamā may surface suddenly in violence.

\section{The Concept as a Whole}

What is unique about whakamā is that it subsumes so much under a single heading, putting together ideas which English speakers treat as separate and distinct. This is due to a different way of perceiving and ordering human experience. Under all the non synonymous descriptions there is a common theme which ties them all together, a theme involving the concept of mana. Whakamā is bound up with the lack or loss of mana in relation to others.

Māori place primary emphasis on disparity and playing down the importance of the question 'who's at fault?' to which English speakers give such prominence. Māori address the problem of the cause once the existence of disparity has been established. Thus in Māori thinking the attribution of blame comes after the identification of whakamā, not before.

This is very important in terms of its relatedness to the youth court and the MBYC as these two processes for attributing blame are different. 


\section{Variations of Whakamā}

Whakamā is felt on different levels of intensity and duration. Variations in the expression, intensity and duration of whakamā are closely related and can be traced to differences in immediate cause, in the identity of the person experiencing it, and in surrounding circumstances. If the disparity which caused the whakamā is minor, if the person experiencing it is relatively secure, has highself esteem and is surrounded by the support of whānau and friends, he would be expected to come to terms with the incident fairly quickly and with little help. But if the disparity is major, if breaking a moral code occurred, rather than an innocent mistake, and if the incident occurs in public and/or before strangers, the whakamā is more intense. If handled wisely whakamā may pass without any lasting effect. But if allowed to linger unhealed it becomes more permanent and chronic.

Whakamā is also influenced by, and has influence on people around the person directly involved. The audience present at an incident is a major factor influencing the severity of the resulting whakamā. In general whakamā is less serious following an incident in the presence of the family and familiar surroundings, and it increases in public and unfamiliar settings with strangers present. Whakamā can also effect multiple people, as individuals may feel whakamā for someone else as well as for themselves. Groups can also be affected by whakamā such as iwi, hapū and whānau. As a result, iwi, hapū, and whānau are often keen to be part of reconciliatory processes.

\section{The Causes of Whakamā}

Whakamā for individuals can be categorised into six groups;

1. Perception of lower status: Māori become whakamā as individuals when and because they perceive themselves to have lower status than particular others, whether in general terms or in respect of some valued quality, such as senior descent, age , knowledge, schooling, wealth or occupational status. Whatever the objective 'facts', it is the individual's own assessment of the situation that matters.

2. Uncertainty and confusion: Māori can become whakamā when and because they find themselves in a situation of uncertainty or confusion, when the right course is not clear or when they feel they ought to know what is right but do not. 
3. Recognition of fault: Māori become whakamā when and because they recognise or are told that they have done something 'wrong', whether their fault entails a breach of social conventions, the community's moral code, the law, or simply their own standards. But many feel and act whakamā before their fault comes to the attention of others because they themselves judge it to be so.

4. Being put down: An individual becomes whakamā when and because other people insult them, belittle them, or trample on them, directly or by failing to recognise their presence and status, or criticise them or something they have made or done. The whakamā is intensified if the charges are just or repeated and if the recipient cannot retaliate.

5. Being singled out: Many Māori become whakamā when and because they are singled out, separated from their peers and placed in a special category, whether inferior, superior or simply different.

6. On behalf of others: A Māori can feel whakamā for or because of someone else. This happens most often and is deeply felt with regard to people with whom they are closely linked: children, parents, close kin, close friends.

\section{The Treatment of Whakamā}

In mild cases the person afflicted may come out of their state of whakamā on their own, but in most cases they need help from others. Both whether help is there and what form it takes depends on bystanders recognising the condition and correctly diagnosing its cause and intensity. At this stage it is essential to determine whether or not the afflicted one brought the whakamā on themselves by doing something wrong.

\section{In cases of wrong doing}

Where a person is whakamā because they have breached the moral code or deviated from a prescribed pattern of behaviour, those in a position to help stand back at least for a while, leaving that person to suffer, to be 'punished by whakamā'. How long they wait before taking positive steps depends on the seriousness of the offence and the intensity of the whakamā. Not everybody who 
has done something wrong is prepared to admit it or pay the price of reacceptance voluntarily. Some bury both fault and whakamā and need to be forced to bring it into the open. Some have become so used to being whakamā that they are not aware of it as a condition and so do not recognise the necessity or even possibility of doing anything about it.

\section{Where wrong doing is not involved}

When the person who is whakamā has done no wrong, other people act much more quickly to provide healing. When whakamā is even moderately deep you must be careful not to try and reverse it too quickly. Trying too hard to get the person to 'snap out of it' may drive them deeper into whakamā. In such cases the best thing to do is to back off a little, leaving them to be whakamā as long as that person needs.

\section{Re-integration back to society}

Except in the case of serious offences, whakamā should be a temporary condition. In mild cases of whakamā the person emerges from it on their own. However others intervene when they feel that their withdrawal has lasted long enough. The process of restoration begins by means of physical contact, often without words such as a hug, hongi, etc. The first move may be made by those whose superiority or criticism caused the whakamā in the first place, or by witnesses. The words which accompany or follow the making of physical contact may be words of forgiveness or encouragement or they may make no reference to what has happened. It is the fact of renewed contact which is significant rather than what is said. Accepting expressions of aroha may be enough but when the offence is great or the hurt is deep the process of re-integration may take time. Even when a person has ceased to display the outward signs of whakamā, the inner feeling may linger inside. Aroha can be used as a means of healing the hurts which cause people to withdraw from interaction with others.

Whether those who become whakamā emerge from it and are re-integrated into social life depends firstly on the cause and the intensity of their whakamā, secondly, on the discernment and kindness of others in diagnosing and treating it appropriately, and thirdly on the availability of escape routes. 


\section{The consequences and functions of whakamā}

Whatever its intensity, the experience of whakamā leaves its mark. It has consequences and functions in the short and long term, for the individual and community. Consequences and functions of whakamā are predominately negative. But if you take into account the sufferers and the community it can be seen to have positive aspects. It must be noted that whakamā is not always well handled or healed. The problem is compounded when Pākehā are involved, because of the frequency with which they misinterpret the meaning of the āhua whakamā or fail to recognise it at all.

\section{Out of Touch}

The immediate consequence of whakamā is the disruption of social interaction. In all but the mildest cases those who become whakamā withdraw from both physical and social contact and put up an invisible wall around themselves. Literally and figuratively, the whakamā are out of touch.

\section{Holding Back}

Loss of mana, which is the underlying cause of whakamā, means loss of the power to act effectively and loss of protection. Holding back is not always a bad thing. Whakamā can work to prevent the socially inept or unwise from acting precipitously, angering or hurting others by ill considered remarks or actions.

\section{Running Away}

The person concerned may remove themselves bodily from the whakamā producing situation.

\section{Hitting out}

The person concerned may strike back, this may be with words, both polite and angry.

\section{Paying the price}

When an offence has been committed, whether against Māori custom or the law, endurance of whakamā has a conciliatory effect on Māori members of the same community. Endurance also helps in coming out of whakamā and opens up the way for re-integration. Whakamā in this context is interpreted by most Māori adult 
wrong-doers, as both admission of fault and part of the punishment that purges the offender of his guilt. This is part of the price of forgiveness.

These understandings place Māori at a disadvantage in the national justice system. Māori offenders often plead guilty in the expectation that whakamā and confession will be counted as part of the punishment. When they find that their whakamā is misinterpreted, their sentences are not affected and they are still subjected to a dressing down from the bench. Moreover they are robbed of an incentive to amend their behaviour. Any study of Māori offenders motives and attitudes will be incomplete if it does not give due consideration to the pattern of behaviour and ideas associated with whakamā.

\section{Profiting from whakamā}

If the whakamā is not too extreme, it can play a part in learning, especially in children. Even adults can profit from whakamā. While whakamā causes most Māori to hold back, some take it as a challenge and fight to regain mana by achievement. Security of identity, upbringing and personality are factors of this but where there is a positive response there are usually close associates in the background providing encouragement and support.

\section{When Whakamā Goes Untreated}

If whakamā is left untreated, or if it is mishandled, both long and short term consequences are extremely damaging for the individual and for the society at large. Sometimes whakamā goes untreated because the sufferer deliberately conceals the depth of his whakamā, playing down the outward signs, especially if the cause is not generally known. Sufferers may find themselves in the company of people who do not recognise the outward signs of whakamā, misconstrue them or if they recognise the condition, do not know how to diagnose and treat it.

Many young Māori who act in whakamā have absorbed their knowledge of whakamā unconsciously from parents and other Māori associates in the process of growing up. The extent to which they recognise and handle it varies with their personal sensitivity and their own experiences with whakamā.

\section{When whakamā becomes chronic}

In the case of chronic whakamā, Māori may be diagnosed by doctors or mental health professionals as having a psychiatric disorder. By Māori they would be 
considered as mate Māori. A large proportion of Māori today, especially of those born and bred in the city, show the signs of chronic whakamā. Māori show whakamā in their dealings with Pākehā in power: teachers, welfare officers, bureaucrats and police, and in these circumstances they are blamed and punished instead of being helped and handled. The prevalence of whakamā is particularly problematic for contemporary urban Māori as they often lack the knowledge and expertise to counter whakamā that was commonly held by earlier generations of Māori, including present Kaumātua.

\section{Do Young People Get Whakamā Today?}

Some suggest that whakamā is becoming less common as young people brought up in the city lose touch with their taha Māori and pick up Pākehā ways. According to those who hold this opinion, whakamā belongs more to the extended whānau and hapu, and to the rural situation. Those who hold this opinion might also suggest that for rangatahi today, the group context that is most influential to them often is not the whānau or the hapū but largely their peers. However, others would disagree with these views and assert that young Māori do feel whakamā. Although they often hide it or express it in aggressive ways, the signs are there to be seen for those knowledgeable enough to recognise them.

The present generation, even more perhaps than previous ones, experiences a lot of whakamā when participating in Pākehā dominated institutions and encountering Pākehā in positions of power. In these situations whakamā may be exacerbated by Pākehā who do not recognise whakamā, misunderstand it and handle it in unhelpful ways.

\section{Whakamā in Māori-Pākehā Relations}

It is noted that while the concept of whakamā is a distinctive feeling firmly rooted in Māori culture, the whakamā in relation to Pākehā can be particularly deep, so much so that it can be regarded as a special kind of whakamā. Some of the causes of this whakamā of Māori in relation to Pākehā are the obvious disparities in material circumstances, in income, housing, employment (and unemployment), qualifications, and occupation. Māori can see these disparities for themselves, and they are continually reminded by the media. 
All the main institutions of public life in Aotearoa/New Zealand are grounded by Pākehā culture and dominated by Pākehā in positions of power. By law Māori must participate in these institutions and their participation is judged by Pākehā standards and values.

Pākehā may argue that this highlights the difficulties Māori face and overlooks important changes that are currently underway. Where whakamā is concerned, what matters is the subjective perception of those affected. Defensiveness and counterattack are not helpful responses on the part of Pākehā. Nor, on the other hand, is indulgence in excessive feelings of guilt, which tend to cloud judgment and misdirect action.

\section{Muru}

In the process of take-utu-ea, muru is a form of utu that refers to a "ritual redistribution of wealth as compensation/punishment for an offence" (Mead, 2003, p. 363). Muru was the means in which traditional Māori society sought justice.

Although muru is a form of utu there are notable differences. Muru does not hold the same obligatory characteristic that utu does. Once a muru is completed there is no obligation for the people who have the muru done on them to reciprocate. Muru in traditional Māori society was a sure way of achieving ea.

As stated above, there are variables that influence the process of take-utu-ea. For the utu portion of the process the influence of these variables can elicit the use of the muru. If there is a considerable amount of mana involved or if the take was of great significance then these would be suitable grounds to enact a muru. Mead (2003) refers to some of the take or reasons for a muru to take place:

1. Threats to the institution of marriage

2. Accidents of a serious nature that threatened life

3. Damaging a wāhi tapu and trampling on tapu

4. Defeat in war

(Mead, 2003, p. 151-152).

Each one of these take illustrate the diversity for the enactment of muru. The first take concerning marriage is illustrated by Mead (2003) in an example referring to the last great muru of Taranaki, and a love affair between a chief and another chief's wife (Mead, 2003). The chief with the love infatuation convinces the wife to elope with him. They both run off and, as tikanga proclaims, utu will be enacted for 
this transgression. The people of the wifeless chief prepare to muru the people of the transgressor chief. It must be noted that when a muru happens it is not just the immediate conflicting parties involved but extends to their whānau and hapū as well. This particular muru continued for six days with the various whānau of the wifeless chief coming to take whatever they could from the whānau and hapū of the transgressor chief. At the time of the muru it is tikanga that the transgressor chief's whānau and hapū show manaakitanga by feeding the people who came to muru. This signifies the end of the muru and the issue coming to a satisfactory end for both parties and the achievement of ea. When the eloped couple returned and saw that a muru had taken place they were joyful because not only had the issue been dealt with, but the enactment of a muru signified the acceptance of the new relationship.

In today's society it would be most unusual for people to show manaakitanga (hospitality) to another group of people who have just taken their possessions. It would also be unusual for one to imagine a chief to be joyful for being the subject of a muru. However, for Māori, muru was related to the mana and tapu involved.

Muru was used as a means to rebalance transgression. Manaakitanga was an integral part of tikanga that helped regain this balance to achieve ea and to whakanoa people so they were free from restraint. As in all tikanga Māori and the Māori worldview the taha wairua (spirituality) is involved in everything. Therefore, everyone involved in the muru is in a state of tapu and it is through manaakitanga and hākari that tapu is returned to a state of safety free from restrictions. Not only does the hākari bring the individual back to a safe state, it also is an important step that helps to re-establish mana and reintegration back into the community.

The reason for a chief's joy for having a muru relates to mana and an acceptance of an individual's mana by others. The process of muru empowers the transgressed by allowing them to choose whether or not to use a muru. If the transgressed choose not to use muru then acceptance of the issue is not warranted and most likely war would break out between the two groups. This option is much more detrimental for both parties. If the transgressed choose to use muru then he/she accepts the situation and is reimbursed accordingly.

The second reason for grounds to enact a muru relate to accidents of a serious nature that threatened life. Manning (Carr, 1996) refers to a muru he observed in approximately 1912 that relates to careless protection of his child who he allowed to 
come to harm. Mead (2003) also makes reference to this example. While the child was in the care of his father he was accidently burned by fire. It was said that this child had the potential to be a toa or exceptional warrior which therefore made him a huge asset and could bring great mana to the entire hapū. Consequently, the whānau of the young boy's mother placed blame on the boy's father for negligence resulting in their child coming to harm. Although the incident was purely accidental it still invoked muru because of the potential asset that could have been lost to the hapū and the simple fact that a life was at stake. Māori have always valued life as reinforced by a well known whakatauki 'he aha te mea nui o tēnei ao? He tangata, he tangata, he tangata' - 'what is the most important thing this in this world? It is people, people, people'.

Once the mother's family had decided to muru they then left and went to the hapū of the father. The muru party was lead by the boy's uncle who sought compensation from the father's hapu. The father and his people spent days preparing for the muru by placing all their cartable possessions on the marae atea and killing animals for the hākari (feast). When the muru party were in sight the father asked how many people were there. He was delighted when he heard there were many. Once they arrived to the marae of the father they were greeted with a haka pōhiri. As they went on the uncle stepped out with his taiaha and the father did the same. They fought with everyone watching. The fight went on for some time as they were both taiaha experts. Once both men had shed blood the fight was over and the uncle told his people to commence the muru. While the people were gathering the possessions the two men sat down and talked socially. After the possessions had been taken the father's people showed manaakitanga by feeding them. Once this had been done the muru was over and the issue was settled.

Manning describes how the parties were affected by feelings of anger, grief, fear, and for the offender feeling whakamā. Both parties involved came from Rangatira lines, with great mana. They were leaders, therefore any loss of mana or feelings of whakamā would be greater than for persons of ordinary rank.

As leaders of their whānau, hapū and maybe their iwi, their whakapapa would give them greater personal mana and they would also gain mana from their leadership roles. Any offending behaviour would probably mean a greater price would have to be paid and this was the case in this case study. To mend the 
relationship the victims (the child's mother, her whānau and hapū) needed to be compensated and the father needed to acknowledge his wrong-doing, feel ashamed and be prepared to follow through with the muru process. The major value that was transgressed was mana (personal and collective). This was a significant transgression because the child could have been deformed or killed.

What is interesting to note is that although the boy obviously did not have as much mana as his father, what was recognised was the potential mana that this boy possessed and the significance of the life of a child with such status. The father's inquisition into the numbers of the muru party was again an issue of mana. Knowing that there was a big group coming gave the father the opportunity to restore his mana amongst the people. Thus, the process of muru enabled the father the ability to regain standing in the community by public acknowledgement of wrongdoing.

It is reasonable to suggest that the traditional Māori concepts that have just been discussed are interconnected and complementary to each other. However, the question must be asked, how relevant are these concepts in today's society where another culture dominates? More specifically how do these concepts relate to the rangatahi who find themselves engaging with the criminal justice system?

Firstly, the fact that the Māori culture and its people are still alive today makes these concepts relevant. They are an active part in the lives of many Māori who continue to live according to the Māori worldview and also those Māori who do not. This is capable because not understanding these concepts does not make you immune to feeling their presence. This knowledge is passed down through whakapapa from the atua to Māori (Mead, 2003) whether they identify as Māori or not.

Secondly, the principles of these concepts are very applicable today for rangatahi who are engaging with the criminal justice system because these concepts function on a different philosophical base than that of the standard court system. Mana is certainly an influencing factor within the court system which in turn make tapu, utu, whakamā and ea influential as well. The degree of influence is another matter that will be discussed later in chapter 6 . These concepts have adapted through time and continue to do so. An example of this is restorative justice. Restorative justice functions on a similar philosophical base as the Māori system. Although different, they do have many commonalities and may serve to mutually 
benefit each other. Restorative justice has become a major player in the youth justice sector and presents an opportunity for Māori to promote their ability to have a say in their futures.

\section{Restorative Justice}

It is claimed that the Māori voice was loud in calls for reform in the decades leading up to the passing of The Children and Young Persons and their Families Act in 1989. This was understandable given the statistical data. For more than a century, Māori whānau, hapū and Iwi have felt powerless and frustrated as the New Zealand Justice system continued to consume a disproportionate number of their young and their not so young. This Act sets out the youth justice system in Aotearoa/New Zealand (Maxwell, 2007).

It is nearly two decades since the inception of the Act. A significant amount of research has been carried out on all aspects of this Act, and in particular the process called the Family Group Conference. The first evaluation was carried out in 1999 by Maxwell and Morris, and the second in 2001 with a much larger sample of 1,118 young people (Maxwell et al., 2004). It is creditable and valuable that so much research and literature is available on the effectiveness and the shortcomings of implementing the goals and principles of this Act. When one ponders as to why this Act has received so much attention there are several possibilities to consider:

A. The Government was committed. It had taken nearly a decade of hard work by practitioners on the ground, professionals, researchers, policy makers and Iwi Māori before this Act was passed.

B. Those working with youth in the area of welfare and justice knew that the systems in place were not working. They wanted something that did work.

C. The Government wanted to move away from the welfare model and its high cost to the State. As Emily Watt explained, "the economic and political climate in the 1980s was most receptive to any cost cutting measures and there had been a progressive lessening of State responsibility for family and child welfare (Watt, 2003, p. 8)."

D. The Māori voice was calling loudly for its right to participate in all areas of Government decision making that affected them. They decried the mono-cultural nature of the 1974 Act (Watt, 2003). It was now Government policy that the Treaty of Waitangi be reflected in all its policies. 
E. The availability of an academic research team was committed, passionate and credible.

F. and, after the fact, discovering that part of the new process, the Family Group Conference, was almost a perfect model of the restorative justice concepts being developed in other parts of the world. In 1990, Howard Zehr's book "Changing Lenses" was published. This book introduced to the International community the idea of a restorative approach to justice in a modern context (Maxwell et al., 2004).

This approach was becoming popular in the international circles and Aotearoa/New Zealand had the research to support this approach. Gabrielle Maxwell attributed this interest to the fact that; "it is the only national system in the world and, because, it has been in operation for more than 12 years, judgements can be made about its ability to deliver what it promised in its early years, and is the first examination of the impact of all aspects of the system as opposed to an analysis of specific aspects such as conferencing" (Maxwell, 2007, p. 112).

Once again the notion of restorative justice is not unfamiliar to Māori. Māori conflict resolution processes came from a world view which is not at odds with most of the restorative justice values and processes. Concepts of mana and utu find their place within a restorative context, but more importantly the interconnectedness and holistic objective run parallel to the Māori system which achieves this interpersonal dynamic. There are many Māori who have reservations about the traditional justice system being able to be effective in responding to Māori and delivering appropriate processes (see Consedine, 1999; Hall, 1996; Ministerial Advisory Committee, 1998). Halls recommendations to the Ministry of Justice a new system by offering them control of the decision making process" (Liu, 2007, p. 35). Hall is not talking about a separate justice system but wants Māori to take responsibility for their own members in whatever community they live. She wants this factored into the existing system and adequately resourced.

From the literature, it is clear that there are different positions on how to make improvements in the justice system for Māori. At one end of the continuum, there is support for a separate system that would run parallel to the existing system. It would be based on philosophies from the Māori Worldview. Its principles and practises would be made relevant for today and it would be delivered /administered in a way that made sense to Māori. Moana Jackson (1988) has supported this position for many years and has presented papers to Government on this position. No 
Government of the day seems interested in this idea. Along the continuum is the notion of accommodating part of the Māori View into the existing system. The views of Consedine (1993) and Hall (1996) would place them here and the Children's and Young Persons and their families Act would also find a place at this position of the continuum.

The principles and objectives of the Act are summarised as to "emphasise the importance of diverting young people from courts and from custodial options; dealing with young people in the community and within their families wherever possible; holding young people accountable for their offending; involving victims, families and young people in processes of decision making; putting in place measures to assist with reducing reoffending; ensuring timely intervention; ensuring the completion of tasks agreed at the family group conference and making processes and services culturally appropriate" (Maxwell \& Morris, 1993, p. 42).

To ensure that these goals would be achieved six new processes were put in place. According to Maxwell (2007) they were; Police warnings, Police youth diversions, the family group conference, the youth court, youth offending teams, and community response teams. There is no doubt that this was a radical change from the previous model of justice. Judge F.W.M. McElrea, Youth court liaison judge for Auckland, identified three main changes:

A. They involve the transfer of power from the state to the community

B. The use of the family group conference as the mechanism for producing a negotiated community response

C. The involvement of victims as key participants, making possible a healing process for victims, offender, and the community.

The State has transferred its power to the family group conference where the offender, his or her family, the victim, and their support group, with the facilitator, the police and other professionals are all present in helping roles. "They assist the offender to recognise the damage done, and require the offender to be confronted by the victim as to the negative effects being experienced" (McElrea, 2007).

In this process the victim can also make suggestions for reparation and once the offender and the family have had a meeting they bring back a plan to the group for their approval. If the process thus far has followed best practise then the "mana" of all would have been maintained! 


\section{Conclusion}

Perhaps it is erroneous to continue referring to concepts such as mana, tapu and utu as traditional Māori concepts. Conceivably, as they are discussed at the start of the chapter, it would be preferable if they were referred to Māori concepts, as they were in traditional times. It has been established that these concepts are not locked in history but have evolved through time and continue to thrive today. Mana is a key factor in the criminal justice system. It is affected by the act of committing a crime, by the process of the criminal justice system, by the people controlling that process and by the victim. During this, feelings of whakamā are experienced by different people and induced by different situations and acts. Reparations and community service could be seen as the utu for the take. However, the end results of utu are more desirable than community service or reparations. A muru as described would most likely not be feasible due to an entrenched notion of individual possession. Nevertheless, the principles of this concept are still applicable today.

Restorative justice has a lot of potential for Māori in the youth justice sector. There are many challenges for restorative justice to overcome and understanding how these Māori concepts can integrate with restorative justice is just one of them. The importance of this integration is crucial to the success of this process as it can easily be done wrong and has a mediocre influence. Full commitment is a necessity so that tokenistic gestures are not seen.

This is perhaps is what Judge Taumaunu had in mind when he first started the MBYC in 2008. An integration of Māori concepts with the current youth justice process is the ideal goal. This thesis will contribute to integrating Māori concepts into the justice system. This will be done by examining the MBYCs, where Māori institutions, worldviews, and tikanga collide with the mainstream legal system. Observations of the MBYCs will be presented, as will information gathered from both organisers of the MBYCs and rangatahi who have come into contact with the MBYCs.

\section{Research Aim}

\section{Broad research aim}

The aim of my studies over the last three years is to work out how 'rangatahi' who have come into contact with our criminal justice system can reach their full 
potential as Māori New Zealanders, not reoffend and develop the tools to make a worthwhile contribution to our society.

\section{Specific research aim}

The specific aim of my study is to analyse the MBYC from the perspective of rangatahi, lay advocates and Kaumātua. The purpose of this was to better understand the processes that rangatahi go through when they came into contact with the criminal justice system and how cultural philosophies may better inform this process, so that improved outcomes may be achieved for these rangatahi. 


\section{CHAPTER 3: \\ METHODOLOGY}

\section{Epistemological view}

My research is based on kaupapa Māori philosophies and objectives with the use of a process based on qualitative methods. This is the best fit for my enthusiasm and passion of providing the benefits and relevance of values from Māori worldview philosophies for today, my desire to gain a more in-depth understanding of the life of young Māori in the criminal justice system, and my understanding of the importance of using culturally and age appropriate research methods.

Qualitative research methods allow the consideration of the all important social setting of the participants - the 'how' and 'why' a participant gives an answer, as well as the answer itself. It is understandable that some people find it difficult to express themselves verbally, and some are uncertain about their opinions. This was particularly evident when I was interviewing the rangatahi. This is where my ability as a so called 'insider' played a pivotal role. Being able to see inconsistencies or 'errors' as points of reference and understanding the potential meaning of them was important to this research. Furthermore, body language and slight nuances also contributed to the understanding of some of these inconsistencies.

The use of qualitative methods was chosen on the premise that it was of great importance to record the experiences that not only young Māori had with the criminal justice system but also those Māori who work in it and those who support the young Māori going through it, without bringing in too many preconceptions. I acknowledge that the conclusions and reasoning's I came to in this research were influenced consciously and unconsciously by the decisions I made through this research. I was not objective or isolated as a researcher from this research and made no attempt to be. I recognised the influencing factors and how they contribute to this research, which in many ways enriches this research.

\section{Kaupapa Māori research}

In the current academic climate it is very unusual to come across a piece of Māori focused research without it referring to the term Kaupapa Māori (KM). 
However, this term did not always have a common place in research. In terms of the history of Kaupapa Māori in academia, it is a fairly new concept. However, as the concepts stem from Māori conceptual frameworks, this research approach is not novel to Māori. Kaupapa Māori research has been around for as long as Māori themselves. Given the varying definitions of Kaupapa Māori research within academia, this chapter will explore the notion of what Kaupapa Māori research means in the current research that I have undertaken. Furthermore, this chapter will examine the emergence of Kaupapa Māori as an academic theoretical concept and also as it pertains to the Māori worldview. This will include exploring the fundamental principles and defining characteristics of this concept.

Kaupapa Māori is a concept, the origins of which can be traced back hundreds of years (Pihama, Cram, \& Walker, 2002). Although it has not always been called Kaupapa Māori, its existence has always been known. Indeed it could be stated that Kaupapa Māori is the theoretical basis that Māori have used in their research for a long time, but only now requires definition in order to distinguish it from what have become mainstream (Western) research practices in Aotearoa/New Zealand. It has now become necessary to label this approach Kaupapa Māori in order to comprehensively communicate the approach that is being taken when research is being conducted academically, not just by Māori but also by those researchers who wish to work with Māori people or within Māori communities (Barnes, 2000). Having this Māori framework identified today by a huge body of academic research has enabled Māori to articulate their practices and methods in the academic world which has otherwise been dominated by Western narratives (Smith, 1999).

As discussed in earlier chapters, the colonisation of the Māori people has transformed the landscape of the Māori world. This was not only the case during the historic colonising processes but still occurs today with forms of neo-colonialism. One facet that has been at the forefront of colonisation and that has evolved over time is research. Research has played a pivotal part in the dismantling, discrediting and demoralising of Māori knowledge and way of life. Smith (1999) states that research is a central component of the colonising process because it is concerned with defining legitimate knowledge. Merata Mita aptly articulates the relationship between Māori and research by commenting that "We have a history of people putting Māori under the microscope in the same way a scientist looks at an insect. 
The ones doing the looking are giving themselves the power to define" (Mita; cited in Smith, 1999, p.58).

For Māori, having the ability to define and legitimise one's own self in the realm of research is an important element in the search for self-determination. As Māori being one of the most researched people in the world (Smith, 1999; Bishop, 1997) it is of little wonder then that most Māori are distrustful of research. This distrust is further heightened when we consider that the benefits go to the researcher and not the researched (Bishop, 1997; Smith, 1999; Pihama et al., 2002). It is interesting to also note the process in which this type of research is undertaken, from collection to classification then dissemination to the West and then finally full circle back to those who were researched, but through Western eyes (Smith, 1999; Walker et al., 2006). Bishop (1997) adds that research has contributed to, and continues to contribute to the continual attacks on the integrity of Māori culture, resulting in Māori political and economical marginalisation and the ensuing impoverishment of Māori people today (Bishop, 1997).

While the number of Māori researchers continues to be substantially lower than those of the dominant culture, the articulation of appropriate practices when engaging with Māori has been supported by the efforts of emerging Māori researchers in the 1980s. Once these Māori researchers established themselves within academia and came to understand how the mainstream knowledge system functioned, they were able to challenge the legitimacy of the processes involved that served to exclude, control and exploit other knowledge systems. The increase in discourse surrounding ‘safe’ practice among both Māori and Pākehā research practitioners is encouraging in the progression towards appropriate research where Māori empowerment is promoted.

\section{Emergence of Kaupapa Māori methodology}

The emergence of Kaupapa Māori as a theoretical framework started during the so called 'ethnic' revitalisation movement (Levy, 2008; Pihama et al., 2002). The revitalisation of Māori language and culture were a result of the urbanisation, post World War II (Walker, 1996). Walker, Eketone, and Gibbs (2006) attest to the emergence of Kaupapa Māori research being influenced by several developments: the world wide movement of indigenous peoples to increase their self determination over land, culture and language; a greater commitment to the intentions of the 
Treaty of Waitangi resulting in a better understanding of the partnership between Māori and non-Māori and the protection of taonga Māori; and also the revitalisation movement as mentioned, such as education (Kōhanga reo and Kura kaupapa), language and tikanga and health models based on tikanga Māori (such as Te Whare Tapa Whā and Te Wheke; Walker, Eketone, \& Gibbs, 2006).

Smith (2003) makes reference to the 'real' revolution. He makes mention to the above movements as being the outward visible signs of a much more profound revolution. This 'real' revolution was a shift or reawakening of the mindset of a large number of Māori people:

... a shift away from waiting for things to be done to them, to doing things for themselves; a shift away from an emphasis on reactive politics to and an emphasis on being more proactive; a shift from negative motivations to positive motivations (Smith, 2003, p. 2).

This empowering psychological revolution of the Māori mind reignited the imagination and consciousness for Māori to realise their potential. What was of extreme importance here was that the Kaupapa Māori movement challenged and critiqued the dominant hegemony of Western research (Cram, 2001; Smith, 1999; 2003). Tired of being the ones who were being researched and dissatisfied with the Western methodology that encapsulated this research, the Kaupapa Māori movement was seen as a decolonising tool and a vital step towards selfdetermination (Cram, 2001). The term self-determination has a two pronged approach in the current context. From a political view point, self-determination refers to the reclaiming and ownership of Māori in social-political settings and is the common definition given for the concept of Tino Rangatiratanga. Concurrently, from a psychological view point, self-determination is derived from positive psychology and shows correlations to wellbeing (Ryan \& Deci, 2000). In essence, it is about empowering people to decide their futures and this is one of the aims of Kaupapa Māori.

\section{What is Kaupapa Māori methodology?}

According to Irwin (1994) Kaupapa Māori research is "a paradigm that stems from a Māori world-view" (Irwin, 1994, p.24). Smith (1999) gives meaning to the word kaupapa by referring to it as a plan, a philosophy and a way to proceed. She further explains that within this concept of kaupapa is a notion of acting 
strategically, of proceeding purposively. The defining feature of Kaupapa Māori is that it is grounded within Māori knowledge bases, world views, cosmology, philosophies, language and culture, all of which are considered valid in their own right (Henry \& Pene, 2001; Smith, 1996; Smith, 1999). This research has also been described as research by Māori, for Māori and with Māori (Powick, 2002). One area that much of the literature on Kaupapa Māori research highlights is the fundamental element of whānau as a structure to form research methods. The concept of Whānau is based around the fundamental relationships within the Māori world. Mead (2003) defines the concept of whānau highlighting the unique relationship Māori hold with blood ties. He explains that "The whānau principle, which is described by anthropologists as the kinship principle and by Māori as the whakapapa principle, underpins the whole social system" (Mead, 2003, p. 215). This principle of kinship and whakapapa acknowledges the responsibility and obligations of the person doing the exploring to nurture and take care of these relationships and also the intrinsic connection between the researcher, the researched and the research (Pihama, Cram, \& Walker, 2002).

Graham Smith summarises by stating that Kaupapa Māori:

- is related to 'being Māori'

- is connected to Māori philosophy and principles;

- takes for granted the validity and legitimacy of Māori, the importance of Māori language and culture; and

- is concerned with 'the struggle for autonomy over our own cultural wellbeing'. (1990; cited in Smith, 1999, p.185)

Barnes (2008) further supports this summary by suggesting that Kaupapa Māori is first and foremost about being Māori. This summary positions Kaupapa Māori research within the realm of self determination. Positioning Kaupapa Māori research within the search for self-determination is critical here as in order to produce systems of successful discipline for Māori youth offenders the summary would suggest that implementing these concepts would have more relevance for rangatahi.

\section{Fundamental Principles of Kaupapa Māori Methodologies}

Over the years Māori scholars have expanded and developed how we look at Kaupapa Māori research. As Māori academics delve deeper into deciphering 
Kaupapa Māori, some key principles have emerged as a foundation in which to discuss this methodology. Although Graham Hingangaroa Smith (2003) had identified six key elements when discussing alternate schooling and education, more elements have been further developed by other Māori Academics. The primary principles as highlighted by the Rangahau (2010) website are:

- Tino Rangatiratanga - The Principle of Self-determination

- Tino Rangatiratanga is concerned with having more meaningful control and autonomy over one's life. Kaupapa Māori is directly supportive of this notion as it has derived from a Te Ao Māori worldview and way of being. Pihama, Cram, and Walker (2002, p.34) go further to say that "Tino Rangatiratanga goes straight to the heart of Kaupapa Māori. It has been discussed in terms of sovereignty, autonomy, and mana motuhake, self-determination and independence."

\section{- Taonga Tuku Iho - The Principle of Cultural Aspiration}

- This principle refers to fundamental cultural concepts which include Māori language, knowledge, values and beliefs. The Kaupapa Māori paradigm is established within these concepts and seeks to validate and legitimise their existence (Smith, 1997).

\section{- Ako Māori - The Principle of Culturally Preferred Pedagogy}

- This principle asserts the use of Māori teaching and learning practices that have derived from a Māori pedagogy. Smith (2003) also notes that these learning practices do not necessarily exclude other forms of learning, and 'culturally preferred' practices can also be utilised.

- Kia piki ake i ngā raruraru o te kainga - The Principle of Socio-Economic Mediation

- This principle acknowledges the need for Kaupapa Māori to actively be involved in helping Māori communities who are disadvantaged and experience negative pressures (Rangahau Website, 2010). A point of interest highlighted by Smith (2003, p. 10) is that Kaupapa Māori practices have the ability to level unequal power relations as "Within the collective cultural structures and practices of whānau (extended 
family) some alleviation of the impact of debilitating socio-economic circumstances can be obtained".

\section{- Whānau - The Principle of Extended Family Structure}

- Similar to Tino Rangatiratanga, the principle of whānau and whānaungatanga is an essential aspect of Māori identity and culture and is central to the heart of Kaupapa Māori (Pihama, Cram, \& Walker, 2002). This principle acknowledges the responsibilities and obligations of the researcher to those being researched and can also help to dissipate unequal power relations that hinder traditional research methods.

\section{- Kaupapa - The Principle of Collective Philosophy}

- This principle refers to the meaning of 'Kaupapa' within the wider context of not only being concerned with research but also encompassing a broader purpose of benefiting the needs and aspirations of Māori communities (Rangahau Website, 2010).

- Te Tiriti o Waitangi - The Principle of the Treaty of Waitangi

- The Treaty of Waitangi was signed in 1840 as a governance partnership between Māori and the Pākehā. Leonie Pihama (2001) suggests that The Treaty of Waitangi should be considered as a principle within Kaupapa Māori because it is a document that defines Māori relationships with Pākehā and the Government. The Treaty provides a platform to "critically analyse relationships, challenge the status-quo, and affirm Māori rights” (Rangahau Website, 2010).

- Ata - The Principle of Growing Respectful Relationships

- Ata is a concept that highlights the importance of building and maintaining relationships. Taina Pohatu helped develop this principle to consider and understand relationships and how to maintain mana and integrity when working within Māori communities (Rangahau Website, 2010).

These fundamental principles have been articulated through academia and have shown that this methodology has been derived critically from an epistemological and metaphysical foundation as described by Tuakana Nepe (Smith, 
1999). The discussion on Kaupapa Māori seems strong within academia and no doubt more principles may develop in time.

\section{Participatory Action Research}

Participatory Action Research (PAR) is an action driven methodology that has a lot of commonalities with Kaupapa Māori and thus, can be interwoven into Kaupapa Māori. PAR is different from other research methods that are concerned primarily with research and investigation. PAR has change and action as the fundamental components of its approach (Walter, 2009). Reason (1998) describes this approach to research as having dual objectives:

One aim is to produce knowledge and action directly useful to a group of people through research, adult education or sociopolitical action. The second aim is to empower people at a second and deeper level through the process of constructing and using their own knowledge...(p. 71)

PAR is a methodology that aims to improve situations or environments by changing them through collaborative participation by both researcher and those being researched (Baum, MacDougall, \& Smith, 2006). According to Baum et al. (2006), PAR differs to more conventional approaches to research in three main ways. The first being, the purpose of the research is to promote change, which is achieved through a reflective cycle where data is collected and then the best means of action to improve the circumstances is chosen. Secondly, PAR is concerned with the power relationships between researcher and participant. Promoting a more shared approach in the research. Thirdly, most research approaches give the participants passive roles as "subjects". PAR encourages those being researched to be more actively involved, to which degree they are involved will depend on how willing the participants are. These differentiations help to build a clearer picture of what PAR is and how it fits in to the wider framework of methodologies.

PAR and Kaupapa Māori research have many similarities within their processes and approaches. Kaupapa Māori research supports the direct involvement of the researcher. This supports PAR's role as a major ingredient within the wider methodology of Kaupapa Māori Research:

Mutual understanding and control between both the researcher and the participants constitutes the degree of involvement of the researcher 
undertaking Kaupapa Māori research. This means that the researcher does not act as an individual agent but works alongside their participants in a reciprocal manner. (Powick, 2002, p.13)

The way researchers acquire their knowledge of indigenous communities is of extreme importance. As previously stated, Māori have not had a trusting history with research. The practices and approaches from researchers have undermined and dehumanized Māori while allowing the Western world view reign dominant denying validation of Māori knowledge (Smith, 1999). A collaborative approach from Kaupapa Māori research and PAR serves to empower its participants. In this respect the two are quite consistent.

\section{Kaupapa Māori and Psychology}

Argument over whether or not Māori have a psychology has fuelled debate over the last few decades. Lawson-Te Aho (1994) comments that Māori psychology lacks clarity or definition or does not exist as Western psychology does. However, for some Māori Psychology has been around since Māori themselves, al beit not theorised in the same way as Western Psychology (Durie, 1997; Nikora et al., 2006). Therefore, both sides generally agree that Māori psychology (if we agree that Māori have a psychology) is different to Western psychology. This section will explore the relationship between kaupapa Māori and psychology. This section will consider the different terms used to describe what a Kaupapa Māori psychology might look like, what it means to Māori and how it contributes to the realisations of Māori aspirations.

Terms such as cultural, native and indigenous are seen in psychology to have some degree of relatedness to a first-nations people or non-Western cultures' psychology. More specifically here in Aotearoa/New Zealand terms such as Māori, Kaupapa Māori and Māori centred psychology is often heard (Levy, 2007). Some writers have commented that there is a psychology specific to Māori and is created based on Māori forms of knowledge (Lawson-Te Aho, 1994; Milne, 2005; Levy, 2008). These forms of knowledge are based on tikanga and access to this knowledge is through mātauranga Māori (Durie, 1997).

For Aotearoa/New Zealand what this means is that psychological knowledge that is Māori-based and is derived from Māori knowledge is referred to as indigenous psychology for Māori and is also called Kaupapa Māori psychology. 
Therefore, what is the relationship between Kaupapa Māori and indigenous psychology? Firstly, let's consider indigenous psychology and its conception compared to what has just been presented regarding Kaupapa Māori.

Indigenous psychology academically is a field that has stemmed from a defiance to the overwhelming dominance of Western psychology, more specifically that of the United States of America (USA) (Nikora et al., 2006). This dominance has resulted from the belief that Western psychology could be applied to nonWestern peoples with equal relevance and validity (Levy, 2007). Not only was it imposed on non-Western people, Western psychology refused to recognise any other non-Western knowledge, disregarding interests and research done in other countries and languages, thus, solidifying Western psychology's dominance over the discipline (Kao, 2006). As a body of non-Western psychologists grew, so too did dissatisfaction with what they had learned from Western disciplines for solving the problems of their homelands (Kao, 2006; Shweder, 2000). Nikora et al. (2006) characterise the emergence of indigenous psychology as a search by indigenous peoples for a say in their future. Allwood and Berry (2006) expand on this by stating that: "The Indigenous psychology approach can be characterised as attempts by researchers in mostly non-Western societies and cultures to develop a psychological science that more closely reflects their own social and cultural premises." (Allwood and Berry, 2006; p. 245)

What this statement emphasises is the importance of culture and context. These are two concepts that struggle to fit within Western psychology and directly defies Western domination in psychology. Culture and context vary among different peoples and develop through time. Consequently, it is difficult to quantify, categorise and generalise which is what Western psychology aims to do (Moghaddam, 1987).

The conception and indigenous approach has a lot of commonalities to that of Kaupapa Māori, such as:

- A defiance to the supremacy of Western ways of knowing

- A fight for the legitimisation of indigenous forms of knowledge

- Self-determination to have a say in their own future

- Recognising culture and context as crucial 
These commonalities are also aligned with Levy's (2008) principles. Levy (2008) illustrates three fundamental principals describing a Māori, Kaupapa Māori, Māori-centred or Indigenous Psychology:

1. Māori knowledge bases and worldviews are central, positioned as the norm.

2. Control of knowledge base development rests with Māori.

3. Western psychology is not excluded, but must be critically analysed to ascertain value for Māori (Levy, 2008, p. 96).

It must be noted that Kaupapa Māori or indigenous psychology (in the Aotearoa/New Zealand context) does not wish to totally disregard Western forms of knowledge. It is about Māori taking control over their future to succeed in this world and critically analysing the value of Western knowledge (in accordance with Levy's third principle). Thus, Kauapapa Māori and indigenous psychology share an alignment that resists the importation of Western psychology without careful scrutiny.

\section{Kaupapa Māori and the criminal justice system}

The relatedness of Kaupapa Māori to the criminal justice system can be seen on two levels. The first is concerned with research and using Kaupapa Māori research as a significant tool of those who do research within this system. The second level is the framework and philosophies that Kaupapa Māori is based on to serve as a model for self-determination of Māori to have control over their future with the criminal justice system.

The first level of this relationship is concerned with research and method. This is of huge importance because research is critical to the decision making processes for the various policy makers within the criminal justice system. Therefore, being able to produce quality and reliable research is crucial to inform these decisions. According to Dixon (2006) one of the most successful treatments for Māori offenders is the delivery of Kaupapa Māori treatment by Māori themselves. As Māori are so heavily involved with the criminal justice system, best practise would be to use Kaupapa Māori. However, as Walker et al. (2005) commented, the majority of literature does not tell you how to do Kaupapa Māori research. Despite this, writers such as Linda Smith have commented on the basic requirements and protocols that must be adhered to when doing research with Māori. It must be noted 
that the following is not restricted to research just within the criminal justice system but all Kaupapa Māori research.

One of these requirements or protocols that has caused and continues to cause debate is that the research be done by a Māori researcher (Smith, 1999). The issue surrounding this debate is that there are so few qualified Māori researchers and those that are capable are over-worked (Walker et al., 2005). According to Walker et al. (2005) where there are gaps with no suitable Māori researchers then more training of Māori researchers is needed as well as some Pākehā involvement. Bishop (1996) explains that Pākehā can play a part in Kaupapa Māori research as long as they do not define, control or dictate the research. Pākehā also have an obligation under the Treaty of Waitangi to share knowledge and skills in ways that are of benefit to both Māori and Pākeha. Māori researchers will always be able to bring a deeper and comprehensive view because of their position as insiders. This is so that the views and realities of those Māori being researched can be accurately reflected. Outsiders may have more difficulty recognising cultural subtleties, nuances and sometimes the significance of what takes place (Kiro, 2000).

Researchers must also have a level of competence and display respect for tikanga, practises and people. This includes identifying yourself through your iwi, hapū and whānau affiliations, that is acknowledging whakapapa and the links that the researcher might have with the researched. Also sharing background information such as cultural background, professional background and research background (Walker et al., 2005). This, in a sense, changes the power dynamics of research with the researched assessing the researcher and the research to see if it is acceptable to them. Moreover, an important part of tikanga Māori is reciprocity. This is the notion of sharing and giving back, not just taking as has been the experience for most Māori that have been researched by non-Māori.

Following from this, a Kaumātua is crucial to any Kaupapa Māori research. This is crucial firstly, because Kaumātua are experts in tikanga Māori and can help a researcher understand, follow and respect tikanga. Secondly, a Kaumātua can help with gaining access to communities and participants as they are leaders within communities. Third and finally, they can be somewhat of a sponsor for your research, acting as a quality control and making sure that things are proceeding well and according with tikanga. That is why having experts in tikanga and Kaumātua are vital inclusions to the criminal justice system. 
The understanding of Kaupapa Māori as it pertains to data collection is very important. Walker et al. (2005) state that getting the process right must be the first consideration, then answering the research questions comes next. Many Māori researchers that are trained in Kaupapa Māori come from many different disciplines and those disciplines may inform the methods (e.g. questionnaire, experiment, ethnography) to be used but the process before that is to take into consideration and adhere to the Kaupapa Māori protocols. The information that is collected does not solely belong to the researcher as in Western research. Rather, it continues to belong to those who participated in the research. The researcher in this case is simply a kaitiaki (guardian) of that information. This is a huge responsibility. This is why it is important to constantly return to those participants throughout the analysis process making sure that their points of view are being correctly represented, and then seeing to a proper dissemination of the research through both academic and non-academic channels to make sure everyone benefits. The main point of all of this is cultural safety. Irwin (1994) articulates it to be about producing research that is culturally safe and can satisfy the rigours of academic research. She continues by saying that it is about "undertaking research as a Māori academic, not as an academic who happens to be Māori.” (Irwin, 1994, p. 27). These are just some of the guidelines and protocols for anyone who wants to do research with Māori within the criminal justice system and anyone who wants to do Kaupapa Māori research.

The second level of Kaupapa Māori and the criminal justice system, (the framework and philosophies that Kaupapa Māori is based on is to serve as a model for self-determination) is simple, uncomplicated and has been talked about earlier. It is about Māori aspirations of self-determination and to have a say in their future (Durie, 2005). Māori power within the criminal justice system is minimal, yet Māori make up the majority of those in prison. According to Jackson (1988):

"Each of the steps in the criminal justice process, from the enforcement role of the police through prosecution, legal representation, jury deliberation, probation reporting, judicial determination, and departmental oversight, are moulded by the same values and needs. The values are Pākehā, and the needs are the maintenance of a system which upholds Pākehā traditions and concepts of justice. (p. 154) 
This is most definitely the biggest obstacle for Māori to overcome. There have been attempts to use Māori tikanga in the prison system such as Māori focus units (Durie, 2003). Nevertheless, these Pākehā values and needs that Jackson discusses are too far entrenched for Māori tikanga to have a meaningful long-term effect. Kaupapa Māori is located at the other end of the scale to this system and its aims are to challenge the values and needs of these Pākehā entrenched systems.

Moana Jackson (1988) has been an avid support of having a separate justice system to cater to the needs of Māori. This system would be based on Kaupapa Māori practice and principles. No Government of the day has ever supported this idea.

Therefore, where does this leave Kaupapa Māori and the criminal justice system? There have been attempts to merge the two systems. However, the great difficulty and the reason why it has had little success is that these two systems have very different philosophical bases and, at times, they are in conflict with one another. The MBYC is an example of the merging of these two systems. The challenge is finding the right formula for it to be successful.

\section{Rangatahi Māori and research}

The issues surrounding rangatahi and research are very much similar to those of any other group of youths and research. Researchers have commented on the difficulty of getting young people to participate in research due to the connotations that academic research is over reaching (in terms of academic complexity) for them (Coomaraswamy, Dejanovic, \& Pridmore, 1998; Mayo, 2001). There is also the risk of youth being taken advantage of or manipulated. The related factor in these issues is power.

One of the major issues for youth is that of autonomy and decision making in relation to the research projects that they find themselves involved with. When considering the relationship between the youth and research the type of participation that the youth has in the research is important. Hart (1997) devised a ladder addressing the different forms and varying extent of participation for children and young people (Hart, 1997).

$$
\begin{aligned}
& \text { Child-initiated, shared decisions with } \\
& \text { adults }
\end{aligned}
$$




\begin{tabular}{|c|}
\hline Child-initiated \\
\hline $\begin{array}{c}\text { Adult-initiated, shared decisions with } \\
\text { children }\end{array}$ \\
\hline Consulted and informed \\
\hline Assigned but informed \\
\hline Tokenism \\
\hline Decoration \\
\hline Manipulation \\
\hline
\end{tabular}

The points of most importance here are the bottom three rows. This is what is commonly seen when research is conducted with youth that is not seen as 'participative'. In Tokenism, they are asked what their opinion is but they do not have a choice in the way they express that opinion (Hart, 1997; Mayo, 2001). Decoration is when young people take part but are unaware of the reasons or do not understand the issues (Hart, 1997; Mayo, 2001). Manipulation, the lowest level of the ladder, is when the researcher consciously uses young people's voices to promote their own message (Hart, 1997; Mayo, 2001).

These types of research are what must be avoided in any research with children. Because my research has an important rangatahi aspect to it, it would be detrimental to the validity and credibility of my research if it was conducted in a non participative way. Although the rangatahi I interviewed were not directly involved in the framing of this research prior to the interviews, they were well informed of the purpose of this research and given full reign to express their opinions and experiences as much or as little as they wanted to.

The fundamental difference with my research is that I approached the interviews with the rangatahi with a different notion of power. They were the ones that were the so-called 'experts' and I was there to learn from their experiences. In many other cases it is the expert researcher who comes in to do the research. Smith (1999) refers to this in Kaupapa Māori research where the table is flipped with the participants as the experts and the researcher as the less knowledgeable one (Smith, 1999).

Another issue of importance is giving voice to rangatahi. Rangatahi Māori are the ones most affected by this process of the MBYC, so it is important to listen to 
their voices when issues concern their own future. According to Fraser et al. (2004) it must be recognised that when youth are positioned as a 'social subject' rather than an object of study they can start to give us insight into the complex world of what it means to be a youth (Fraser, Lewis, Ding, Kellett, \& Robinson, 2004)

\section{Cultural appropriateness and cultural safety}

Irwin (1994) explains that Kaupapa Māori research is about doing research that is culturally safe and that can withstand the rigors of Western academia. This statement encapsulates both cultural appropriateness and cultural safety as it pertains to Māori. Cultural appropriateness is about having a research that is framed with the particular culture in mind and using methods that are suitable for that culture. Kaupapa Māori like Participatory Action Research puts the participants at the centre. To promote participation and a sense of ownership over of the research outcomes, it is crucial that the participants are comfortable with the methods used and the manner in which the research is carried out (Smith, 1999; Walter, 2009). Because of my 'insider' status as Māori and the fact that a large portion of my University education was dedicated to best practise for Māori research I was able to adhere to this.

For Māori, ethical issues surrounding research are far more complex than the standard consent forms and ethical application (Smith, 1999). Māori researchers have obligations that extend beyond the required ethical constraints of their academic institution. Te Awekotuku (1991) explains some of these obligations as:

- Aroha ki te tangata - a respect for people

- Kanohi kitea - the seen face, that is present yourself to people face to face

- Titiro, whakarongo, ... kōrero - Look, listen, ... speak

- Manaaki ki te tangata - share and host people, be generous

- Kia tūpato - be cautious

- Kaua e takahi i te mana o te tangata - do not trample over the mana of people

- Kaua e mahaki - don’t flaunt your knowledge (Te Awekotuku, 1991; Smith, 1999)

Some of these obligations are general to research. However, some are culturally specific. These are the obligations that Māori researchers put on themselves and these should be considered for non-Māori researchers who have Māori participants in their research. Adhering to these obligations can better insure that cultural appropriateness and cultural safety are better upheld. 


\section{Key informant interviews}

\section{Narrative interviews}

Individual narrative interviews offer meaningful information about the lived experience (Denzin \& Lincoln, 2003). Interviews are a way of collating information and are a setting to allow participants to tell their stories, or personal narrative in reply to interview inquiries (Denzin \& Lincoln, 2003; Murray, 2003). Narratives function by providing instances where participants are invited to recount and construe their experiences and also communicate issues and events that are significant to them (Hodgetts, Cullen, \& Radley, 2005). This interview technique allows the researcher flexibility to ask for clarity over concepts, stories and discussions that were not clear or ambiguous (Shaughnessy, Zechmeister, \& Zechmeister, 2006). This also allows the researcher the chance to ask supplementary questions. Supplementary questions are useful to explore further concepts and to engage with the participant in a way to show interest to promote discussion (Murray, 2003). Examples of supplementary questions are 'how did that make you feel?' 'why do you think you did that?'

\section{Semi-structured interview schedules}

The interviews will be largely semi-structured and open-ended. This format allows the question schedule to serve as a guide rather than a strict sequential frame that must be adhered to. Its format also permits the participant to control the production of information and explores a participant's experiences by using their own perceptions of the world. There are several key elements to a semi-structured interview; 1) there is an attempt to establish rapport with the respondent. 2) The ordering of questions is less important. 3) The interviewer is free to probe interesting areas that arise. 4) The interview can follow the respondent's interests or concerns (Smith \& Osborn, 2003, p. 56).

This interview technique allows the power dynamics of researcher and researched to be flipped, making the participant the expert as the topic is the social and psychological word of the participant (Smith \& Osborn, 2003; Smith, 1999). Breakwell (2006) comments that the order of questions is frequently unfixed and develops as a result of the flow of discussion. This also allows participants to engage as much or little as appropriate (Breakwell, 2006). 


\section{Participants}

Over the course of the interviewing process 5 rangatahi, 4 adults and 2 Kaumātua (erudite elders) were interviewed (total $=11$ ). The ages of the participants ranged from 16 to 75 . Two participants were female and nine were male. All participants were Māori and either came from Gisborne or had resided there for a period of time. All adults were involved in the MBYC on some level either working directly in it or supporting it. Efforts were made to obtain interviews expressing divergent attitudes by recruiting participants who performed different roles in the community, such as Kaumātua and lay advocates. All of the rangatahi had gone through the MBYC process (except for one who was supposed too, but did not turn up to the marae). It must be understood that the views expressed in the interviews are centred on the Mārae Based Youth Court at Te Poho o Rāwiri Marae and produced by people who have an understanding of the MBYC as it pertains to Te Poho O Rāwiri in Gisborne. Therefore, the opinions expressed by them are not to be generalised to any other MBYC or Marae based youth justice initiatives.

\section{Materials and Equipment}

The interviews were recorded using an Olympus WS-100 Digital Voice Recorder. Microsoft Word was used to transcribe the recording. Transcripts were then transferred for coding into the data software programme NVivo 8.

A semi-structured schedule was followed. With the rangatahi, open ended questions related to their experiences with the MBYC and the justice system in general were asked. With the adults of the study, open ended questions related to their role within the MBYC and any issues surrounding their role. With the Kaumātua, open ended questions related to their role in the MBYC and the taha Māori of this process.

\section{Audio recording of interviews}

Once consent forms have been signed (see appendix 2,3) and the participant is aware of their rights and the interview process, they are then advised that the interview will be recorded. They are also made aware that they have the right to stop the interview at any time. Using an audio recorder can bring about a more relaxed and open discussion compared to a video recorder, yet, limits the analysis to just the discussion. This can be overcome with observational notes by the 
researcher. Following the interview, transcribing will occur for content analysis purposes (Breakwell, 2006). Interview reviews summarising main themes for interviews will be compiled and used for the data analysis stage.

\section{Procedure}

The following procedure was used for both focus groups and individual interviews. A time and place was arranged for each interview. Prospective participants had a choice where they wanted to do the interviews. All interviews were either conducted at participants' homes or work places. At each interview an explanation was given about:

- The purpose of the research (see appendix 1a, 1b, 1c)

- The process of the interview

- Their participation being voluntary

- Their identity being kept confidential

- The ethical requirements placed on the research by the University

- The need to get their written consent if they wished to participate (appendix 2) and/or that of their parents or caregivers if they were under 17 years old (appendix 3)

- How they would be able to see the results once they had finished (if they chose to)

- The length of time; approximate minimum 20 minutes, and maximum 90 minutes

All interviews followed a semi-structured format following each question sheet pertaining to that particular demographic (e.g. rangatahi, adults, Kaumātua) (see index 4, 5, 6). At the conclusion of each interview a token of appreciation was given to the participants and they were retold that information provided would be treated with confidentiality. All interviews were later transcribed and analysed.

\section{Individual interviews}

The majority of individual interviews (as opposed to focus groups) were conducted with rangatahi. One other was a member of a rangatahi support agency for the MBYC. Decisions made as to whether participants would form part of a focus group or would be interviewed individually were made based on availability and willingness of participants. There was no strategic planning to try and put some participant in focus groups and others not. 


\section{Focus groups}

Three focus group interviews were conducted. The first was with three rangatahi, the purpose of which was to gain an understanding of their experiences in the MBYC. The second focus group interview was with three Lay Advocates. The purpose of this interview was to gain an understanding of their experiences in their roles and some of the issues that they come across. The third was with Kaumātua from Te Poho o Rāwiri Marae who have an active role in the MBYC. The purpose of this was to gain an understanding of the role that the marae plays in this process.

\section{Research questions}

As stated previously, the research questions were formalised into three sections, one for the rangatahi, one for the adults and one for the Kaumātua (see appendix 4, 5, 6). All questions were open-ended (apart from the demographic questions) and participants had as much time as they wanted to answer the questions. This gave the control of the development of the conversation back to the participants and they were able to expand on themes that were not directly the focus of the question.

\section{Research questions for rangatahi (appendix 5)}

The research questions for the rangatahi were structured under subheadings of 'Demographic', 'Experiences with the justice system' and 'Post court'. A typical 'Demographic' question would be - "what is your age?". Demographic questions are useful to understand the background and to also break the ice with questions that are non challenging. A typical question for the sub category of 'experiences with the justice system' would be - "Is this the first time you have been to a youth court?". These questions were vital in understanding how the rangatahi viewed the justice system and MBYC. A typical post court question would be - "When this is all over do you think you will come back again to other hui on this Marae?". This was important to establish whether or not the rangatahi had made a connection to the Marae and get a better understanding of the outcomes.

\section{Research questions for adults (appendix 4)}

The research questions for the adults were structured under sub-headings of 'Context', 'Process', 'Outcomes', 'Tikanga' and 'Other'. A typical 'Context' question would be - "What is your role in the MBYC?". This was again important 
to gain a background understanding not only of their role but the MBYC in general. A typical 'Process' question would be - "How would a young person's experience of the MBYC be different to the regular youth court?". This was important for understanding the practical steps and what is involved in the MBYC. A typical question for 'Outcomes' would be - "Are there factors that limit the achievement of outcomes?". This was important for the understanding of the effects that the MBYC was having and the issues around achieving successful outcomes. A typical question for 'Tikanga' would be - "Which concepts of tikanga Māori are working in this programme?". This was a very important part as Tikanga Māori is what differentiates the MBYC to other courts. A typical question for 'Other' would be "How transferable do you think the MBYC is to other communities?". This was to help the understanding of the MBYC - if there are any aspects that are particular to Gisborne that adds to the success.

\section{Research questions for Kaumātua (appendix 6)}

The research questions for Kaumātua were structured under the sub-headings of 'Demographics', 'Context', 'Tikanga' and 'Marae'. A typical question for 'Demographics' would be - "e hia o pakeke?" (“what is your age?”). A typical question for 'Context' would be - "I roto i tō tūranga hei Kaumātua, he aha tō mahi i roto i te Kooti rangatahi?” (“As Kaumātua, what is your role in MBYC?”). This was important to know how Kaumātua interacted with the MBYC and what they added to the process. A typical question for Tikanga would be - "he aha ra ngā tikanga Māori kua uru atu ki roto i te Kooti Rangatahi?” (“what are the types of tikanga Māori that have been introduced to the MBYC?”). This was important because Kaumātua are experts on tikanga Māori and have a deep understanding of how this tikanga interacts with the MBYC. A typical question for 'Marae' would be "E tika ana kia kawengia he Kooti Pākehā ki runga i wā tātou Marae?" ("Is the Marae the right place to be running Pākehā court systems?”). Again, Kaumātua are experts when it comes to the Marae and its functions. Therefore, Kaumātua have the understanding of whether or not the Marae has the capabilities to take this responsibility on. 


\section{Analytical approach}

Exploratory analysis was used as the attitudes of Māori towards the criminal justice system, youth offending and the MBYC in particular are yet to be significantly seen in the psychological literature. Transcripts were subjected to an inductive thematic analysis, according to recommendations outlined by Braun and Clarke (2006). This approach fuses content and discourse analytical methods. Extracts were taken from the transcripts based on their connectedness to the research question. These extracts were further examined and divided into themes according to the frequency of like response. The extracts relating to these themes were re-examined to determine whether they offered support to the extracted themes. Specifically, data was reviewed to ensure each theme was supported by numerous extracts to indicate patterned responding, coherence within themes, distinctiveness between themes, and relevance to the research question. This review allowed for a final set of main themes to be determined.

\section{Ministry of Justice}

The following chapters will give a practical insight into the mechanics of Kaupapa Māori research by reflecting on the research that I have done on this kaupapa. Firstly, this chapter will discuss how the Youth Court is structured and functions. Then it will look specifically at the role of the lay advocate, as this is a new addition to the Youth Court since the establishment of the MBYC. This chapter will also discuss, explore and compare the observations that I made 1) during a research trip conducted by the Ministry of Justice which I accompanied and took part in and 2) my own research conducted under Kaupapa Māori principles. Both of these were examining the MBYC (referred to now as the Rangatahi Court) in Gisborne on Te Poho o Rāwiri Marae. I will be considering the method used, the reactions of participants in both of the studies, how they respond to the differing agendas of each study and assumptions on the meanings of the non-verbal communication. This will be discussed through the format of: Process, Access gained, Preparation for doing the research, Conducting the research and Results.

To understand the context in which these two pieces of research were conducted, an analysis is needed of the Youth Court and its functions. The following is as described by the Ministry of Justice (2010). 
The standard Youth Court operates under the Children, Young Persons and Their Families Act 1989 (CYPF Act). The standard Youth Court is part of the District Court and deals with young people aged 14-16 years old whose offending is of a nature that it cannot be dealt with any other way except by bringing the young person to court. There are a variety of Government agencies that are involved with the Youth Court including, CYPF, police and the courts. There are currently seven roles within the Youth Court.

- Youth Court Judge - Youth Court Judges are specialist District Court Judges who are chosen for their training, experience, personality and understanding of the importance of different cultural experiences, personalities, cultural perspectives and values.

- Prosecutor - the prosecutor is the person taking a court action. In the Youth Court, the prosecutor is nearly always from the police.

- Youth Advocate - the youth advocate is a lawyer the court appoints to represent a child or young person charged with a criminal offence who is appearing in the Youth Court. The youth advocate is provided free of charge.

- Youth Justice Coordinator - the youth justice coordinator is employed by Child Youth and Family (CYF) and is the manager of the family group conference process, which includes contacting the participants, facilitating the conference, and recording the outcome.

- CYF Social Worker - Child, Youth and Family (CYF) social worker's who can be appointed to support a young person through the family group conference process, assess needs and ensure completion of the family group conference (FGC) plan.

- Court Taker - the court taker is employed by the Ministry of Justice and they are responsible for the smooth running of the court and ensuring that records of the hearing are accurately kept.

- Lay Advocate - the lay advocate is responsible for ensuring that the Youth Court is made aware of all cultural matters that are relevant to the proceedings and representing the interest of the young person's family or whānau to the extent that those interests are not otherwise represented in the Youth Court.

These are also the roles that are used at the MBYC. The only additional roles that are at the MBYC are the Kaumātua and Kuia to make sure that the tikanga and 
kawa of the marae are adhered to. However, the other roles do show subtle changes in their functioning. This will be discussed further in this thesis.

One of the more contentious aspects of the MBYC was the usage of the lay advocate role that had not been used previously. The following is an in-depth look into the role and its functions.

The role of the lay advocate is set out in section 327 of the Children, Young Persons, and Their Families Act 1989. The lay advocate is appointed by the court to support a young person at any point after a charge has been laid in the Youth Court. The primary responsibilities of a lay advocate as set out by the Act are to:

- Ensure the court understands any cultural matters to do with the case and provide the court with the cultural context of the young person;

- Assist and support the provision of appropriate cultural advice and information to the Youth Court;

- Provide the court with the cultural context of the young person's family; and

- Represent the interests of the child or young person's family to the extent that those interests are not otherwise represented in the proceedings (Ministry of Justice, 2010).

According to the Ministry of Justice the key tasks of lay advocates are to:

- Assist and support the provision of appropriate cultural advice and information to the Youth Court. This may be verbally or in writing;

- Provide additional and complementary services to the court and young person and young person's family in respect of culture. These services are in addition to the core services provided by existing youth justice professionals that ensure that the case proceeds;

- Explain the young person's family (in terms of cultural context) to the Youth Court;

- Represent the interests of the young person's family or whānau;

- Provide expertise to the court on the young person and the young person's family's culture; 
- Identify opportunities/sources of support/potential links to agencies or organisations that may assist the young person and their family in connecting with their culture and make appropriate recommendations on these matters to the family group conference;

- Provide support to other youth justice professionals regarding the young person's culture. (Ministry of Justice, 2010)

Moreover, the Ministry of Justice further describes the wider role of lay advocates:

Lay advocates work closely with Youth Court and Family Group Conference stakeholders and participants including the young person and their family, Child, Youth and Family staff, Youth Court staff, Police Youth Aid, Youth Advocates, cultural report writers and the Youth Court Judge.

Lay advocates liaise with a number of Government and non-Government agencies to assist the young person and their family. This work includes:

- Identifying potential opportunities for the young person in relation to community and culture;

- Identifying agencies that may be able to offer assistance to the young person and their family; and

- Making appropriate referral recommendations to the family group conference and Youth Court (Ministry of Justice, 2010).

Understanding the structure and functions of the Youth Court and the Lay Advocate position is vital for understanding the following sections as the issues surrounding them will be discussed.

The following section will compare two pieces of research that I was involved with. One was conducted under Kaupapa Māori principles and the other was not. This comparison will be made so the differences are visible.

\section{Study 1 - Ministry of Justice research}

This research was conducted and funded by the Ministry of Justice (MoJ). The objective of the study as far as I understood was to gain a better understanding of the MBYC or Rangatahi Court as it is known now.

My involvement with the MoJ was the result of discussions with Te Puni Kokiri (Ministry of Māori Affairs) about my topic of research. They were aware that the MoJ was planning on doing some research on the MBYC and initiated 
conversation with them to allow me to join their research group. This was a very exciting time for me as I had never worked with a Government agency before. My involvement in this study, although not specifically articulated, was that of a research assistant.

\section{Process}

Once everything was arranged, it was decided that there would be a meeting with all the team members at a later date. This meeting was to brainstorm and discuss the formalising of the research questions. It was here that I discovered that some of the members of this research team were from different sections of the MoJ and were responsible for finding out specifics in relation to their sector. Therefore, the questions that were formulated varied from general to specific. They were finalised and set.

Following this step in the process was the organising for the trip and then the actual travel to Gisborne. Once in Gisborne we were briefed on the movements for the following day and instructed on how we were going to conduct the interviews. We were to be split into teams of around 2-3 with one member being the primary question asker while the others took notes. Putting us into these groups enabled efficiency with interviewing as we had a short amount of time with a number of people to interview. Having the one person as the primary questioner and the other taking notes was important as none of the interviews were recorded and it can be distracting and disruptive if a person is asking questions and taking notes at the same time.

After the questions had been completed, participants were thanked, in appreciation of their participation. Each interview was approximately one hour long. All interviews were conducted with individuals, none as focus groups.

Once all the interviews were completed it was time to return to our home. Before we left we were instructed to share the notes (via email) we had taken with the others in the same interviews to compare and fill any gaps that may have been missed. Within one to two weeks of arriving home we had written up our notes and passed them on. To my knowledge the primary question asker had the task of collating the notes. During this time the only notes that the researchers were privy to were those interviews that they sat in on (at least that was the situation in my case). On the conclusion of this, my part in the research was over. 


\section{Access gained}

The MoJ funds all courts in Aotearoa/New Zealand. As such, they have an interest in how their money is spent. They have expected outcomes which would normally be monitored through milestone reports, visits and statistics. The MBYC as a new initiative was subjected to this research process to better inform the MoJ. As the funder requested this research I would assume that the MBYC would have not much option but to comply. This power dynamic between the researcher and the researched was a key element in this process and throughout this research project.

\section{Preparations for doing research}

As stated in the process portion of this section the preparations I was involved with was simply the meeting to formulise the participant questions. However, the trip was very well organised and would have taken far more preparation than this. Coordination with the Judge and the court coordinator would have been integral to the organising of interviews and locations. Time would have been spent organising accommodation, food and transport for the research team. For the people in Gisborne, they would have had to organise times when they were free to do the interviews and have to let people know that the MoJ were going to be around at court hearings and doing interviews. All of this would have had to take place for the preparation of this research. However, I was not part of this organising and these are my simple observations during the research project.

Because of this fact, I will look at the part I was involved with, question preparation. Present at this meeting were all members of the research team (some people at this stage were in the team but did not eventually go on the trip). One of the senior members of the team was the facilitator. We were told to write down on stick-it's what exactly we wanted to find out on this trip. Following this the facilitator put them all on a white board and we proceeded to identify and group common themes amongst them.

Once we had identified the themes we were put into groups and assigned a theme to formulate questions concerning that particular theme. This is where members that had a particular interest (based on the sector of the department that they were from) were assigned related themes. For example, if one member of the research teams job was to look at a specific role within the MBYC process and there was a theme related to the role then that person would be assigned the theme along 
with anyone else who had a interest in that theme. This is how the groups were formed. Discussions within these groups continued and questions were formed. It was at this point I realised that some of the things that I thought should be priorities were different to those of my team members and some of course were the same. Once all the questions were done the meeting was over and it was then passed onto the facilitator to edit and finalise the questions. Before everyone departed there was a brief on the travel arrangements.

\section{Conducting Interviews}

Interviews would begin with introductions from everyone in the room, stating their name and occupation. Once this was completed the questions started. We had a set question sheet with the specific questions that had been derived from the meeting prior to the trip. I had noticed that in the interviews I was involved with the primary questioner did not always ask the same questions to all participants. I do understand that there were some questions that may have been irrelevant for some participants but there were definitely questions that were relevant that were not asked to some participants. This may have been due to time constraints. However, for me, I think that it showed that priority was given to certain issues and perhaps valuing some people's opinions over others.

My observation of the participants was that some of them were guarded in their response to some questions and the way they answered questions. It was as if they were going to be made redundant and had to explain why they should keep their jobs. This again illustrates the power dynamics between researcher and researched. Because the MoJ take this power with them they inevitably influence the research before a single interview has started or word spoken.

\section{Results}

Unfortunately I was not privy to the final write up of the report. As stated previously my part in the research project was completed once I had passed my notes on to the MoJ. Therefore, I am somewhat limited in my ability to discuss the results of that report. However, the results for me were that I was able to gain an invaluable experience working with the MoJ, it showed me how this particular Government agency conducted research and it also allowed me to meet and connect with some of the people working in the MBYC. 


\section{Study Two - Participant Observations: My research}

This research was conducted by me. The objective of my study was to further understand the issues surrounding the MBYC from the perspective of not only the people who work in it but also those rangatahi who go through it.

\section{Process}

When any University student wants to conduct interviews they must first seek ethical approval from the ethical committee of their university. In this ethics application you must show a detailed description of your research, purpose, nature and your research questions.

The first step in the practical side of doing this research I had to ask permission to do interviews within the MBYC community. Once I had this permission I had to ask someone to help me identify potential participants. This was all done 'kanohi, ki te kanohi' (face to face) so I had to travel to Gisborne as this was the most appropriate way to do this. No interviews were done at this stage.

Once all was agreed upon, I returned home to prepare to for the next trip to Gisborne which would include interviews. Interviews were either to be conducted one on one or in focus groups. Once preparations were completed and the participants were ready I returned to carry out the interviews.

I would start the interviews with an introduction of myself and the research. This would normally lead in to a conversation about where I was from and the links between us which was useful in breaking up the formalities and making people feel more comfortable. Once each of the interviews was completed I reiterated that the interviews were confidential and expressed my appreciation with a small token of appreciation.

Once all the interviews were completed appreciation was given to those who helped make the interviews happen. I explained to everyone involved that I would be back to share the findings with them.

On return home, all interviews were transcribed, analysed and returned to those who wanted to double check their transcriptions. On completion, I returned to Gisborne to share the results with the participants and the whānau of the MBYC. 


\section{Access gained}

Gaining access was very different for me compared to that given to the MoJ. I believe that accompanying the MoJ in the previous research may have initially hindered gaining access for me as people made an association between me and the MoJ. This is why it was so important for me to go to Gisborne and meet people kanohi ki te kanohi. This was so I could explain to them my purpose and agenda. Another important factor I used in gaining access was my whakapapa and whānau links. My whakapapa links to Ngāti Porou were important as another 'insider' point and having whānau that lived in Gisborne that were known in the community also helped. This was instrumental in knowing who the right people to talk to were and who could offer assistance.

This is a time consuming process but it is necessary in any kaupapa Māori research. By comparison, the MoJ research worked under much tighter time constraints. However, they did not have to go through this process of relationship building to gain access. As stated previously the power dynamics were such that they did not have to.

The most positive aspect of the process I had to go through was that it was about forming meaningful relationships that are long term. This is in comparison with the MoJ research that seems to me to just come in, extract information, and leave.

\section{Preparations for doing research}

The preparation for this research can said to have started when I enrolled for my masters. However, for the purposes of this section I will start from when I formulated the questions. Interview questions had to be included in my ethics proposal. The way I formed the questions were not too dissimilar to those of the MoJ. I wrote down what I wanted to find out from the MBYC and formulated some questions around the themes that I could see. I decided on who I wanted to interview and shaped my questions around the different demographics I had chosen. What was not similar was the way in which I checked them. Once my questions were formed I sent them to my supervisor to look over and made adjustments as required. Then I showed them to my whānau to make sure that the questions were targeted correctly with the theme that I wanted to explore. It was important for me 
to have my whānau perspective on the questions because they serve as a check point for me and the research I am doing.

Once the ethics application was approved it was a matter of starting to gain access to the MBYC community (as stated above). I also had to organise food and accommodation for all the trips to Gisborne. On the completion of this, I was able to start to prepare for the actual interview trip.

To do this I had to make sure that I had all the paper work that I needed all printed out and in order, I had to make sure that all of the questions I had were in order, that all the ethics forms and parent/caregiver forms were in order, that I had all the taonga for all the participants and extras just in case, and I also had to prepare a time schedule for whom and where I was going to interview and on what day. I also had to keep in contact with people in Gisborne to update them on what was happening.

However, on arrival I soon found out that things do not always go to plan. What I am referring to is that my interview schedule went pretty much 'out the back door'. Although I was able to interview the people I wanted to I was very much at their mercy about where and when. Therefore it paid to be flexible and ready anywhere and at any time. This did not surprise me and to a certain degree I expected it. Therefore, in preparation I made arrangements to stay for a few more days if necessary.

\section{Conducting Interviews}

I would start by introducing myself which on most occasions would lead into an informal discussion about where I was from and who I knew. This was important to make the participants feel at ease. Once this was completed I started to ask the questions. I had a written individual question sheet for the different demographics I was interviewing and all summary sheets used language suitable to these demographics. Although these were the formal parts of the interview I made an effort to try and make them as understandable for the participants as possible. This was in order to make them feel as comfortable as possible.

Questions were followed accordingly although did not always follow in order. This was dependant of the direction of the conversation and was part of the semiinformal nature of the interviews. 
On completion of each interview participants were debriefed and presented with their token of appreciation. Participants were asked to indicate if they would like a copy of the results on completion.

My observations of the participants during the interview process were that they seemed more relaxed and comfortable compared to the participants from the MoJ interviews. This was evident after the introduction and informal conversations that had nothing to do with the research. There are many factors that could be attributed to the participants feeling more comfortable like the fact that the researcher was a Māori, that the researcher had whakapapa to that area or perhaps they were just having a good day. Whatever the reasons may be, it is the responsibility of the researcher to make the participants feel as comfortable as possible. Sometimes factors can influence this before the interviews have started, as noted in the research with the MoJ.

\section{Results}

The results from this research for me was the forming of meaningful and positive relationships which resulted in genuine and quality interviews, the production of a report that can help the community of the MBYC which may result in some better outcomes for the rangatahi who go through it and a culturally informed and conducted piece of research that is culturally safe and can stand the rigors of Western academia.

\section{A comparison between Ministry of Justice research and my own research: Concluding comments}

In conclusion I believe that although both pieces of research were about the MBYC and on some levels had the same objectives the methodology behind them, the methods used were very different. One interesting and important feature to note was the power relationship that both researchers had with the MBYC community. This was important because this has an influence on the research before it has even started. This is directly linked to the Kaupapa Māori principle of Tino Rangatiratanga - self-determination. The MBYC community had the power to stop my research at any time they wanted and withdraw any comments they had made. They also had the power to use or disregard this research in whatever manner they chose. Whereas, in the MoJ research, they did not have the power to stop the 
research (apart from simply not participating) or withdraw their comments. They did not have the power to decide what to do with the research.

The Kaupapa Māori principle of Taonga Tuku Iho - cultural aspirations was another point of difference for the two studies. In my research participants were given the option of speaking in Māori or English. In the MoJ research they were not. Because of my background as a Māori researcher I was able to understand cultural concepts and nuances and represent them accordingly. This level of understanding was not present in the $\mathrm{MoJ}$ research.

The Kaupapa Māori principle of Whānau - Extended Family Structure was evident in my research. This was apparent in the fact that I whakapapa to that area, so I took up obligations to the MBYC community when I decided to conduct this research. This obligation was to produce a research that was of benefit to this community and to do this I had to dissipate the power relations between researcher and researched. The MoJ research did not have this obligation. This relates directly to the Kaupapa Māori principle of Kaupapa - Collective Philosophy. This refers not only to the specific research but to the kaupapa in a wider sense. That is, the overall benefit for the entire community which was the goal of my research. This may also have been the goal of the MoJ research. However, the methods used and conduct carried out by them would have very little influence on the entire community. Whereas, my research has the potential to strengthen the marae, and therefore, the community.

These are just some of the Kuapapa Māori principles I have used to illustrate the value in Kaupapa Māori research and how the research method based on this can produce better outcomes for those who are researched. The MoJ research is the standard way the Government conducts their research and it may well be fine for non-Māori. However, as has been shown above, when Māori are involved, Kaupapa Māori is the best methodology to use to produce desirable outcomes for Māori.

The MoJ are restricted somewhat in their ability to produce quality Kaupapa Māori research because of Government requirements. Therefore, to remedy this, the MoJ not only needs to hire more Māori researches trained in Kaupapa Māori research but to also work with Kaupapa Māori researchers outside of the MoJ. These researchers must have the lead role in the decision making for how the research is conducted and interpreted. Until this is done, the MoJ will not be able to produce research that is fully representative of Māori communities. 


\section{Conclusion}

My epistemological view which this research stands on is that of Kaupapa Māori. This was chosen because of its cultural appropriateness and coupled with qualitative methods allowed an understanding of the social context of the participants. This in turn brings more value to the research. It has been well established now that Kaupapa Māori is a credible methodology within academia. It serves as a means to resist the overwhelming dominance of Western research paradigm that used research as a colonising tool. Kaupapa Māori was part of revitalisation revolution for Māori to regain their culture and to have a say in their futures. This was the move for Māori self-determination over their lives.

The defining feature of Kaupapa Māori is that it is grounded in the Māori worldviews, knowledge bases, cosmology, philosophy, language and culture, all of which are considered as valid in their own right. Kaupapa Māori is related to 'being Māori', connected to Māori philosophy and principles, takes for granted the validity and legitimacy of Māori, the importance of Māori language and culture, and connects to the struggle for autonomy over our own cultural wellbeing. Kaupapa Māori is grounded on the fundamental principles of Tino Rangatiranga - Selfdetermination, Taonga Tuku Iho - Cultural Aspiration, Ako Māori - Cultural Preferred Pedagogy, Kia Piki Ake i ngā Raruraru o te Kainga - Socio-Economic Mediation, Whānau - Family Structure, Kaupapa - Collective Philosophy, Te Tiriti o Waitangi - Treaty of Waitangi and Ata - Growing Respectful Relationships.

Participatory Action Research (PAR) has many commonalities with Kaupapa Māori. PAR is about promoting change for the better for the communities who are being researched. It is about power relations between researcher and researched, breaking down the traditional constructs of this relationship. It encourages those being researched to be more actively involved with the decision making of the research process. These aspects of PAR are well suited to Kaupapa Māori and, therefore, the two can be used in conjunction with one and other.

Kaupapa Māori and the relationship it has with psychology is credible. It can be said that Kaupapa Māori has more commonalities with the branch of psychology called Indigenous Psychology. Terms such as 'native' or 'cultural' have also been used to describe a psychology of Indigenous peoples. Indigenous psychology like Kaupapa Māori has stemmed from a defiance of the overwhelming dominance of 
Western Psychology, a fight for the legitimisation of indigenous knowledge bases, self-determination and cultural context as being fundamental elements of analysis. For Māori, reference to Māori Psychology or Kaupapa Māori Psychology has been made. This refers to psychological knowledge that is based on and derived from Māori knowledge bases. However, it does not disregard Western knowledge bases but it is about taking control over the research process and to critically analyse the value of Western Knowledge for the betterment of Māori.

Kaupapa Māori and the criminal justice system can be viewed as two opposites of a scale. Both are entrenched in totally different philosophies and principles and on many levels clash with one another. However, because the criminal justice system consumes a disproportionate number of Māori, the meeting of these two opposites would be inevitable. The MBYC is an example of this meeting and the challenges that it faces are mainly to do with the differences in these two systems. The challenge now is to find a common ground for theses two systems to work together to produce positive outcomes for Māori.

Rangatahi Māori and research identified that a lot of the research issues with other youth are similar to those of rangatahi. The three lower levels of Hart's participatory ladder identified situations of exploitation, tokenism and manipulation of youth. These are common situations for youth to find themselves in. However, it must be understood that conducting this type of research is neither beneficial nor ethical. As in Kaupapa Māori, participation and a sense of involvement in the outcomes of the research from the participants are desired. All of these are connected to cultural appropriateness and cultural safety. Māori researchers are obligated to extend past the ethical requirements of academia and adhere to the obligations of being a Māori researcher. These obligations ensure that cultural appropriateness and cultural safety are guaranteed. 


\section{CHAPTER 4: \\ PERSONAL BACKGROUND}

This section begins with an explanation of my own personal background, as this greatly influenced the way in which this research was conducted, fashioned and presented.

\section{My upbringing}

I approached this research as a young (23 year old) Māori male, passionate about rangatahi, my whānau, hapū, iwi and being Māori. My upbringing in a small rural community in the Eastern Bay of Plenty was amongst a predominately Māori population. Within this Māori world I was nurtured and grew, accepting and valuing Māori philosophies and practices. I spoke both English and Māori but Māori was my first language and the language in which I first learned to read and write. It is the values from this world that provided me with tools to better inform the way I conducted myself and this research.

\section{Secondary schooling}

Another influential period of my upbringing was the four years I spent at boarding school in Rotorua. I did not realise it at the time, but this experience enabled me to see how Māori interacted in an urban environment, how Pākehā and Māori interacted together, how very few of my peers could speak Māori, how many young Māori came in contact with the law and where Aotearoa/New Zealand was placed geographically in relation to the rest of the world as I travelled overseas on sports exchanges. This experience taught me that I had the ability to work out how I could fit in despite this environment being very different to the one I grew up in.

\section{Me as an 'insider'}

As previously stated, an important aspect of Kaupapa Māori research methodology is the significance of the researcher being an 'insider' (Smith, 1999). My background experiences could be considered as positioning me as an insider (Humphrey, 2007), when working with Māori youth. Thus, you could expect more genuine responses from the young Māori I interviewed. Firstly, because I am 23 years old and I am still considered a rangatahi in te ao Māori and the fact that I am 
only 5-6 years older than most of the rangatahi I interviewed might facilitate open response from them. Secondly, being both Māori and male positioned me as an insider, as all the rangatahi I interviewed were Māori males. Thirdly, having a rural upbringing in a predominately Māori community allowed me to connect with those rangatahi that had a similar upbringing. Fourthly, having spent my High School years in an urban environment allowed me to connect with those who were brought up in the cities and towns. It must also be noted that Rotorua and Gisborne are not too dissimilar in terms of population, with both having a large Māori population compared with other urban cities.

\section{Me as an 'outsider'}

All of these elements of my upbringing enabled me to better relate to the rangatahi I interviewed and I believe made them more comfortable. However, there were some aspects of my background that may have put me in the position of an 'outsider': namely, my education at University and perhaps my education at High School. The majority of these rangatahi had either left school or were expelled from school. Therefore, knowing that I was at University and that the reason for me seeking to interview them was because of my studies at University may have positioned me as an 'outsider'. Also, following the ethics and processes surrounding interviewing people formalised, to a degree, the interaction I was having with the rangatahi and might have caused social distancing.

Despite these possible 'outside' factors, I believe that my background circumstances that place me as a so called 'insider' overcame those of the 'outsider'.

\section{My training in psychology}

My training in the field of Psychology and in particular that of qualitative research, has guided and informed the method in which I conducted this research. This training has informed what I note is of 'interest' and 'important' during the course of this research and has contributed to some of the conclusions I have reached. My training in this field has provided a framework to be guided by. However, the substance of this frame is heavily influenced by my upbringing and experiences as a Māori. Therefore, this also serves to inform what I note are of 'interests' and 'important'. This combination is integral to informing my research. 


\section{CHAPTER 5: RESULTS/DISCUSSION}

The objective of this study was to analyse the MBYC from the perspective of rangatahi, lay advocates and kaumatua. The purpose of this was to better understand the processes that rangatahi went through when they came into contact with the criminal justice system and how cultural philosophies may better inform this process, so that improved outcomes may be achieved for these rangatahi. Interviews were conducted in Gisborne with the three demographic groups. Following this, they were transcribed and then later analysed using thematic analysis (Braun \& Clark, 2006). Interview data were coded into basic units of meaning, the codes were arranged into subthemes, and finally subthemes were arranged into overarching themes (more details on the analysis is provided in Chapter 3, under the heading 'Analytical Approach').

This analysis produced four major themes: Tā te Ture ki te Rangatahi, Whakamā, Te Wairuatanga o te Marae and the Potentiality of the Lay Advocate Role. Within each major theme were a set of subordinate themes that were directly related to the major themes. These themes are analysed and discussed below. It must be noted that the extracts that have an 'H:' at the beginning represent the researcher and all other letters represent different participants.

\section{Tà te ture ki te rangatahi (Law as it pertains to the Rangatahi)}

Throughout this research it was of utmost importance to gain an understanding of how rangatahi perceived law and the processes surrounding law. It was also important to see how this law and process were impacting on them and if the desired outcomes of these laws were being achieved. In short, this section is concerned with understanding what parts of the process of law is having the most impact on the rangatahi and how this effects them. This will be done by considering generally the parts of mainstream law that influence rangatahi the most, followed by the MBYC law and its influences on the rangatahi. Thereafter an analysis will be presented on the process called the family group conference (FGC) in relation to rangatahi. Finally, a discussion on the distrust of the rangatahi towards law will be offered. 


\section{Rangatahi and the law}

It was apparent that the majority of the rangatahi that were interviewed had a great deal of procedural knowledge about the consequences of lawbreaking and court processes. The following are typical responses from the rangatahi illustrating this point:

H: What happened after your court hearing?

G: We got a curfew, I got remanded with a curfew .... then I was called again for my last one (court hearing)

H: So what happened after your court hearing and all of that?

O: For the first and second court case we had a FGC, a FGC conference I got 32 hours of community service and reparation and just a curfew.....

It is interesting to note that despite the questions not being directly targeted at the consequences or outcomes of the process, this seemed to be the most significant part of the process to the rangatahi. This suggests that the rangatahi are interested in the outcome or consequences of the law. To put it simply, they are interested in what they have to do to 'get off'. It was also apparent that these rangatahi were testing the process of the law, getting to know how far they could push it and again, understanding what consequences would arise. This rangatahi was commenting on the plan that was made for him in his FGC:

O: I went and sussed out my drug counselling at the hospital, they told me I had to go back six times a month. I didn't even go I only went once, after court. I never even got chased up on it.

These rangatahi are focused on the outcomes of their offending that directly impact them, and they have an understanding of how far they can push the law. A contributing factor to why the rangatahi are so focused on personal outcomes is that the rangatahi have little understanding of what is actually going on in terms of legal procedures, as is evidenced in the following extracts.

$H$ : when you went to court the first time did you understand what was happening?

G: Oh nah, not really

$H$ : When you went to the court in town, did you know what was happening?

N: Nah-all their fancy words..... 
H: So you didn't understand?

M: Like that word adjourn that's all I heard at the district court and I was like ay?...

There are many contributing factors to why these rangatahi are so focused on the consequences (and some of these consequences will be further discussed in this chapter). However, having a significant lack of understanding of what is actually going on is an essential and important contributor. Because being in a situation where you are the subject at the centre but are unable to understand what is going on results in a reaction of "well just tell me what I have to do" or as one of the rangatahi put it "I just want to know at the end of the day at my court case is whether I'm going to jail or not". This lack of apparent concern about wrongdoing and focus on consequences in terms of punishment is most prevalent when the rangatahi are talking about the standard court in town. On the other hand, this is an area that the MBYC seems to be addressing.

$H$ : When you went to the court in town, did you know what was happening?

N: Nah-all their fancy words and at the Màori court they explain what's happening to you.

\section{Rangatahi and the Marae-Based Youth Court (MBYC)}

There seemed to be a unanimous agreement that the MBYC was better than the standard court in town. What was interesting were the reasons offered as to why MBYC was better.

H: Why do you think when you went to the marae one, why did you and your whannau choose to go to that one?

N: Because it's better

H: Why?

N: I don't know because they give you heaps of chances

H: What do you think are some of the differences between the Māori court and the one in town?

O: ...it's faster than the Pākehā court... because not many people go to the Māori court aye gee. It's just like boom and you're straight in. 
This was a difficult question for the rangatahi to answer. These two responses were very typical. Although the rangatahi were able to express that they preferred the MBYC, the difficulty was centred on their ability to articulate why the MBYC was better. This could be expected due to the age of the rangatahi. However, it also highlighted that the court process does not give them the words to articulate why they think the MBYC is better. Because of this the rangatahi resort once more to the procedure and outcomes for them of not having to wait as long and the perception of having more chances.

This perception of having more chances can also be interpreted as having more opportunity. The rangatahi expressed that the MBYC gave them more opportunity in terms of things to do after court.

H: Do you think going to the marae court will help you not reoffend? $N$ : Yes, the marae court gives you more opportunities, like the marae court was the one who appointed me to (name removed) and this course. It gives me something else to do in the day other than robbing people and growing dope plants...

$N$ : (name removed - same as above) is a positive role model he takes us to kickboxing, mau rakau and takes us to youth work, that's where I do my community hours...

This is one of the important factors that influences recidivism. The MBYC seems to be directing the rangatahi into meaningful relations and programmes after the court process. This is having a direct impact on the rangatahi as stated above with the comment: "It gives me something else to do in the day other than robbing people and growing dope plants".

\section{Family Group Conferencing}

The introduction of restorative justice and in particular family group conferencing was a dramatic change for Aotearoa/New Zealand's youth justice sector (Watt, 2003). One of the main objectives of this process was to hold young people accountable for their offending. This was to be achieved by having the victims and their whānau present, and also the whānau of the rangatahi offender (Maxwell, 2007). This was to put a face to the offending of the rangatahi which they previously never saw and to incite self-reflections and feelings of remorse (Maxwell, 2007). 
In theory, this process seems logical. However, reality does not always portray a similar picture. This was certainly the case when discussions concerning the FGC took place, as in the following two extracts.

$H$ : did you have a FGC?

N:Yeh, they made me a plan, I got 40hrs community

work...Wednesday, Thursday, Friday night and they extended my curfew...

H: so going back to your FGC, can you tell me a bit more about it?

N: Just got more hours and that

H: what happened during that? Who was there?

N: My mum, my dad that I was staying with, my mates mum and yeh

the cop.... just more hours and attending that programme and

complete my hour. Oh and pay my reparation.

Once again this demonstrates the significant focus the rangatahi put on the consequences and outcomes of the process. This part of the process is supposed to encourage self-reflection, accountability and feelings of remorse (Maxwell, 2007). And yet, throughout all the interviews with the rangatahi there were very little signs indicating any of this. One of the major contributing features to this was the fact that the majority of FGC that these rangatahi attended, the victim/s was/were not present. The only times that there were any signs of remorse or accountability was when there would be discussions about the victim or on the rare occasion when the victim was at the FGC.

H: Did you ever see the victim after it?

$N: N a h$

H: Would you have wanted to?

$N: N a h$

H: Why not?

N: Because

H: Do you think it would have made you feel stink?

$N:$ Yeh

The next extract is from when a victim was present at the rangatahi FGC.

$H$ : What happened at your FGC? 
M: They made me a thing (plan) and I got community hours. The victim was there too.

H: How did that make you feel?

\section{M: Raatshit}

Notwithstanding the lack of articulated descriptive remorseful feelings, it was evident that remorse was felt. It is not in the nature of these rangatahi to discus personal feelings or expect an in-depth soul searching journey. These rangatahi (and most other youth) lack the communicative skill to articulate such feelings and likewise a desire to do so. This is where other cues need to be taken into consideration. These are personal observations such as; noticing that after the rangatahi would say "stink" or "raatshit" there would be a long pause before the conversation would continue. Furthermore, there would be a slow descent of the head and in addition to this would be a reduction in volume of the words being spoken during the topic of the victim indicating whakamā (Metge, 1986). All of these factors contributed to my belief that these rangatahi were feeling some level of remorse.

At the same time, there is another side to having the victim involved. This is of a concerning nature and shows how this process can be taken advantage of and contribute to the dissatisfaction that the rangatahi have towards the law.

H: What happed at your FGC?

O: The fullah recons he was gonna punch my face through the window, the victim, "come on then bro" went to court, bullshit, got curfew and all that

$H$ : ... did they do you up a plan at your FGC?

O: Yeh, reparation

$H$ : Did the victim have anything to do with your plan?

O: Nah, but tried too. Tried to make the reparation higher and put things in there that I didn't even take.

Despite this being a rare occasion, it exemplifies how an FGC can go wrong. Having open confrontation between the two parties involved defeated the entire point of the FGC, that of generating feelings of remorse from the rangatahi as a result of the victim being there. Behaving in a confrontational way towards the rangatahi automatically triggered a defensive response from him. Consequently, this shut off the path to remorseful feelings and thus turned the victim into the enemy in 
the eyes of the rangatahi. This extract also highlights a limitation of the process. The social psychology rule of equity follows that for maximum fairness within a relationship the input to output of the two parties must be equal (Liu \& Hanke, 2007). Within this context, the two parties are the offender and rangatahi. Liu and Hanke (2007) identify that that this equity rule is qualified by the self-serving bias, or the tendency for people to overestimate their own contribution or cost. The victim may have overestimated the cost of reparations to fulfil his/her self-serving bias. This obviously leads to perceptions of unfairness and no feelings of remorse or accountability. Therefore, in this situation, the combination of antisocial behaviour and self-serving bias from the victim has lead to a disillusioned rangatahi. This leads to the following section where further discussions on these matters will take place.

\section{Feelings of distrust towards the law}

The relationship that rangatahi have with law and the processes of law have never been pleasant and understanding the nature of this relationship can lead to explanations as to why this is the case. The role law and its processes plays is to punish 'wrong doing' and it is our rangatahi who are doing a lot of the wrong doing. This relationship is never going to be one of mutual agreement, nevertheless, there are standards that regulate this relationship. Although this may be true, the above example suggests that these standards are not being met. This is not a stand-alone incident:

H: How did they treat you when they picked you up?

$N$ : The second time they (the police) picked me up was when I was breaching curfew, and they beat me up, but I defended myself ....got back to the cells and they tried to beat us up in the cells. I don't know if they are allowed to do it but they took all my clothes off me, had me in the cell with only my undies on there was about nine of them in the cells and they were trying to beat us up.. They must have been thinking "we will fix you up", they were just being funny guys.

H: So do you have more respect for the marae court than the other court in town? 
O: Yeh, yeh, because like... like people who always judge me at my court case like (name removed) saying that I'm nothing but a little asshole and I was standing right behind her.

H: Where was this?

O: This was at the district court

H: Who is she?

$O$ : She is the police woman.

Moreover, these accounts are also supported by the lay advocates that were interviewed. These lay advocates have witnessed firsthand some of the instances that these rangatahi mention.

$U:$....there are certain processes that we go through like the FGC which personally I think has been a letdown in NZ history ...unfortunately depending on who you get to coordinate that meeting it can be outright racist and volatile setting, unsafe. kids have been called dumb maoris, ugly, one of them had been called a 'dog'.

It is well understood that young people have a tendency to over exaggerate things especially when they are in the presence of their friends. Regardless of this, these exaggerations are conceived from a level truth and despite how grand the story may be the fact that it is happening at all regardless of what level is unacceptable.

This poses problems on many levels, but in particular the level of restorative justice. The point of restorative justice is about accountability and remorse. However when rangatahi are treated in this way it is they that become the victim and they begin to put up barriers of protection. One of the outwards signs of these barriers or protective mechanisms is to put up a front or persona. I will refer to this as the 'façade persona': this is a front detached from feelings, with a heightened sense of self portrayal in a particular image. Jackson (1988) locates the origin of this persona as an ideal forged in the Western past where masculinity was equated with dominance and emotional suppression. It is an ideal which has shaped not only the Pākehā male's concept of acceptable behaviour, but also distorted and oppressed traditional attitudes to the male/female relationships in Māori society (Jackson, 1988).

Once a person is immersed in this persona, it is almost impossible to get any remorse or accountability from them. One of the main catalysts of this persona is 
police. This is because the police threaten this self image of a tough, lawless and care free individual which is popular in their peer group. This in its raw form is about notions of power relations and mana. Police also give opportunity for the consolidation of the 'façade persona 'because the youth see it as an opening to show their lawlessness against the enforcers of law. That is why it is not uncommon to hear the rangatahi talk about 'beating up the cops' or 'breaking their noses'. However true or untrue these statements may be, they illustrate the need to consolidate this 'façade persona'. This is supported by this extract from one of the lay advocates:

$V$....I've had parents tell me a story of their son walking home to meet his curfew, a cop car pulls up and the police officers are friends and watch this boy go from just chillin and when he saw the cop car he turns into this aggressive person....

$U:$... they put on the face for the CYF worker or the police, that staunchness...

The existence of this persona is also supported by the Kauamātua:

T: Ae, ka kite rātou i ngā Pirihimana e haerere ana e haere ana, a, ka kite koe i a rātou e whakatū ana i a rātou, e whakapakari ia rātou, kāore mō te kōrero, engari mō te whawhai...

(T: Yes, when they see the police walking you see them making themselves bigger and look more stanch, not for the purpose of talking but to fight...)

The Kaumātua also note that this behaviour or persona is not seen at the marae:

T: I kite mātou i a rātou $i$ waho o te kooti e whawhai. Kāore koe e kite i tērā āhuatanga ki tō mātou marae.

(T: we saw them fighting outside of the (District) court. You do not see that happening at our marae.)

This is one of the major challenges in achieving restorative justice. Because the current law system presents so many opportunities to consolidate this persona. As the rangatahi get older and more experienced at playing this 'game' this persona becomes more solidified and real to them. A key factor in whether this takes place is how feelings of whakamā are handled by the justice system. It also seems as if the marae abolish the façade persona. This is valuable so that restorative justice practises can take place without being hindered by this persona. 


\section{Whakamā}

Whakamā is a concept that is of great importance to the discussion of Māori and the criminal justice system. Metge (1986) testifies that any study of Māori offenders' motives and attitudes will be incomplete if it does not give due consideration to the pattern of behaviour and ideas associated with whakamā. Whakamā is a concept that was evident throughout the interviews. Although not always verbalised as such, behaviour and concepts discussed were of a whakamā nature. Whakamā can be defined variously as shy, embarrassed, feeling ignominious; it often involves loss of mana or lack of mana (Ryan, 2005).

Understanding whakamā and how it relates to rangatahi who have come into contact with the criminal justice system can be exemplified through Metge's six causes of whakamā (as discussed earlier in chapter 1). This will take into consideration both the MBYC and the standard youth court.

The first cause of whakamā is the perception of lower status. This is a perception that is predominately evident in the standard youth court. The environment is set up to emphasize this with the multilevel layout of the court. As stated by this kaumatua:

\section{T: Ko te tū hoki o te kooti Pākehā, ka haere koe ki roto nā ko koe te} mea kino, ko te kooti Pākehā nei kei te tū i konā ki te whakawā ia koe...

( $\mathrm{T}$ : it is also the way the standard youth court is set out, you go in there and it is you the one that is bad, the youth court is standing up here to judge you...)

Becroft \& Thompson (2007) state that the majority of youth courts hearing are held in adult court rooms, there are few youth courts purposely built. Therefore, these courts are set up to operate in the traditional adversarial manner (Becroft \& Thompson, 2007) which exacerbates the feelings of whakamā.

Another factor is the way the standard court is conducted. Engagement from the rangatahi in the standard court is minimal with their lawyers doing the majority of the speaking. The manner in which dialogue proceeds is as if the rangatahi were not in the room. This is pointed out by this rangatahi:

O: At the DC they are talking amongst themselves and we don't know what they are saying or what's happening. It's the lawyer's case, we are charging the lawyer not the actual client. They are talking to the 
lawyers about my case and I don't even know what they are talking about.

Not only does this extract illustrate this point, it also is an excellent representation of the next cause of whakamā, which is uncertainty and confusion. A common theme that has been discussed before is the lack of understanding that the rangatahi had about dialog and in-court procedures as shown by the above extract.

This also has great implications to cultural alienation. Metge (1986) comments that Māori can feel whakamā when they feel they ought to know what is right but do not. This can be related to the rangatahi who missed his court hearing at the marae. When discussing the reasons why he did not go to the marae it was apparent that this rangatahi was uncertain and uncomfortable with his Māori identity.

\section{G: Just coz you don't have to do all that Māori stuff... What is it? Your whakapapa or something}

Although the rangatahi did not outright say that he was whakamā about this, he was displaying some of the outward signs of whakamā as according to Metge (1986), such as looking down, hand fidgeting, pausing for a long period, and reducing the volume of his voice while discussing the issue.

The third cause of whakamā, which is more beneficial from a restorative justice standpoint is recognition of fault. Within the restorative justice context this is about accountability and taking ownership of your actions that have lead to contact with the law (Maxwell \& Liu, 2007). The intensity of whakamā when caused by recognition of fault can be increased with the presence of the victim/s (Becroft \& Thompson, 2007). Also, in cases where whakamā is not felt despite recognition of fault, the presence of the victim/s can cause whakamā. The presence of the victim gives a human face to the offending (Maxwell \& Morris, 1993) of the rangatahi which the rangatahi do not often see and helps the rangatahi recognise their fault and the human implication it has. This resonates with restorative justice extensively (Maxwell, 2007). This was evident in the discussions with rangatahi about victims:

$H$ : what happened at your FGC?

M: they just made me a thing (plan) and I got community hours. The victim was there too.

H: how did that make you feel?

M: Raatshit 
H: did you see the victim?

$N: n a h$

H: would you have wanted to?

$N: n a h$

H: why not? Would it have made you feel more stink?

N: Yeh

Once again, during the discussion of this topic there was overt behaviour of the outward signs of whakamā such as looking down, hand fidgeting, long pauses and a reduction of volume of voice (Metge, 1986).

The fourth cause of whakamā is being put down. This is concerned with the belittling of people and the trampling of mana. This can be observed in the following extract of a rangatahi describing how a victim did this to him:

O: The fullah recons he was gonna punch my face through the window, the victim, "come on then bro"

This showed how a situation of potential whakamā can change due to the actions of the victim, essentially (in the eyes of the rangatahi) turning from victim to enemy by their own hand.

Being put down by court staff was also an issue for rangatahi. When discussing the differences between the adults running both courts this was said by one of the rangatahi about the adults in the standard youth court:

N: They just judge us so fast, I'm sure when they were young like us they would have got into mischief like us, no one's perfect.

This rangatahi is expressing his views that they are not bad people because of their offending, but this is adolescent behaviour.

The fifth cause of whakamā is being singled out. In essence the whole court process is about singling out the offender. This can be both positive and negative. A positive example is where a rangatahi would be singled out so that he may feel remorse and accountable for his offending then he would be treated for his whakamā once sufficient time had passed (Metge, 1986). A negative example would be when a rangatahi is singled out and the whakamā is left untreated or if there was anti-social behaviour involved.

The sixth and final cause of whakamā is on the behalf of others. People can feel whakamā for or because of someone else. This happens most often and is deeply felt with regard to people with whom the person is closely linked: children, 
parents, close kin, close friends (Metge, 1986). This is exemplified by this rangatahi extract:

H: did your whānau go with you?

O: I went by myself, I don't like my whānau coming with me because it feels like I'm shaming myself in front of them, coz then they will know I'm a mischief little bastard.

This rangatahi expresses a dislike of having his whānau at the court because he does not want his whānau to feel whakamā because of his actions. By them feeling whakamā it intensifies his own whakamā because of the notion of collective responsibility (Mead, 2003) and enforces the fact that the rangatahi does not represent an individual but a collective (Jackson, 1988).

It can be deduced from these causes of whakamā that it can have both a negative and positive side. What is of interest here is that the situations that cause whakamā in a negative manner are seen predominantly in the standard youth court. What differentiates between the two is the intensity and duration of the whakamā. According to Metge (1986) variations in the expression, intensity and duration of whakamā are closely related and can be traced to differences in immediate cause, in the identity of the person experiencing it, and in surrounding circumstances. In terms of negative whakamā seen at the standard youth court, the immediate cause is the process itself and the environment that the process takes place in. The identity of these rangatahi varies resulting in different intensities of whakamā. The surrounding circumstances for the standard youth court add to the intensity of whakamā, resulting in less engagement from whānau and lower general support. This is recognised by the kaumatua:

W: Ka kite koe i ngà mātua me ngà tīpuna o ngā rangatahi nei e haere ana ki te marae, engari kāore rātau katoa he whakawhaiti ki te haere ki te kooti Pākehā.

(W: you see the parents and grandparents of these youth coming to the marae, but you do not see them all go over to the standard youth court.)

It must be understood that when dealing with whakamā, if it is handled wisely whakamā may pass without any lasting effect or even with positive effects in terms of shaming the offender into wanting to make restitution, but if allowed to linger unhealed it becomes more chronic (Metge, 1986). 
The negative consequences of allowing whakamā to linger can be seen in the rangatahi who go through this process. Metge (1986) describes some of the consequences, holding back being one of them. This can be observed in the rangatahi at the standard youth court; When addressed by the judge they will use the least amount of words possible or perhaps no words at all and answer with a gesticulation of 'yes' or 'no'. Another consequence is running away. This can be exemplified with example of the rangatahi not wanting to go to the MBYC. His whakamā will continue until it is addressed. Hitting out is another consequence. This can be physical or verbal. Rangatahi have commented about their charges being "bullshit", becoming violent at police, and trying to have an intimidating presence around the court.

The final consequence can be directly linked to the 'façade persona'. Whakamā that is left untreated can manifest itself into this protective persona. This is a deep whakamā that has taken full hold of the person. It is also used as a form of resistance. Because mana is the underlying theme of whakamā, resistance is about the powerless getting their own back on the powerful (Metge, 1986). This is observed in the 'façade persona' with overt displays of defiance towards authorities.

Treating whakamā before it becomes permanently chronic is vital. Treating whakamā is no easy feat and requires someone of skill to be able to recognise it, and then have the knowledge to treat it. In many cases whakamā has become chronic because no one has been able to recognise it or treat it (Metge, 1986). This is definitely applicable to the standard court where this concept is not recognised nor is there anyone involved in the process to recognise it or treat it. When treating whakamā for cases of wrong doing, the supporters stand for a moment to allow the person to be 'punished by whakamā. How long they wait before taking positive steps depends on the seriousness of the offence and the intensity of the whakamā. Some people have become so used to being whakamā that they are not aware of it as a condition and so do not recognise the necessity or even possibility of doing anything about it (Metge, 1986). This is definitely an issue for the rangatahi involved in the courts and maybe with Māori who have lived their lives in deprived circumstances. The challenge is to provide these rangatahi with an environment that can induce whakamā in a beneficial way, have the skilled personnel to recognise and be able to treat it, and have the resources to be able to reintegrate these rangatahi back into society. 
Whether those who become whakamā emerge from it and are re-integrated into social life depends firstly on the cause and the intensity of their whakamā, secondly, on the discernment and kindness of others in diagnosing and treating it appropriately, and thirdly on the availability of escape routes (Metge, 1986). In instances of a non-serious nature whakamā should be temporary. In mild cases the person should be able to come out of it on their own, but if not, people in supportive roles may step in to help. A physical embrace is then followed with a show of forgiveness. This represents a renewed contact with the community or aroha, feeling of acceptance. Aroha is the healing part of the process. Once this is done, reintegration back into the community is accomplished.

Whakamā has important implications for restorative justice. When whakamā is appropriately dealt with it is very effective in achieving the goals of restorative justice such as remorse, accountability and reintegration. The two are compatible and with effective integration in to the MBYC could serve as very valuable mechanism to stop recidivism, especially if the wairua of the marae is intact.

\section{Te Wairuatanga o te Marae}

Walker (1992) refers to the marae as an institution deeply rooted in the foundations of Māori culture. In traditional times it was the focal point for all Māori social activity and through time has evolved with the needs of the people (Walker, 1992). Today the needs of rangatahi have resulted in another evolution for the marae. However, this time it faces a challenge that it has not seen or dealt with before. This challenge is the transplanting of another institution onto the marae, and this institution is not rooted in Māori culture, but is deeply rooted in the Westminster system of law and justice. These two institutions are profoundly incompatible but are required to meet the particular needs of rangatahi today. The complication now is to find grounds of compatibility without one system undermining the other.

From the beginning the Marae has played a pivotal role in the entire process of the MBYC. In spite of the common knowledge of its importance to the process, how, what and why it is important is less clear. Furthermore, it is unclear exactly the effect that the marae has on the rangatahi or if there is any effect at all. This section will endeavour to explore the relationship the marae has with rangatahi, law and the process as a whole. 


\section{Te marae me tōna wairuatanga}

As has been duly noted in the previous section, the rangatahi were having trouble articulating why they thought the MBYC was better than the standard youth court. There was consensus from all the rangatahi (apart from the one that did not show up to the marae) that the MBYC was better. This can be attributed to the fact that these rangatahi are young and do not yet have the verbal skill to articulate what they feel. However, another factor also is that the majority of the rangatahi that do go to the MBYC are not connected to their Māori culture and thus, would not be able to explain the aspects of this that affect them. Kaumatua are experts in Māori culture and are able to articulate what the rangatahi could not. The following is an extract from a kaumatua who gives an example of one boy who went though the MBYC and he also acknowledged the fact that rangatahi do not know exactly what effect the marae has on them:

T: Têtahi tamaiti i noho nei ko (name removed).... Nō Tūhoe kē te poi nei. Tōna taenga atu ka kite ia i ngā poupou e tū ake mai rā,ngā whakairo. I puta mai têtahi hì ki roto i a ia. kei reira tonu te poi, toru tau e whakahaere ana te kooti kei reira tonu poi nei e mahi ana. (T: One boy by the name of .... He was actually from Tūhoe. On his arrival he gazed upon the carved wall figures that stood there and all the other carvings. There was a powerful awakening within him. The boy is still there, the court has been running (on the marae) for 3 years now and the boy is still there.)

H: I tino rongo rātou i te wairua o te marae?

(H: So they really felt the spirituality of the marae?)

T: Ae, kāore ia i te tino mōhio he aha te mea rā $i$ roto $i$ a ia, engari $i$ puta mai i roto i a ia. Koia ngā āhuatanga e pangia ki a ia, ka hoki tonu ia ki te marae. Ka haere mātou ki te kooti kei reira ia e whakareri ana i te whare, whakareri ana i te wāhi e whakahaerengia te kooti, a, ka hoki ki te kainga.... aha koa kāore rātou e mōhio he aha ngā $\bar{a}$ huatanga e pā ana ki ngā poupou me wera whakairo, engari kei te kite rātou.

(T: Yes, he did not really know what exactly it was that was inside him, but it was awoken inside of him. Those are the things that touched 
him, and are the reasons he continues to return to the marae. When we go to the court (MBYC) he is there getting the meeting house ready and the area where the court is to be held, then he goes home.... Even though they (rangatahi) do not know what the meanings or significance of the carved wall figures and other carvings are, visually seeing them has an impact.)

This extract provides a number of discussion points. One is the example of the boy having a type of inner awakening. This awakening was a result of the marae and the sacredness it possesses (its wairuatanga). It is difficult to explain exactly how the marae does this. However, if consideration is given to Walker's (1992) notion of the marae being deeply rooted in Māori culture, then in essence we are talking about identity. According to Mead (2003) culture is the foundation of one's identity. Therefore, with a lot of these rangatahi not knowing their Māori identity (but knowing that they are Māori) and the marae being rooted in Māori culture it serves as a trigger for that dormant identity within the rangatahi to be awakened. This is what happened to the boy in the kaumatua's example. Once cultural confidence is established, individuals are better prepared to deal with their futures (Mead, 2003). This rangatahi has not reoffended since.

When a rangatahi going through this process has their identity awoken, they come to the realisation that the reasons that got them there in the first place do not define who they are. It is the pride for their Māori heritage that does. This results in feelings of whakamā, remorse and guilt, because this newly found pride does not condone the actions that brought the rangatahi to the attentions of the courts. This is why within a restorative justice construct it makes sense to have family group conferences on the marae as this is one of the central aims of restorative justice. Once the rangatahi have taken responsibility for their actions and acknowledge the wrong they have done then the healing of the whakamā has already begun.

\section{Levels of effectiveness}

It must be noted that the example given by this kaumatua is not a common occurrence within the MBYC. However, it must be understood that this awakening that the marae induces occurs on many different levels depending on the rangatahi. This was apparent in a casual discussion I had with one of the lay advocates before I interviewed the rangatahi. He pointed out that there would be variations in the 
attitudes from the rangatahi towards the MBYC - from liking it to not liking it, being scared to not being scared, from being comfortable to uncomfortable. What the kaumatua's example illustrates is the most ideal scenario possible for this situation, where the marae and what it represents is enough to substantially awaken the rangatahi identity. However, there are variations and some rangatahi need more stimulation of this identity for it to awaken.

There are factors that influence the potency of the marae to awaken identity. One of the factors is about how much do the rangatahi already know about their Māori identity. One rangatahi indicated a strong Māori identity:

H: how did saying your mihi in the marae court go?

O: Yeh it was easy. I knew my mihi since I was 4yrs, brought up in kura kaupapa

This rangatahi further commented on having more respect for the marae then the court room and feelings of being more comfortable. In fact, the majority of rangatahi indicated that they had feelings of being more comfortable in the Marae than the youth court in town.

\section{H: Did you feel way more comfortable (in the marae court)? $\mathrm{N}:$ Yeh}

Having a strong Māori identity does not make you immune to finding yourself on the wrong side of the law. There are many other mitigating circumstances that contribute to rangatahi who have a sense of their Māori identity that come into contact with the criminal justice system. This is supported by an extract from one of the lay advocates:

$V$ : one of the things that stood out for me is the ... rangatahi who do know who they are... you have got that knowledge of who you are, where did it go wrong in your story of your life...

When considering where it did go wrong for these rangatahi, it can be linked at times to a disruption in the formation of this identity. According to this lay advocate:

U: ...Just that transition of being taken out of the kohanga/kura kaupapa system and put into the mainstream. I have been amazed at the kids that have been but in that situation...

Rangatahi are faced with this challenge of having to know how to navigate between the two cultures in their world, Māori and Pākehā. It is a challenge 
understanding how one fits into these two cultures, then having to deal with the occasions when they clash. This is something Pākehā youth do not have to deal with.

Another factor that influences the potency of the marae to awaken cultural identity is cultural alienation. This can be considered as the opposite to the example given by the kaumatua and the rangatahi who are familiar with their Māori identity. This is exemplified by the following extract from this rangatahi who was scheduled to attend the MBYC but did not.

H: You know when you were supposed to go to the marae court, why do you think you didn't go?

G: On the day I forgot and then it was like lOam and I knew because I remembered an hour before I had to go to court, I just didn't go.

H: You didn't go because you forgot or because you didn't want to go really?

G: I didn't really want to go....

H: What one would you prefer to go to, the one in town or the marae court?

G: The court in town

H: Why is that?

G: Just coz you don't have to do all that Māori stuff.... What is it? Your whakapapa or something

This rangatahi did not have much exposure to his Māori identity and did not have much pride in being Māori. When questioned "when people ask you, do you say you are Māori" he was the only rangatahi interviewed that said "nah". What is of interest in his extract is the reasons why he chose to miss the court hearing at the marae. He starts off by not revealing the true reasons and giving clouded statements around his reasons. Then with further questioning he identifies that it is the "Māori stuff' that he does not like doing.

Cultural alienation is when someone knows they are from that culture but have not had any knowledge of their culture. Some become frightened to engage in this culture because they know that there is much they should know but they do not (Durie, 2003). They also experience feelings of whakamā when confronted with their Māori culture because of their lack of understanding. This rangatahi has these feelings which have resulted in him preferring the option were he does not have to 
confront this. One lay advocate extract discusses this and the potential of culture to be liberating:

$V$ : ... what I have found from their (rangatahi) journey is that it goes back to that concept of 'culture', culture should always be liberating and not confining, it was made to embody us as a people not really to weigh us down... I've seen a lot of young people become liberated by standing up... and I think that should be the way it should be, but that is not always the case.

The perception of this rangatahi is that his culture is weighing him down. This is the challenge that needs to be overcome for rangatahi like him, to realise that their culture is liberating.

$U:$...the challenges are understanding some of our rangatahi don't really want to go to the marae court because they are really whakama they haven't grown up on a marae, and a marae is actually where tangi happen, so another challenge to initiate getting people to the marae court...

The majority of the time, cultural alienation is inter-generational. Rangatahi who have these feelings have normally had it passed down to them. For rangatahi who feel this way, it is not enough to try and reconnect them alone to their culture, but an effort must be made to reconnect the whānau. If these feelings are derived from their whānau then they will simply remain until their psychological mind set is changed. Perhaps the abilities of the marae can serve to remedy this.

\section{Influences on adults}

Not only is it important to know how the marae affects the rangatahi, it is also important to know how the marae affects the adults running the court. This awakening of identity that the marae induces is not subject only to the rangatahi but extends to the adults running the court as well. As one lay advocate explains:

U: ...I had to learn my pepeha because a part of our role is to kōrero to the young person about standing up and doing their mihi at the marae and I didn't know my own and in the course of my first year I learnt...

This illustrates the positive effects that the marae has on the people who are involved with it connecting with their identity. 
This also includes other roles, not just the lay advocates. Personal observation of the MBYC allowed me to witness this first hand. Observation was made of the lawyers of the court, who before stating the formalities of their role, started with a mihi themselves. This suggests that despite these lawyers being Pākehā they recognise that the marae is an institution itself that has its own formalities. There was no expectation for these lawyers to do this and it showed an acknowledgement by them that this is not just another court room.

The rangatahi also noted a vast difference in the adults running the MBYC. This can be observed through one rangatahi talking about how one of the adults (police staff) talked about him in the standard youth court in town:

O: ...saying that I'm nothing but a little asshole and I was standing right behind her...

Compare this to what another rangatahi said about the MBYC:

$H$ : The adults who were running it, did you see any difference in them? $N:$ Yeh

$H:$ What were some of the differences?

$N$ : Just nicer in there (the marae court)

The effect that the marae has on the adults running it is evident and is being acknowledged by the rangatahi. Behaviour such as the one described by the rangatahi of verbal abuse is not tolerated (one would think that it would not be tolerated in the standard youth court either) in the marae and the adults seem to be affording respect to the marae. This behaviour is having flow-on effects to the process as well with the rangatahi finding that the adults are explaining what is happening to them better, which is resulting in better understanding and engagement from the rangatahi. According to one rangatahi:

M: ... I like being at the Màori court they explain what's happening, its better.

This is in comparison to, as mentioned before, not having an understanding of what is going on in the standard youth court. This rangatahi demonstrates this point:

$H$ : Do you think there was a difference between the adults running the marae court and the district court?

$O$ : Yes. At the district court they are talking amongst themselves and we don't know what they are saying or what's happening. It's the lawyer's case, we are charging the lawyer not the actual client. They 
are talking to the lawyers about my case and I don't even know what they are talking about. The judge says what's happening but still he only explains it a little bit to you aye.

The effect that the wairuatanga of the marae is having on the behaviour of the people involved with the MBYC is positive. Not only is it having positive effects on identity (both rangatahi and adults) it also seems to be having effects on the legal process and those who enforce this process. Speculation can only be made to the reasons why. However, the kaumātua have a logical reasoning for this.

T: Ka haere koe ki tēnei kooti, koia nei te mea tuatahi mōhou, whakahaerengia tō pepeha. Ka tū te tamaiti ka kī, koinei au, koinei ōku mātua, nō reira au. He tino àtaahua tērā ki ahau anyway, ae. Ka haere koe ki te kooti Pākehā kāore èrā āhuatanga e kite, he tamaiti kino koe tū mai rā, koinā te kooti Pākehā. Ka haere mai koe kia whakawangia mātou ia koe. Ka whakawangia koe.

(When you go to this court, the first thing for you to do is to say your pepeha. The youth stands and says, this is me, these are my parents, and this is where I am from. That is a beautiful thing, to me anyway. When you go to the standard youth court, you don't see those things happening. You are a bad youth standing there, that's at the standard youth court. You have come to be judged by us. You will be judged.)

Essentially, this is about the atmosphere of the two courts. The standard youth court is seen as having connotations of rangatahi being bad. You are sent to the standard youth court because you are bad and you will be judged. What complements this notion is the way in which the standard youth court is set up. Youth have to wait for hours to be called in for their court hearing. They are called in and stand in front and at the bottom of multileveled seating for the officials. They are talked about and are very rarely talked to. This all contributes to the negative feelings that the rangatahi have about themselves.

Compare this to the MBYC where a pōhiri is used to call the rangatahi on. A pōhiri is done for all visitors despite their status as bad or good and there are no special pōhiri processes to discriminate between bad or good people. As stated by this kaumatua who is referring to the kuia of the marae: 
T: Ko tāna, ko te pōhiri, he manuhiri hoki, he iwi èrā e tū mai rā. Ko tāna te reo karanga tuatahi. Kāore i tīningia ngā āhuatanga o te marae.

(T: her role is to pōhiri the visitors, they are iwi that are standing there. Her welcoming call is the first voice heard. The protocols of the marae are not changed.)

Once the pōhiri is over everyone retreats to the kitchen for light refreshments and an opportunity to mingle. Once the formalities of the court begin the rangatahi are called into the wharenui where four tables are placed, all at the same level. The rangatahi is asked to say who he is first, compared to hearing what his chargers are first. This all contributes to the belief as one lay advocate put it that "they are there because they made a bad choice, not because they are a bad person”.

\section{Potentiality of the lay advocate role}

The lay advocate role has been a contentious issue since it has been established and like most new things it will take time to find its feet. In terms of its usage in the MBYC, it is a role of great importance. It is important because not only does it serve to help the rangatahi through the court process, it facilitates the relationship between the marae and the rangatahi. Furthermore, this would hopefully extend to the whānau of these rangatahi, thus, creating community bonds to the marae. This does not only have benefits for the rangatahi and their whānau, but also for the marae. This is why it was of great importance that this role be analysed and explored to uncover some of the issues and possibilities for the future.

\section{Role description}

Despite the role of the lay advocate being introduced during the inception of the Act in 1989, the role had not been utilised until the establishment of the MBYC in 2008. As this lay advocate states:

U:...we were noted in legislation that every youth has a right to a lay advocate to sit with them and work through the process with them, so it was actually written in legislation and from my understanding Judge Taumanu, who got this going, he said that he couldn't understand why they weren't being used so he went about it as part of the process at Te Poho o Rāwiri... 
It must be noted that the detail described in chapter 3 for the role of the lay advocate was not formed during the inception of the MBYC. This is evident in this lay advocates extract:

$V:$... we have never officially been given a job description per se like you would normally get in a contract of any form...

However there seems to be a level of optimism about this. When discussing the lack of role description with the lay advocates it was common to hear comments such as:

$V$ : But what I think what we have actually done is we have forged a job description through our work as lay advocate...

U: I think with this role the element of not having a job description and now for us to create as much of ourselves within it because of our role in the community...

\section{Meaning of the role to the lay advocates}

Throughout the interviews with the lay advocates they would often discuss their perception of the role. This would happen regardless of being prompted or not. What was interesting about these discussions was the level of depth that the lay advocates showed. For example, they varied from the standard role description as outlined in the Children, Young Persons, and Their Families Act 1989:

T: My role is a cultural supporter...

To detailed discussions into what that supports looks like for Māori:

$U:$...our role is all about them and their whakapapa and whannau...

It was evident that the lay advocates had tailored their role to better fit with Māori philosophies and took on extra responsibilities to fulfil this:

$V$ : My role is a bit more than that my main role at the moment ... is carrying out the marae function and support of our kaumātua. I see that as my most important role, just making sure that the kaumātua and kuia know what the dates are, any changes, letting them know who's appearing at the court, so that if there's some whakapapa attachment they can bring that into their mihi...

What was noticeable here is that these lay advocates play two roles. One being the fulfilment of their obligations to the courts that hire them and the second being 
the fulfilment of their obligations as Māori to uphold tikanga and kawa of the marae. This does seem to be an underlying premise throughout this study, that is, the relationship between two different institutions trying to work together despite coming from different philosophical bases. These lay advocates are the ones that have to navigate the best path through these institutions for the rangatahi so that desirable outcomes are achieved. Emphasis on relationship building is critical, particularly a relationship with the marae:

V: You're looking at their taha Māori, and I guess the journey is getting them to build a relationship to that place (marae)...

$U:$...working on their āhuatanga we are just trying to bring some balance to things that are so stuffed up in their lives...

These two extract highlight firstly, the need as Māori to have a meaningful relationship to the marae and secondly, once that relationship is established, it can serve as a positive influence to regain balance in the lives of these rangatahi. The lay advocates see this as their role helping the rangatahi navigate through it to achieve this.

$T:$...we are wanting to lift them up because when you are lifted up you see how much of value you are...

These are the goals that the lay advocates see for themselves and many others do to. However, as with most things it is not as black and white as this. There are many challenges in the way of the achievement of this goal for the lay advocates.

\section{Challenges of the role}

Because of the fairly new inception of this role into the youth court, it was inevitable that these lay advocates would be confronted with a number of challenges. Some of these challenges were personal, such as conquering fears about entering court:

$V$ : I haven't had firsthand experience with the court system itself. I was initially quite overwhelmed it was quite scary going into the courtroom as a support person and feel far out is this what it's like, it's quite a daunting place...

U: I had to learn my pepeha 
There were also systematic challenges, such as collaboration with other stakeholders working in the youth court.

T: we have had friction with other agencies

This was one of the major challenges that the lay advocates discussed. One of the reasons for this is that the lay advocate role at times crosses over into other agencies roles. As this lay advocate states:

$U:$...generally you're trying to be a little bit of a lawyer, a little bit of a social worker a little bit of a police officer...

According to the lay advocates the value and worth of their role was seen as not very high by the other agencies involved in the youth court:

$U:$ There has been outright blatant statements that we are a waste of time that we shouldn't be, that the money would be better spent in the government sector, so we have had that comment given to us out-front, which is nice to know out-front but gave you the sense that who has really brought into this, we have had to prove ourselves to a degree...

This is unfortunate and has the potential to undermine the entire process. Commitment is vital for the success of this process. However, these feeling towards the lay advocates are also being transferred to the MBYC itself:

$U$ : because we see this is the absolute opportunity to make a change in the statistics but unfortunately there are those who we work alongside who still haven't brought into the marae court and that just something that we just ride alongside

This did not seem to be that much of a shock to the lay advocates. The discourse that these agencies have about this process is dissimilar to that of the MBYC. However, this does not serve as an excuse for this type of behaviour. Ironically, these agencies behave this way with the lay advocates and the MBYC but recognise their worth when it suits to promote their agendas:

$V:$ In many cases CYFS used us to get through the door, to the inner core of these young people...

This agency recognises the limitations it possesses and seeks to exploit rather than valuing that position. As one lay advocate states:

$T: .$. in all the years that I've watched CYFS I have yet to find an example where they have come in and worked with a family and they have gone away better for that experiences, the family that is... 
This agency is not the only beneficiary of the lay advocate role. The lay advocates commented on how their role makes the job of other agencies easier. For example:

$U:$...paperwork, reporting are challenges for us, I'll be honest, the government agencies don't care what we say or write,... the judge and the lawyers, they actually appreciate it...

$V:$...They do that because we are having more contact with them then the Lawyer does so they have a lot more information coming in from us about these clients, these young people than they can ever hope to gather, their job has been made easy, you know, they are going to still invoice the court the $\$ 900 \ldots$ for maybe 5, 10 minute piece of work...

Furthermore, it can be said that an indicator of the worth of someone's job can be seen in the salary that job generates. These lay advocates expressed dissatisfaction with the way their wages were being dealt with and the amount they were getting paid:

$V$ : the other agencies are on higher salaries they get paid wether the kid shows up to the meeting or not there was a time where I didn't charge because we have to charge an invoice per 10 minutes like how a lawyer charges and it's so frustrating and you send them to the youth court who then decide when to pay you so you might not get paid for up to 4 weeks depending on who's doing the paper work because they think we are not that important...

T: I'll be honest with you now I'm considering what to do with this mahi (lay advocate role), we get given a sheet and on that sheet it outlines our hourly rate per client and it works out to be $30 \mathrm{hrs}$ per young person that we are paid for and yet we work over and above that....

This reinforces the belief that others are not valuing the lay advocate role as highly as other roles and because it is to do with salary, this sentiment is not simply at the ground level but at the Ministry of Justice level as they decide on these matters. What these extracts also highlight is that 30 hours per client is insufficient and that they try and do more to execute the aims of their role. However, due to the lack of pay and heavy demands of the role, these lay advocates are finding it 
difficult to survive economically and fulfil, to the standard that they believe they should be, the lay advocate role.

This also has a follow-on effect to the rangatahi who should be benefiting from the support given to them by the lay advocates but because of these issues this is not happening. According to these rangatahi:

$H$ : who helped you the most during the whole time of your court stuff?

N: My mum and dad

H: Did anyone help you with the understanding of what was going to happen to you at court?

$N$ : Yeh, my lawyer

These were common responses to this question. It was not until there was a specific question about the lay advocates was asked before the rangatahi mentioned them:

H: what about the lay advocates?

M: mine is (name removed), she's alright

$N$ : I don't know who my one is, a white lady, she didn't help me much

It is evident from these extract that the amount of time allocated to these rangatahi is insufficient and it does not allow the time for these lay advocates to form meaningful relationships with these rangatahi and their whānau. What is needed is a re-evaluation of the lay advocate role as it pertains to the MBYC and another, for the standard youth court.

The potential of the lay advocate role is great. However, there are circumstances that hinder this role preventing the role reaching its potential. Some of these have been discussed above. What is needed for this role is the space for it to flourish in the way that best achieves the desired outcomes for these rangatahi. This space needs to be free of restrictions that encumber the development of this role and needs to be enriched with kaupapa Māori ideals and philosophies.

\section{Conclusion}

The four major themes outlined above represent the main issues as discussed by all the participants in this study. The first theme, Tā te Ture ki te Rangatahi, identified issues such as that fact that throughout the whole process the thing that these rangatahi are most focused on is the is the consequences, what punishment are they are going to get. They are also getting to know the 'game', how far they can 
push the law and what kind of consequences happen along the way. There was also a lack of understanding of what was actually happening in the court. However, this did not seem to be the case in the MBYC where processes were better explained to them. The rangatahi also expressed that the MBYC was better than the standard youth court. However, they were not able to express exactly what about it was better apart from the consequential aspects like it "it's faster" and "you don't have to wait around as long". This may have been because the majority of the rangatahi lacked the cultural knowledge necessary to be able to express what it was about the marae that was better. It was also established that restorative justice in terms of the FGC was not having the desired effect and, therefore, not leading to the desired outcome. This was because the victims rarely went to the FGC's and according to Maxwell (2007) the victims are central to the restorative justice process. The rangatahi did show feelings that aligned with restorative justice when discussing the victims but these were brief. Feelings of distrust by the rangatahi towards the law were also highlighted. This distrust was the result of anti-social behaviour from the justice providers to the rangatahi.

The second theme, Whakamā, identified issues such as how whakamā influences the different people involved with the court process. There was also identification of the positive and negative forms of whakamā and it was established that during the standard court process, rangatahi were experiencing more of the negative forms of whakamā, in contrast to the MBYC where they were experiencing more of the positive forms of whakamā. Negative forms would most likely contribute to the 'façade persona', whereas positive forms of whakamā would contribute to remorse, accountability and other forms of restorative justice. It was also shown that victims who have the right attitude can also contribute to the feeling of the positive type of whakamā, whereas victims with the wrong attitude can contribute to the negative type of whakamā. In addition, it was revealed that the presence of the whānau members of the rangatahi can also induce feelings of the positive type of whakamā. This is due to the self-image of the rangatahi in front of his whānau and the notion that the rangatahi does not represent an individual, but a collective. The whakamā can also be felt by the whānau and then whakamā can be induced once more in the rangatahi for making his whānau whakamā.

The third theme Te Wairuatanga o te Marae, identified issues such as how the wairuatanga of the marae affect the rangatahi. What was apparent was that the 
wairuatanga of the marae had the ability to awaken a dormant Māori identity within these rangatahi. This was discussed in the context of levels of effectiveness. This meant that for some rangatahi just the presence of the marae and being in it was enough to have a significant identity awakening. However, at the other end of the scale were those who just viewed the marae as another courtroom. This is because they have no notion of what the marae is used for and for many of them it is their first time on a marae. Therefore, their first association of the marae is as a court. What was also apparent in this theme was the influence this wairuatanga had on the adults running the MBYC. It is evident that each role within the MBYC was influenced in one way or another. For example the lay advocate s experienced identity awakening similarly to the rangatahi, and the lawyers showing recognition of the institution of the marae and its protocols by saying a mihi before beginning with Pākehā formalities. The unique atmospheres of the two settings were also commented on. Once was recognised as a place where you go if you are bad and the other was not. This has a direct effect on the mindset of the rangatahi where at the marae they do not need to personify the 'façade persona'.

The fourth and final theme, Potentiality of the Lay Advocate role, identified issues such as the meaning of the role to the lay advocates. This showed that they had tailored their role to better fit Māori tikanga and philosophy and were able to do this because they did not have a specific job description. Challenges to the role were also discussed. These challenges included personal challenges such as overcoming fears about learning their pepeha. Other challenges came systemically, such as working with multiple agencies. The lay advocates found that their role crossed over into other agencies' roles which created friction. Another challenge was buy-in from these agencies. The lay advocates expressed that they received comments saying they were "a waste of time". There also concerns over agency exploitation of their role. Because of their position in the community they are able to get more information than the other agencies and these agencies are using them for this information but are not valuing their role. This is also depicted in the way these lay advocates are getting paid and the amount they are getting paid. This is having an effect of the quality of service they provide for the rangatahi as they are only allocated a certain amount of hours to each rangatahi which is not enough and are unable to commit any more hours to them. It was evident that the lay advocate role 
has lots of potential. However, there are also lots of challenges for this role to overcome. 


\section{CHAPTER 6: GENERAL DISCUSSION}

The purpose of this thesis was to work out how 'rangatahi' who have come into contact with our criminal justice system can reach their full potential as Māori New Zealanders, not reoffend and develop the tools to make a worthwhile contribution to our society. To achieve this, this thesis aimed to analyse the MaraeBased Youth Court (or Te Kooti Rangatahi as it is now known) from the perspective of rangatahi, lay advocates and Kaumātua. The purpose of this was to better understand the processes that rangatahi go through when they came into contact with the criminal justice system and how cultural philosophies may better inform this process, so that improved outcome may be achieved for these rangatahi. The main goal of the MBYC was to reduce recidivism within rangatahi. This research used Kaupapa Māori methodologies. The defining feature of Kaupapa Māori is that it is grounded within Māori knowledge bases, world views, cosmology, philosophies, language and culture, all of which are considered valid in their own right. This not only informs research methods it serves as a pool of knowledge to inform research outcomes. Kaupapa Māori finds many commonalities with restorative justice which aims to reintegrate offenders back into communities by making them accountable for their crimes and increase feelings of remorse with respect to their victim(s). Interviews for this study were conducted and a thematic analysis was performed. This analysis produced four major themes with a set of subordinate themes with each major theme. The following is a discussion around the issues that were identified in those themes.

\section{Kaupapa Māori principles and the Marae-Based Youth Court}

The following section will consider briefly all principles of Kaupapa Māori methodology (as discussed in chapter 3) and examine the parts of the MBYC that are directly linked to these principles.

Tino Rangatiratanga - the principle of self-determination:

Although, the MBYC is not a fully autonomous Māori process, this principle refers to having more meaningful control over one's life (Smith, 2003). The MBYC has the potential to allow Māori to have more meaningful control over the life of 
rangatahi who come into contact with the criminal justice system, their whānau and the wider community as a whole. This resonates with the recommendations given by Hall (1996) to the Ministry of Justice which generally are about giving Māori a stake in the system by offering them control over the decision making process. This is also consistent with procedural justice where people will more often accept an unfavourable outcome from a third party if they feel that the procedure used to decide the outcome was fair (Liu \& Hanke, 2007). Having the input of all people involved allows this perceived procedural fairness as it gives people a voice and a sense of control over the process (Liu \& Hanke, 2007). Allowing Māori to take full control of this branch of the youth justice system would be ideal for achieving the principle of Tino Rangatiratanga.

Māori do not have any control what-so-ever within the standard court system. They have no decision making power to determine the future of their rangatahi. Unfortunately it is highly likely that the rangatahi who do go through the standard youth court will probably have a future of revisiting that same court.

Taonga Tuku Iho - The Principle of Cultural Aspiration:

Walker (1992) states that the marae is an institution deeply rooted in the foundations of Māori culture. Because of this, the MBYC affirms the use of Māori culture, language and protocols. The cultural aspirations of Māori are to participate in this world as Māori (Durie, 2003). Unfortunately, the criminal justice system is deeply connected to the Māori world, nevertheless, the MBYC presents the opportunity for the expression of these aspirations, albeit to a limited degree. Māori do have the capacity to deal with transgressions and have been doing so for hundreds of years (Dixon, 2006). The potential for the MBYC to include more of these cultural aspirations is great and can only be strengthened from having them included.

The current standard youth court does not recognize Māori cultural aspirations, except perhaps in the usage of restorative justice and family group conferences.

\section{Ako Māori - The Principle of Culturally Preferred Pedagogy:}

The MBYC gives rangatahi the chance to learn about their culture. From the start the learning begins with the observation of the pōhiri, how it is conducted and who is conducting it. This is a very typical way of learning for Māori, observation and experience. Despite the formal court proceedings, the environment of the marae 
allows for this initial teaching of Māori protocol. The MBYC has the potential to service rangatahi needs by using Māori methods of teaching. The marae is an obvious environment for this to take place. The environment of the marae is only one step towards culturally preferred pedagogy. The pleasing thing is that it is a step in the right direction.

The current youth court does not recognise culturally preferred pedagogy. Kia piki ake i ngā raruraru o te kainga - The Principle of Socio-Economic Mediation:

According to Jackson (1988) the lack of financial resources can cause frustration that is heightened by a sense of racial injustice which is seldom articulated but frequently experienced and perceived. Research has found that Māori feelings of racial injustice can be validated. A report to the Department of Corrections (2007) identified that Māori who come into contact with the criminal justice system are, relative to non-Māori, subject to different probabilities of discharge from, or continuation within the criminal justice system, resulting in Māori accumulation in the system in disproportionate numbers. This is because each stage in the criminal justice system, from apprehension through to sentencing, contains a significant degree of built-in discretion (Department of Corrections, 2007). There seems to be a bias against Māori which suggests that stereotypes and predispositions are influencing the decision makers. The MBYC is a cultural friendly environment and as suggested by the results these biases do not look like they are affecting decision makers as much here. The MBYC also gives power back to the community a lot like restorative justice does. The ability of the MBYC to empower can have direct effect on the socio-economic indicators of a community. MBYC seems to be opening up more pathways for rangatahi and connecting them to good role models.

This does not seem to be as extensive at the standard youth court as it is at the MBYC.

Whānau - The Principle of Extended Family Structure:

In order for the MBYC to survive it has to build on meaningful relationships. These relationships are on many levels; to the rangatahi, their whānau, court staff, agencies, etc. The way in which the MBYC is conducted allows for these relationships to form by breaking down traditional court power relations in the way it is set out and the atmosphere it produces. This is extremely important if the 
MBYC is to have the desired effect. The MBYC has the potential to (and I believe it does to some extent) extend this relationship to other Māori service providers, thus, creating a wider network so that the marae can be empowered to provide a wide range of services.

The standard youth court does not form relationships in the same way as the MBYC does. The only relationships it needs are the ones that are central to achieving its goals. Its goals are specific and the formalities around achieving these goals are such that there is no need to build or maintain additional relationships. Kaupapa - The Principle of Collective Philosophy:

Kaupapa is about meeting the needs and aspirations of Māori communities. There is a need to stop rangatahi from frequently coming into contact with the criminal justice system and Māori aspire to do this by using Kaupapa Māori philosophies. This, in theory, will strengthen Māori communities to become more influential in deciding their future. The MBYC presents an opportunity for Māori to do this. Building strong identity and self-esteem filters down to the community and can break the cycle of offending.

The standard youth court does not benefit communities as does the MBYC. It satisfies the individual rights of people to 'justice'. The restoration of relationships, mana or identity is not the explicitly stated goal of court proceedings.

Te Tiriti o Waitangi - The Principle of the Treaty of Waitangi:

The Treaty of Waitangi principle represents the partnership between Māori and the Crown. The MBYC is a start of the acknowledgement of this partnership. Despite being a small step, it is a step in the right direction. Pākehā have an obligation to Māori under the treaty to ensure protection of taonga. Rangatahi are taonga and they are the key to positive development for Māori (Jackson, 1988). Being able to restore the mana of these rangatahi is the responsibility of both treaty partners. However, the way in which this is done should be the responsibility of Māori.

There is no partnership in the standard youth court. It is strictly centred on Western ideals and motives.

Ata - The Principle of Growing Respectful Relationships:

Again, this idea of forming relationships is integral. In the MBYC the relationship between rangatahi and marae is of huge importance. From the results of this study we were able to identify that the marae interaction induced identity 
awakening. It also showed signs of inducing positive forms of whakamā. However, the relationship formed with marae was not always meaningful, as some rangatahi viewed it as just another courtroom. This relationship needs to be better fostered so that to ensure rangatahi contact with the marae is meaningful. The relationship between adults and the marae is also important. The results of this study suggest that this relationship was very positive. Recognition of the protocols of the marae and appropriate conduct on the part of the adults involved in the process suggest that they had respect for the marae. This also filtered down to the relationship between the adults and rangatahi. Rangatahi reported far more appropriate behaviour from the adults towards them in the MBYC. One relationship that was of particular interest was that of the marae institution and the criminal justice institution. Fears of the domination of the justice institution over the marae institution have been discussed. The results showed that, in some cases, this fear was warranted, and in others it was not.

The dynamics of relationships in the MBYC were significantly different to that of the standard youth court. It was seen that more meaningful relationships were observed in the MBYC compared to the standard youth court.

What is evident from all of these Kaupapa Māori principles is that the MBYC is resonating with them. The MBYC is exhibiting these principles to a certain level. That is perhaps the key here; the door has been slightly opened but we just have not walked through it yet. One of the most pleasing aspects of these relationships is the fact that potential on the other side of the door is visible. If the MBYC can fulfil these principles then that would be ideal. As long as it keeps taking steps towards this fulfilment, then progress should continue to happen. What was also highlighted was how incompatible the standard youth court is with these principles. This showed the relationship building, cultural appropriateness and principles like kaupapa are not considered or are being considered minimally.

\section{Kaupapa Māori \& Restorative Justice}

Within Kaupapa Māori sit these Māori dispute resolution concepts such as mana, tapu, utu, whakamā, etc. Because of these concepts and the philosophies they are grounded in, they show many commonalities with restorative justice (Liu, 2007). Both Kaupapa Māori 'justice' and restorative justice aim to achieve the same outcomes. Restorative justice is a remedial and a reparative process that engenders 
expressions of forgiveness and benevolence from victims and encourages the reintegration of offenders into the wider community (Taylor, 2007). Kaupapa Māori justice looks to restore the balance of mana and tapu (Mead, 2003) between individuals, whānau, and hapū so that relationships can return to being healthy, and so too society. The general philosophies of Kaupapa Māori justice are about reaching consensus and involving the whole community. The desired outcome is reconciliation and a settlement acceptable to all parties. The concern is not to apportion blame but to examine the wider reasons for the wrong, and, finally, lesser concern with the restoration of harmony (Quincy, 2007).

As stated in chapter 2 the importance of mana was integral in Māori methods of dispute resolution. Within today's justice system this has not changed. For Kaupapa Māori justice and restorative justice it is about restoring the mana of the victims and offenders once they have shown remorse and accountability. As shown in the results, the difficulty is that victims rarely go to the MBYC and this impedes the restoration of mana for them and the feelings of remorse and accountability for the offender. More effort needs to go into finding more ways to engage victims into the process. Mana is also involved in the marae itself. Upholding the mana of the marae is vital. As discussed in the results, the youth court's adversarial nature threatens this mana. Awareness of how the youth court does this must be highlighted and avoided for the restoration process to happen.

The difference between Kaupapa Māori justice and restorative justice is that Kaupapa Māori justice recognises the specific needs of rangatahi, that is Kaupapa Māori justice addresses the fundamental factor which limits the self-esteem of many rangatahi - their isolation from the cultural roots which define them and by which the Pākehā world ultimately judges them (Jackson, 1988). It is not that restorative justice does not allow this, it is simply that this is more of a primary focus for Kaupapa Māori justice and it is more capable of achieving this.

It is evident how compatible the two systems are and they can both complement one another very easily. For instance, having the family group conferencing on the marae where tikanga and Māori protocols are infused with the process of the FGC would combine aspects of both systems beneficially.

There has been a huge commitment from this country to implement restorative justice into the youth justice system (Watt, 2003). This has proven to be valuable. However, the full potential of it has not been realised yet and there are gaps which 
have been left. Perhaps if there was an equally huge commitment to Kaupapa Māori justice these gaps may be filled and the full potential of these systems may be reached.

The major challenge that both these systems face is producing a mutually beneficial relationship with the youth court. The youth court does sit on the marae, but to call this Kaupapa Māori justice is a fallacy. Perhaps once the MBYC reaches its full potential then it may be considered Kaupapa Māori but until then it cannot. Restorative justice commentators (such as Becroft \& Thompson, 2007) have stated that the youth court has too often maintained a formal adversarial model of operation and failed to incorporate restorative processes. There are also suggestions that the formal system is important to maintain the rights of individuals and to determine guilt or innocence (Becroft \& Thompson, 2007). Therefore, there does seem to be a need for the youth court. However, perhaps more focus is needed on establishing the restorative justice and Kaupapa Māori justice processes before the involvement of the court. It has been noted that there has been a huge commitment to divert youth away from the court. According to Broad (2007), 80\% of youth that come into contact with the police are diverted in some form away from the court. Perhaps it is here, where the diversion can lead Māori to a Kaupapa Māori justice system. The point here is that if Kaupapa Māori justice and restorative justice are reaching their potential then the court will not be necessary. Until that time arrives, the youth court can stand in the background, only needed for extreme cases.

\section{Limitations of Marae-Based Youth Court}

Limitations of the MBYC could be its effectiveness to cater to the needs of Pākehā victims. There is a likelihood that Pākehā victims would not want to go to the marae. There may be numerous reasons for this such as; feeling uncomfortable going to a marae, not feeling that the marae is the best place for dealing with crime, feelings of inadequacy towards process, protocol and marae generally.

Although this limitation is an issue, it is not one that cannot be fixed. Techniques need to be developed to overcome these issues. Perhaps, research is needed to identify what the best techniques are to make Pākehā victims feel more comfortable within this environment.

Another limitation could be the ability of the rangatahi to feel connected to an 'urban' marae. For rangatahi who don't know their marae, the difficulty resides in 
getting the rangatahi to understand that the marae also belongs to him. For rangatahi who do know their marae and it is not the one the MBYC is residing, the difficulty is the same. However, there is an added difficulty. These rangatahi feel connected to their marae, not the one that the MBYC resides on despite possibly living in close proximity. The challenge here is to identify a way of instilling a sense of belonging to an urban marae that is not exclusive to a particular hāpu but is generally available to all.

\section{Recommendation}

\section{Fulfilling the potential of the lay advocate role}

The lay advocate role is vital to the success of the MBYC because of its potential to enhance the likelihood of rangatahi to connect to the marae and its ability to also connect whānau and victims. As shown by the results, these are all vital to the restorative process. However, as it stands now, the potential of the role is not being realised. This role has many challengers that have been discussed in the previous chapters and overcoming these challenges is a good starting point in reaching the potential of this role.

The first recommendation I would make for this role is that the role description be amended to allow sufficient time for the lay advocates to make a meaningful connection to the rangatahi and their whānau. It was evident from the results that the lay advocates were not allocated sufficient time to build meaningful relationships. This does not mean that they were not making relationship with the rangatahi, but simply that the relationship between them could be better developed to produce better outcomes. Also, identifying some key goals and pathways in the development of the relationship between the lay advocates and the rangatahi once the allocated time has elapsed is also needed.

The lay advocate role also needs to be fairly compensated for the value that the role brings to the process. This will also alleviate feelings of being undervalued and help reduce agency exploitation. If lay advocates are paid fairly to do a job these feelings would be minimised.

I also propose that it be mandatory for all lay advocates to complete a formal training programme. This programme would have the standard training practices found for such a position (e.g. systematic and procedural training) but also (and 
perhaps more importantly for the MBYC) training (or demonstrated high levels of competencies) in tikanga, kawa and extensive knowledge of the concept of whakamā - how to identify it, how it functions, the positive and negative forms, how to treat it, etc. This training could also include the art of explaining the process and ideals of the MBYC to rangatahi, whānau and more importantly victims. Victims are important because they have the power to induce positive or negative forms of whakamā. If a victim(s) is/are present but full of anger and lashing out (physically or verbally) the objectives of making the rangatahi feel remorse and accountability will not be achieved. This is why it is important for the lay advocates to have the skill to explain to the victim the process and objectives so that they understand and feel empowered within this experience. This training would be extensive and produce lay advocates that are competent in these areas. Kaumātua would serve as a quality check as they are the experts in this area and play a continual guiding role for the lay advocates.

One of the major challenges identified by the lay advocates was rooted in the organization of the justice system. Agency irritation over the overlapping role of the lay advocates was apparent. I simply recommend that the major stakeholders and agencies meet to discuss their relationships with one another, putting the needs of rangatahi as central, and identifying exactly how each role can work together to service these needs. The lay advocate role aligns itself with the institution of the marae (despite being a construct of the criminal justice institution) and its role description allows it to do this to some degree. Therefore, the role has obligations to both sides and at times these obligations clash with one another.

\section{How to Combat the Notion of Marae as Court}

It was apparent that maintaining a formal adversarial model of operation on the marae may reduce the effects of the wairuatanga of the marae on rangatahi. This is one of the concerns talked about with the risk of the criminal justice institution overwhelming the marae institution. I recommend that before the rangatahi are taken to the marae for their court hearing, they be made to go to the marae for a wānanga. It was found that going to the MBYC was the first time many rangatahi had been to a marae. Therefore, the purpose of this wānanga would be to establish the first impressions of the marae, not as a court, but a place where they can find their culture and understand the significance of the marae in this culture. Ideally, 
this wānanga would include a whānau member to support the rangatahi, the lay advocates and Kaumātua, and would perhaps be an overnight wānanga. There could also be potential to run the family group conferences during this wānanga period. This has the potential to not only connect the rangatahi to the marae but also the whānau.

Limitations of this recommendation are that it requires far more time and effort. For instance, if rangatahi are given the option of choosing the MBYC or the standard Youth Court, the likelihood that they chose the standard youth court is high because it takes less effort and they will not be confronted as much with the feelings of whakamā and restorative justice notions of accountability and remorse (which, as shown in the results, they try to fervently avoid). Therefore, there must be equal or greater commitment from the option of the standard court. What this commitment would be is not in the scope of this thesis. However, one would think that it would be along the lines of intensifying the restorative justice aspects of the process.

Another limitation to this recommendation is that going through this process is going to cost more money. Which agency will foot the bill? Again it is not the concern of this thesis to say who should or who should not. Nevertheless, it must be said that investing at this level in an effective early intervention to reduce recidivism will yield greater savings for Aotearoa/New Zealand in the long term. If not, we will have to stay content with building more prisons and paying more to keep prisoners in there as demonstrated in chapter 1.

\section{What to do after Court}

Like any good relationship, effort is needed to keep the relationship going. Post-court programmes need to be run on the marae or they need to be connected to the marae and have frequent contact with the marae. These programmes need to continue to develop the identity awakening and re-affirm this identity within the rangatahi.

Not only does this benefit the rangatahi but it also strengthens the marae by broadening its capabilities. The usage of marae has been in decline as more people become unaffiliated with them (Walker, 1992). Developing the institution of the Marae is integral to its survival. It is unmistakeable that the marae has great ability to strengthen community. 


\section{Limitations of Research and Methodology}

The scope of this research was limited by time constraints. As Kaupapa Māori research does require more time than other research methods, this time was spent focusing on the experiences of a smaller number of people, rather than getting a broad de-contextualised impression of a wider sample. By doing this there may have been some sources of variation that could have been missed in the final findings. Furthermore, the focus of this research was the MBYC at Te Poho o Rāwiri Marae in Gisborne, whereas including other MBYC from around the country may have given a more generalised finding. More specifically, in terms of the MBYC in Gisborne, exploration into all stakeholders may have given a broader perspective of all the elements surrounding the MBYC in Gisborne. These could perhaps be a topic for future research.

\section{Conclusion}

The marae, as a bastion of Māori culture, is an institution that is dynamic and has developed through the years to cater to the various needs of Māori. From the beginning of the MBYC concept there have been fears over institutional domination by the courts. The bureaucratic, adversarial and impersonal institution of the court is the dominating system in this country. The manaaki and aroha principles of the marae are the dominating system in the marae. The fears are that placing the court institution on to the marae institution would dominate the marae and compromise its ability to have positive effects on rangatahi. It was identified in this study that these fears are warranted to a degree with the rangatahi being focused on the consequences of the process rather than feeling the wairuatanga of the marae. Despite this, as noted by both Kaumātua and lay advocates, the observed behaviour (façade persona) of the rangatahi were different at the marae than at the standard youth court and the Kaumātua attribute this to the wairuatanga of the marae.

However, it was also identified that amendments to the process can strengthen the positive elements of the marae to have a more significant effect on rangatahi. Amendments such as wānanga on the marae before the court hearing, developing the lay advocate role so that they can be more effective in connecting rangatahi and their whānau to the marae and running services from the marae afterwards are all to do with associating the marae with its true purpose (not as a court) as a culturally 
steeped and diverse institution that is identity connecting and reawakening. Maintaining positive relationships to the marae can strengthen community.

The issue now is identifying a way in which both institutions can coincide together without one dominating the other. I believe that finding this point of mutual cooperation will serve as the most effective method to not only reduce rangatahi recidivism, but in the long term drastically reduce the Aotearoa/New Zealand prison population. Furthermore, the subsidiary effect of this mutually beneficial relationship is that by strengthening the institution of the marae it will strengthen community and by strengthening community you strengthen society.

I will refer back to the poem I started this thesis with. The situation described in the poem is very common for rangatahi today. These are the types of rangatahi that the youth courts of this country often see. These rangatahi are alienated from their culture which results in them feeling angry, annoyed and frustrated. ' $T u$ ', the speaker in the poem, refers to his fists as his taiaha and this is explained as defiance. Tu has been using his unarticulated fists in defiance of his lack of cultural knowledge. The tekoteko offers him his tongue, a far more effective form of defiance to empower him. This gift is an awakening of identity, of purpose and of life. Every marae has a tekoteko and every tekoteko is willing to offer its tongue. With the development of marae based justice the only questions that remain are how that tongue is presented to the rangatahi, and whether or not they are willing to pick it up. 


\section{REFERENCES}

Allen, C. (2002). Blood Narrative: Indigenous identity in American Indian and Maori literary and Activist Texts. USA: Duke University Press.

Allwood, C., \& Berry, J. (2006). Origins and development of indigenous psychologies: An international analysis. International Journal of Psychology, 41(4), 243-268.

Barnes, H. (2008). Arguing for the Spirit in the Language of the Mind: A Mãori practitioner's view of research and science. Unpublished D.Phil, Massey University, Auckland.

Barnes, H. (2000). Kaupapa Māori: Explaining the ordinary. Whariki Research Group, Massey University, Auckland.

Braun, V., \& Clarke, V. (2006). Using thematic analysis in psychology. Qualitative Research in Psychology, 3(2), 77-101.

Baum, F., MacDougall, C., \& Smith, D. (2006). Journal of Epidemiology and Community Health. Australia: BMJ Publishing Group Ltd.

Becroft, A., \& Thompson, R. (2007). Restorative Justice in the Youth Court: A Square Peg in a Round Hole? In G. Maxwell, \& J. Liu (Eds.), Restorative Justice and Practices in New Zealand; Towards a Restorative Society. Wellington, New Zealand: Institute of Policy Studies.

Belich, J. (1996). Making Peoples. Auckland: Allen Lane, the Penguin Press.

Best, E. (1934). The Maori as he was: A brief account of Maori life as it was in the Pre-European days. Dominion Museum, Wellington, New Zealand: Māori Purpose Fund Board.

Bishop, R. (1997). Māori people’s concerns about research into their lives. History of Education Review, 21(1), 25-41.

Bishop, R., \& Glynn, T. (1999). Culture Counts: Changing Power Relations in Education. Palmerston North: Dunmore Press Limited. 
Bishop, R. (1996). Whakawhānaungatanga. Collaborative Research Stories. Palmerston North, New Zealand: Dunmore Press.

Broad, H. (2007). Restorative Policing. In G. Maxwell, \& J. Liu (Eds.), Restorative Justice and Practices in New Zealand; Towards a Restorative Society. Wellington: Institute of Policy Studies.

Breakwell, G. M. (2006). Interviewing methods. In G.M. Breakwell., C, Fife Schaw, S. Hammond, J. Smith (eds.). Research Methods in Psychology ( $3^{\text {rd }}$ edition). London: Sage.

Carr, S. (1996). How we Began: The True Story of a Pākehā Māori. New Zealand: Seascape press.

Consedine, J. (1999). Restorative Justice, Healing the Effects of Crime. Revised edition Lyttleton, New Zealand: Ploughshares Publications.

Consedine, J. (1993). Restorative Justice-Healing the effects of Crime. Ploughshares Publications.

Coomaraswamy, P., Dejanovic, V., \& Pridmore, P. (1998). Part 5: Children's Participation in Situations of Crisis. In V. Johnson, E. Ivan-Smith, G. Gordon, P. Pridmore, \& P. Scott (Eds.). Stepping Forward: Children and young people's participation in the development process (pp. 157-172). London: Intermediate Technology Publications.

Cram, F. (2001). Rangahau Māori: Tōna tika, tōna pono: The Validity and Integrity of Māori Research. In M. Tolich (ed.), Research Ethics in Aotearoa New Zealand: Concepts, Practices, Critique. Auckland, New Zealand: Longman.

Denzin, N. K., \& Lincoln, Y. S. (2003). Introduction: The discipline and practice of qualitative research. In N. K. Denzin \& Y. S. Lincoln (Eds.), Strategies of qualitative inquiry (2nd Ed.) (pp. 1 - 45). Thousand Oaks, CA: Sage.

Department of Corrections. (2007). Over-representation of Māori in the Criminal Justice System. Retrieved October 18, 2010, from 
http://www.corrections.govt.nz/_data/assets/pdf_file/0004/285286/Overrepresentation-of-Maori-in-the-criminal-justice-system.pdf

Department of Corrections. (2009). Annual Report 2009. Retrieved October 13, 2010, from

http://www.corrections.govt.nz/newsandpublications/statutoryreports/annualr eports.html

Department of Corrections. (2010a). Prison Facts and Statistics September 2010. Retrieved October 13, 2010, from http://www.corrections.govt.nz/aboutus/facts_and_statistics/prisons/march_2 2.html

Department of Corrections. (2010b). The economical impacts of the proposed men's prison at Wiri stage1 report, 2010. Retrieved October 13, 2010, from http://www.publicaddress.net/assets/files/OnPoint/EconomicImpactAssessme nt.doc

Dixon, M. (2006). Crime and Justice. In M. Mulhollland (Ed.), State of the Māori Nation Twenty-first-century Issues in Aotearoa. Auckland, New Zealand: Reed Publishing Ltd.

Durie, E. (2007). The study of Māori offending: Based upon an address to the New Zealand Parole Board Conference. 27 July 2007.

Durie, M. (2005). Ngā Tai Matatū: Tides of Māori Edurence. Auckland, New Zealand: Oxford University Press.

Durie, M. (1998). Te Mana, Te Kāwanatanga: The Politics of Māori Self Determination. Auckland, New Zealand: Oxford University Press.

Durie. M. (1997). Identity, nationhood and implications for practice in New Zealand. New Zealand Journal of Psychology, 26(2), 31-38.

Durie, M. (2003). Ngā Kāhui Pou Launching Māori Futures. Wellington: Huia Publishing. 
Frame, A. (1981). Colonising attitudes towards māori customs. The New Zealand Law Journal, 106-110.

Fraser, S., Lewis, V., Ding, S., Kellett, M., \& Robinson, C. (2004). Doing Research with Children and Young People. London: SAGE.

Hall, D. (1996). The New Zealand Māori Council, a submission to the Ministry of Justice. Restorative Justice. A Māori Perspective. Sponsored by Te Puni Kokiri.

Hamer, P. (2004). A Quarter-Century of the Waitangi Tribunal - responding to the Challenge. In J. Hayward \& N. Wheen (Eds.), The Waitangi Tribunal. Wellington: Bridget Williams Books Ltd.

Hart, R. (1997). Children's participation, the theory and practice of involving young citizens in community development and environment care. New York: Unicef and London: Earthscan.

Henry, E., \& Pene, H. (2001). Kaupapa Māori: Locating indigenous ontology, epistemology and methodology in the academy. Organisation: Speaking Out, $8(2), 234-242$.

Hodgetts, D., Cullen, A., \& Radley, A. (2005). Television characterizations of homeless people in the United Kingdom. Analyses of Social Issues and Public Policy, 5, 29-48.

Humphrey, C. (2007). Insider-outsider: Activating the hyphen. Action Research, 5(1), 11-26.

Irwin, K. (1994). Māori research methods and practices. In Sites, 28, Autumn.

Jackson, M. (1988). The Māori in the Criminal Justice System: He Whaipaanga Hou - A New Perspective. Part II. Wellington, New Zealand: Department of Justice.

Ka'ai, T., Higgins, R. (2004). Te ao Māori - Māori world view. In T. Ka'ai, J. Moorfied, M. Reilly, \& S. Mosley (Eds.), Ki te Whaiao: An Introduction to Māori Culture and Society. Auckland: Pearson Education. 
Kao, H. (2006). In C. M. Allwood \& J. Berry (Eds.), Origins and Development of Indigenous Psychologies: An International Analysis; International Journal of Psychology 41 (4), 243-268.

King, M. (2003). The Penguin History of New Zealand. Auckland, New Zealand: Penguin Books (NZ) Ltd.

Kiro, C. (2000). Māori Research and the social services: Te Puawaitangana o Te Tohu. Te Komako- Social Work Review, 12(4), 26-32.

Lawson-Te Aho, K. (1994). The master's tools: Māori development inside Pākehā psychology. Unpublished Master of Social Science, University of Waikato, Hamilton.

Levy, M. (2008). Critical Mass, tipping point and reaching the point of irreversible change: Indigenous Psychology in Aotearoa. Conference 2008.

Levy. M. (2007). Indigenous Psychology in Aotearoa: Realising Māori Aspirations. Unpublished D.Phil, University of Waikato, Hamilton.

Liu, J. (2007). Social and historical contexts for restorative and retributive justice : Te Ao Po-Te Ao Marama (Worlds of Dark and Light). In G. Maxwell, \& J. Liu (Eds.), Restorative Justice and Practices in New Zealand; Towards a Restorative Society. Wellington, New Zealand: Institute of Policy Studies.

Liu, J., \& Hanke, K. (2007). Refletion on a Psychology of Justice: Implications for Restorative Justice Practises. In G. Maxwell, \& J. Liu (Eds.), Restorative Justice and Practices in New Zealand; Towards a Restorative Society. Wellington, New Zealand: Institute of Policy Studies.

Marsden, M. (1992). God, Man and Universe: A Māori View. In M. King (Ed.) Te Ao Hurihuri: Aspects of Māoritanga. Auckland, New Zealand: Reed Books.

Maxwell, G., Kingi, V., Robertson, J., Morris, A., \& Cunningham, C. in collaboration with Lash, B. (2004). Achieving Effective Outcomes in Youth Justice Research Project. Final Report to the Ministry of Social Development. Wellington: Ministry of Social Development. 
Maxwell, G., \& Liu, J. (2007). Restorative Justice and Practices in New Zealand: Towards a Restorative Society. Wellington: Institute of Policy Studies.

Maxwell, G., \& Morris, A. (1993). Family, Victims and Culture: Youth Justice in New Zealand. Social Policy Agency \& Institute of Criminology, Victoria University of Wellington.

Maxwell, G. (2007). The Youth Justice System in New Zealand: Restorative justice delivered through the Family Group Conference. In G. Maxwell, \& J. Liu (Eds.), Restorative Justice and Practices in New Zealand; Towards a Restorative Society. Wellington: Institute of Policy Studies.

Mayo, M. (2001). Children's and Young People's Participation in Development in the South and in Urban Regeneration in the North. London: SAGE.

McElrea, F. W. M. (2007). Restorative justice for adult offenders; Practice in New Zealand today. In G. Maxwell, \& J. Liu (Eds.), Restorative Justice and Practices in New Zealand; Towards a Restorative Society. Wellington: Institute of Policy Studies.

Mead, H. (2003). Tikanga Māori: Living by Māori Values. Wellington: Huia Publishers.

Milne, M. (2005). Maori perspectives on Kaupapa Maori and psychology - A discussion document: Wellington: New Zealand Psychologists Registrations Board.

Ministry of Justice. (2001). He Hinātore Ki te Ao Māori: A Glimpse into the Māori World. Wellington: Ministry of Justice.

Moghaddam, F. (1987). Psychology in three worlds: As reflected by the crisis in social psychology and the move towards indigenous third-world psychology. American Psychologist, 42, 912-920.

Murray, M. (2003). Narrative psychology and narrative analysis. In P.M. Camic, J.E. Rhodes \& L. Yardley (Eds.) Qualitative Research in Psychology: 
Expanding Perspectives in Methodology and Design. Washington, DC:

American Psychological Association.

Nikora, L., Levy, M., Masters, B., \& Waitoki, M. (2006). In C. M. Allwood \& J. Berry (Eds.), Origins and Development of Indigenous Psychologies: An International Analysis, International Journal of Psychology, 41(4), 243-268.

Olssen, E., \& Reilly, P. (2004). Te Tūtakitanga o ngā Ao e Rua - Early contacts between two worlds. In T. Ka'ai, J. Moorfied, M. Reilly, \& S. Mosley (Eds.), Ki te Whaiao: An Introduction to Māori Culture and Society. Auckland, New Zealand: Pearson Education.

Patterson, J. (1992). Exploring Maori Values. Palmerston North: The Dunmore Press.

Perrone, D., Pratt, T. (2003). Comparing the quality of confinement and cost effectiveness of public versus private prisons: What we know, why we do not know more, and where to go from here. The Prison Journal, 83(3). 301-322.

Pihama, L., Cram, F., \& Walker, S. (2002). Creating methodological space: A literature review of kaupapa Māori research. Canadian Journal of Native Education, 26, 30-43.

Pihama, L. (2001). Tihei mauriora, Honouring our voices, Mana Wahine as a Kaupapa Māori theoretical framework. Unpublished doctoral thesis. The University of Auckland, New Zealand.

Powick, K. (2003). Māori Research Ethics: A Literature Review of the Ethical Issues and Implications of Kaupapa Māori Research and Research Involving Māori for Researchers, Supervisors and Ethic Committees. Wilf Malcolm Institute of Educational Research, School of Education University of Waikato: Hamilton.

Quince, K. (2007). Māori and the Criminal Justice System in New Zealand. In J. Tolmie, \& W. Brookbanks (Eds), The New Zealand Criminal Justice System. Auckland: LexisNexis 
Rangahau. (2010). Principles of Kaupapa Maori. Retrieved October 10, 2010, from: http://www.rangahau.co.nz/research-idea/27/

Reason, R. (1998). Three approaches to participative inquiry. In N. K. Denzin, \& Y. Lincoln (Eds.), Strategies of Qualitative Research. London: Sage.

Ryan, R. M., \& Deci, E. L. (2000). Self-determination theory and the facilitation of intrinsic motivation, social development, and well-being. American Psychologist, 55, 68-78.

Ryan, P. (2005). The Reed Dictionairy of Modern Māori. Auckland (NZ): Reed Pudlishing Ltd.

Salmond, A. (1975). Hui: A study of Māori Ceremonial Gatherings. Auckland: Heinemann Reed.

Shaughnessy, J. J., Zechmeister, E. B., \& Zechmeister, J. S. (2006). Research Methods in Psychology. Taipei: McGraw-Hill.

Shweder, R. (2000). Asian Journal of Social Psychology. Volume 3, issue 3. UK: Cambrian printers LTD, Aberystwyth. Blackwell Publishers Ltd.

Shirres, M. (1982). Tapu. Journal of the Polynesian Society, 2(1), 29-51.

Sinclair, D. (1992). Land since the treaty. In M. King (Ed), Te Ao Hurihuri: Aspects of Maoritanga. Auckland, New Zealand: Reed Publishing.

Smith, G. (2003). Kaupapa Maori Theory: Theorizing Indigenous Transformation of Education and Schooling. Based upon an address to the Kaupapa Maori Symposium. Auckland, NZ. December 2003.

Smith, G. (1996). The Development of Kaupapa Māori: Theory and Praxis. Unpublished D.Phil, University of Auckland, Auckland.

Smith, J.A., \& Osborn, M. (2003). Interpretative phenomenological analysis. In J.A. Smith (Ed.) Qualitative Psychology. London: Sage.

Smith, L. (1999). Decolonising Methodologies: Research and Indigenous Peoples. Dunedin, New Zealand: University of Otago Press. 
Taylor, A. (2007). Restorative justice serving the needs for justice. In G. Maxwell, \& J. Liu (Eds.), Restorative Justice and Practices in New Zealand; Towards a Restorative Society. Wellington: Institute of Policy Studies.

Te Awekotuku, N. (1991). He tikanga whakaaro: Research ethics in the Maori community. Wellington: Manatu Maori.

The NZ Herald (2009). Editorial: Much Mana and Sense in Maori Unit, April 17 2009. Retrieved October 13, 2010, from http://www.nzherald.co.nz/government/news/article.cfm?c_id=49\&objectid= 056703

The NZ Herald (2010). Govt calls for tenders on PPP prison, November 32010. Retrieved October 15, 2010, from http://www.nzherald.co.nz/nz/news/article.cfm?c_id=1\&objectid=10685062

Wagstaff, R. (2009). Private prisons cost more and provide worse service, March 9 2009. Retrieved September 3, 2010, from http://www.psa.org.nz/newsroom/mediareleases/09 0309/Private_prisons_cost_more_and_provide_worse_service.aspx

Walker, S., Eketone, A., \& Gibbs, A. (2006). An exploration of kaupapa Maori research, its principles, processes and applications Int. J. Social Research Methodology, 9(4), 331-344

Walker, R. (1990). Ka Whawhai Tonu Matou: Struggle Without End. Australia: Ringwood, Penguin Books Australia Ltd.

Walker, R. (1992). Marae: A place to stand. In K. King (Ed.), Te Ao Hurihuri: Aspects of Māoritanga. Auckland: Reed Publishing Ltd.

Walker, R. (2001). He Tipua: The Life and Times of Sir Apirana Ngata. Auckland, New Zealand: Penguin Books Ltd. 
Ward, A. (1990). History and Historians Before the Waitangi Tribunal. Some Reflections of the Ngai Tahu Claim. The New Zealand Journal of History, 24(2), 150-167.

Walter, M. (2009). Participatory Action Research. In M. Walter (Ed.), Social Research Methods. South Melbourne, Australia: Oxford.

Watt, E. (2003). A history of Youth Justice in New Zealand. Report prepared for Ministry of Courts.

Williams, H. (1985). Dictionary of the Maori Language. Wellington, New Zealand: PrintLink.

Youth Transitions Newsletter. (2009). Marae-Based Youth Court. March 2009.

Retrieved September 18, 2010, from

http://www.ytsgisborne.org.nz/newsletters/YTS_Mar_09web.pdf 


\section{GLOSSARY}

Āhua - feeling, way

Aituā - accident, unlucky, unfortunate

Aroha - Love

Atua - Māori God

$\mathrm{Ea}-$ satisfaction, completion

Hākari - Big Feast

Haka - Māori war dance

Haka Pōhiri - War dance of welcome

Hapū - Sub tribe

Hara - charge, wrong doing

Hongi - pressing of noses (Māori way of greeting)

Hui - Meeting

Iwi - Tribe

Kanohi ki te kanohi - Face to face

Karakia - prayer

Karanga - a call of welcome

Kai - Food

Kaitiaki - Guardian

Kaumātua - Elders

Kaupapa - plan, subject

Kawa - Commonly used in modern Māori for marae protocols. 
Kīngitanga - Māori King

Kōhanga reo - preschool Māori learning institution

Koroua - Grandfather

Kuia - Grandmother

Kura kaupapa - primary school Māori learning institution

Mahi - work, to do

Mana - Pride, Power

Marae - place for Māori gatherings

Marae ātea - courtyard

Mau rākau - stick training (warfare)

Mauri - a material symbol of life principle.

Manaaki/Manaakitanga - hospitality

Mātauranga Māori - Māori knowledge

Mate Māori - spiritual illness

Māoritanga - Māoriness

Muru - take ritual compensation

Noa - be free from the extensions of tapu

Pākehā - NZ European

Pakeke - Elders

Pepeha - fomulactic identity

Pounamu - Greenstone

Rangatahi - youth

Rangatira - Chief 
Rongo - Make peace

Taha Māori - Māori side

Taha wairua - spirituality

Taiaha - Māori war weapon

Take- utu-ea - principle of cause, reciprocation and balance

Tangata whenua - indigenous people to the land

Taonga - gift, something special

Tapu - sacred, prohibited

Te Reo Māori - The Māori Language

Tekoteko - figurehead on the marae

tihei mauri ora - the sneeze of life

Tika - being right or just

Tikanga - Custom, Rules

Tino rangatiratanga - self-determination

Toa - Warrior

Tohunga - expert

Tomo - marriage

Utu - Avenge

Wāhi tapu - Sacred place

Wairua - Spirit

Whaikōrero - speech making on the marae

Whakaaro - Thoughts

Whakamā - shameful 
Whakanoa - to bless, to get rid of sacredness

Whakapapa - Genealogy

Whakatauki - Proverb/saying

Whakawā - Judge

Whānaungatanga - Relationship, Friendship

Whānau - Family

Wharenui - meeting house 


\section{APPENDICES}

Appendix 1a: Information sheet/Interview and Focus Groups

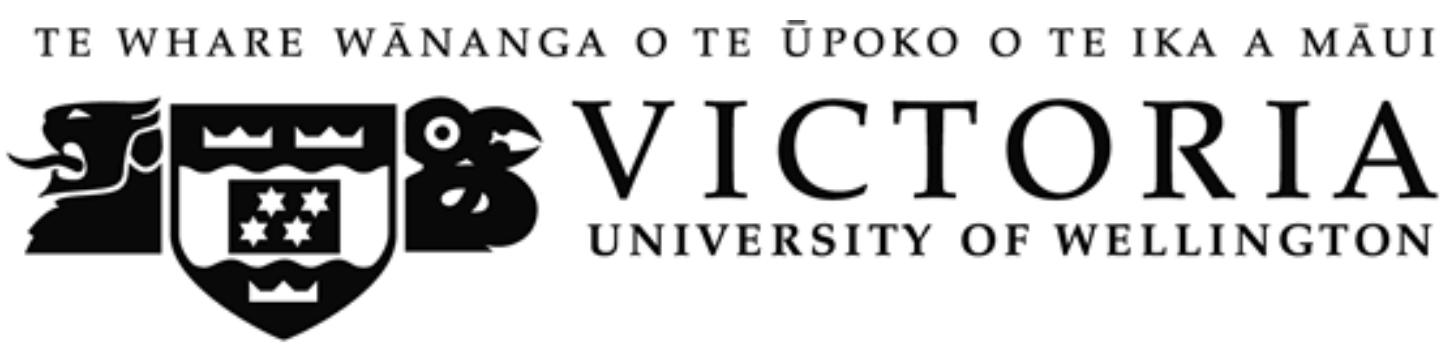

\section{Information Sheet \\ Justice Workers}

Topic: Tino Rangatiratanga for Rangatahi in the Criminal Justice System Who is conducting the research?

- Haimona Waititi is a master's student in the school of Psychology at Victoria University, with Prof. James H. Liu as primary supervisor and Prof. Tony Ward as secondary supervisor. This study has been approved by VUW's human ethics committee.

\section{What is the purpose of this research?}

- The purpose of this study is to gain an understanding about how the Marae Based Youth Court operates. This includes why it was set up, who set it up, how does it work (process), why does it work, who makes it work, etc. This research will serve to inform the current criminal justice system and provided option for discussion amongst Māori communities. This research will identify if an indigenous model and a current system can come together to form a more effective system to deal with crime, specifically youth crime.

\section{What is involved if you agree to participate?}

- If you agree to participate, you will be interviewed. The questions asked will include questions about yourself and questions about your experiences with the Marae based Youth court (MBYC). You will also be asked your opinions about justice in relation two Māori youth and related concepts. Sample questions might be "What is your role in the MBYC?", or "How does the Marae setting impact on the young person?"

- With your permission, the interview will be audio-taped and be transcribed later on. 
- The interview will take no more than two hours. You are free to withdraw at any point up until the completion of the interview, and the data pertaining to you will not be included in the transcriptions.

\section{Privacy and Confidentiality}

- During transcriptions, we will replace your name and pertinent details by codes so that no data will be directly traceable to you. Hence, you will not be directly identified. Only my supervisors and members of the research team will have direct access to data collected. As requirements by some scientific journals and organisations, your coded data may be shared with other competent professionals. No identifying information will be displayed. Your recordings will be wiped when the research is completed.

\section{What happens to the information that you provide?}

- Together with other data, the results of this research will be a part of my thesis. Overall results of this research may also be published in scientific journals, be presented at scientific conferences, and/or brought back to the community.

\section{Feedback}

Results of this study will be available by approximately 10 September 2010 . You can indicate your email address or postal address, if you want us to notify you regarding the availability of the results or the presentation materials. A copy of the report will be available to you for comment if you are interested in providing some input.

If you have any further questions regarding this study, please contact me at waitithone@myvuw.ac.nz, postal address: School of Psychology, Victoria University. PO Box 600, Wellington, or my supervisors at: james.liu@vuw.ac.nz or tony.ward@vuw.ac.nz (phone: 04-463-6789)

Thank you for your participation.

Sincerely yours,

Haimona Waititi 


\section{TE WHARE WĀNANGA O TE ŪPOKO O TE IKA A MĀUI}

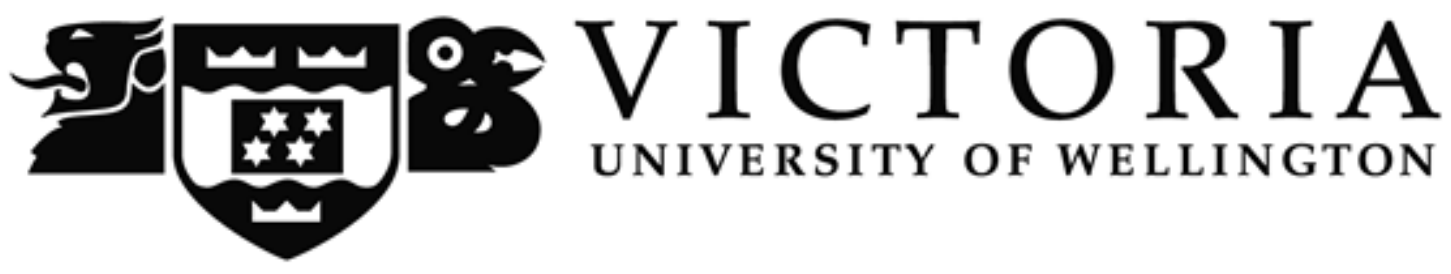

\section{Information Sheet for Kaumātua}

Topic: Tino Rangatiratanga for Rangatahi in the Criminal Justice System

\section{Who is conducting the research?}

- Haimona Waititi is a master's student in the school of Psychology at Victoria University, with Prof. James H. Liu as primary supervisor and Prof. Tony Ward as secondary supervisor. This study has been approved by VUW's human ethics committee. Haimona is from Te Whānau-a-Apanui and was raised in Te Kaha.

\section{What is the purpose of this research?}

- The purpose of this study is to gain an understanding about how the Marae Based Youth Court operates. This will include identifying its strengths and weaknesses by talking with all those involved and asking them for their ideas and thoughts.

I would put all the findings of this research together so that the youth criminal justice system will be able to improve its services, Iwi and other Māori organisations will be better informed and it will contribute to the idea of an indigenous model and the present system working together to maintain the mana of our rangatahi and the value of choosing other positive pathways.

I will also present the research to the University of Victoria to go towards my M.A. degree.

\section{What is involved if you agree to participate?}

- If you agree to participate, you will be interviewed and your voice will be recorded. The questions asked will include questions about yourself and questions about your experiences with the justice system and the Marae based Youth court (MBYC).

- With your permission, the interview will be audio-taped and be transcribed later on. 
- The interview will take no more than two hours. If you do not want to answer any questions you don't have to and you can pull out at any point of the interview and the data pertaining to you will not be included in the transcriptions.

\section{Privacy and Confidentiality}

- During transcriptions, we will replace your name and pertinent details by codes so that no data will be directly traceable to you. Hence, you will not be directly identified. Only my supervisors and members of the research team will have direct access to data collected. No identifying information will be displayed. The recordings of you will be destroyed on completion of the research.

\section{Parental consent}

- If you're participating child is 16 years or under it is necessary that a parent or caregiver gives consent for that child. All of the privacy and confidentiality conditions that are applied to you are also applied to your child.

\section{What happens to the information that you provide?}

- Parts of your korero is put together with everyone else's korero and the results of the research will be part of my M.A. thesis and it could be published in scientific journals. The paper will also be available to those of you who have taken part in the interviews.

\section{Feedback}

You can indicate your email address or postal address, if you want us to notify you regarding the availability of the results or the presentation materials. A copy of the report will be available to you for comment if you are interested in providing some input.

If you have any further questions regarding this study, please contact me at waitithone@myvuw.ac.nz, postal address: School of Psychology, Victoria University. PO Box 600, Wellington, or my supervisors at: james.liu@vuw.ac.nz or tony.ward@vuw.ac.nz (phone: 04-463-6789)

\section{Thank you for your participation.}

Sincerely yours,

Haimona Waititi 


\section{TE WHARE WĀNANGA O TE ŪPOKO O TE IKA A MĀUI}

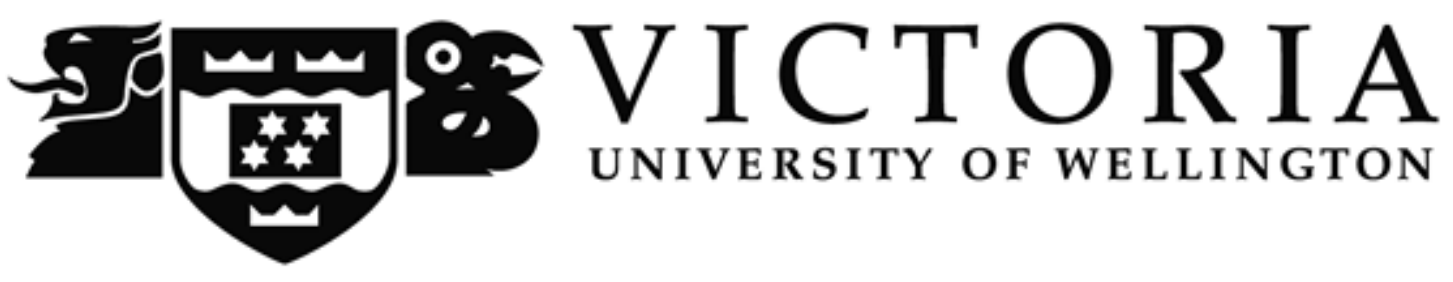

\section{Information Sheet for rangatahi}

\section{Topic: Tino Rangatiratanga for Rangatahi in the Criminal Justice System}

\section{Who is conducting the research?}

- Haimona Waititi is a master's student in the school of Psychology at Victoria University, with Prof. James H. Liu as primary supervisor and Prof. Tony Ward as secondary supervisor. This study has been approved by VUW's human ethics committee. Haimona is from Te Whānau-a-Apanui and was raised in Te Kaha.

What is the purpose of this research?

- I want to find out all about the Marae based Youth court. I want to know what is working well and what is not. I want to know what you think, what your whānau thinks and what the adults who run the court thinks.

- The reasons we want to find out all this is because we want to find a way that will encourage young people not to want to come back before the courts again. We want to find a way that young people who have committed a crime are able to do their "time", maintain their mana and find other ways to share their gifts and talents that will add to our knowledge and help others.

\section{What is involved if you agree to participate?}

- If you agree to participate, you will be interviewed and your voice will be recorded. We will ask you questions. If you don't want to answer a question you don't have to and we can move on to the next one. If you feel uncomfortable you can stop the interview at any time.

- When I go home I will listen to the recordings and will type what you said on my computer. 
- I am not going to write down your real name on the paper. I'm going to give you a 'code' name. This is so no one will know who you are. Your recordings will be destroyed when I finish my research. Only me, my supervisors and my research team will be able to listen to your recordings.

\section{What happens to the information that you provide?}

- Your korero is going to be put together with lots of other peoples stories which I am going to write. A copy will go to the university towards my M.A degree. Parts of the research will go to the youth justice people. Parts to Māori and the iwi of this area. My results can be given to you if you want to see what I have written.

- Results of this study will be available by approximately 10 September 2010. You can indicate your email address or postal address, if you want us to notify you regarding the availability of the results or the presentation materials. A copy of the report will be available to you for comment if you are interested in providing some input.

If you have any further questions regarding this study, please contact me at waitithone@myvuw.ac.nz, postal address: School of Psychology, Victoria University. PO Box 600, Wellington, or my supervisors at: james.liu@ vuw.ac.nz or tony.ward@vuw.ac.nz (phone: 04-463-6789)

\section{Thank you for your participation.}

Sincerely yours,

Haimona Waititi 


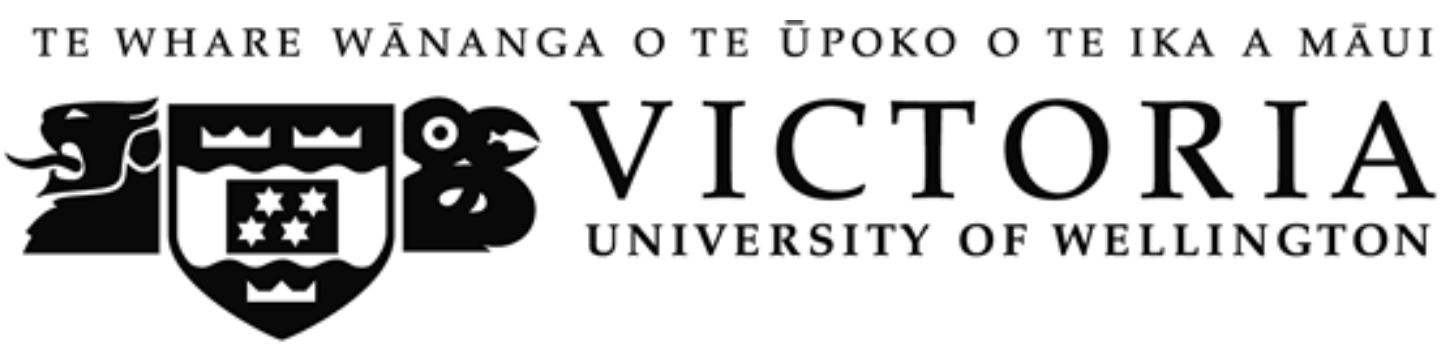

\section{Statement of consent}

I have read the information about this research and any questions I wanted to ask have been answered to my satisfaction.

I agree to participate in this research.

I give my consent to participate in this interview that will be audio-taped and later on transcribed.

I understand that I can withdraw my consent at any time and any information or data I have given will not be included in the research.

Name:

Signature:

Date:

I would like a copy of the summary of the results of this study. YES / NO

(If yes, please indicate email address or postal address below) 
Postal Address:

\section{Copy to:}

[a] participant,

[b] researcher (initial both copies below) 


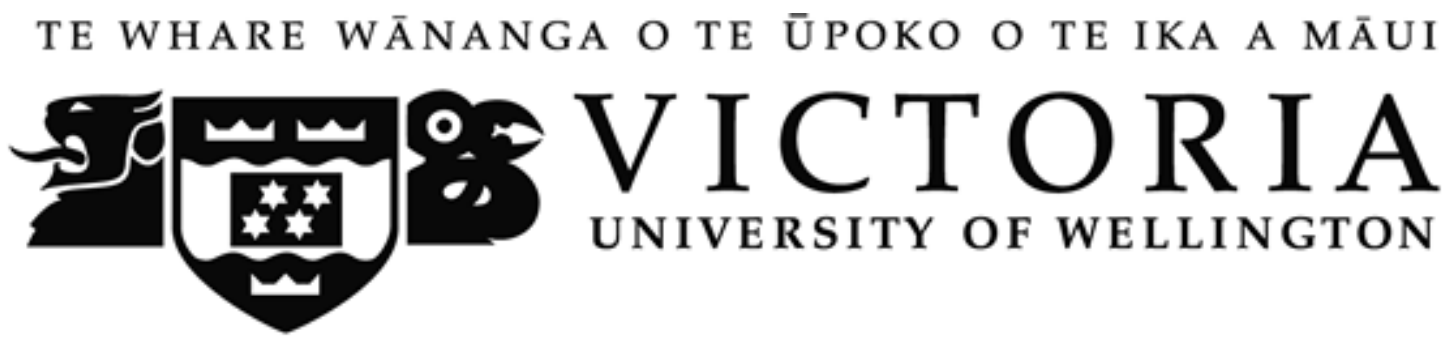

\section{Statement of consent}

I have read the information about this research and any questions I wanted to ask have been answered to my satisfaction.

I (parent/caregiver) give permission for (youth) to participate in this research that will be recorded and transcribed.

I understand that the information given can be withdrawn at anytime during the interview and it will not be included in the research.

Signature (parent/caregiver):

Signature (youth):

Date:

I would like a copy of the summary of the results of this study. YES / NO (If yes, please indicate email address or postal address below) 
Address:

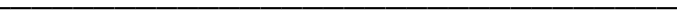

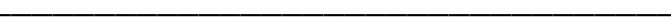




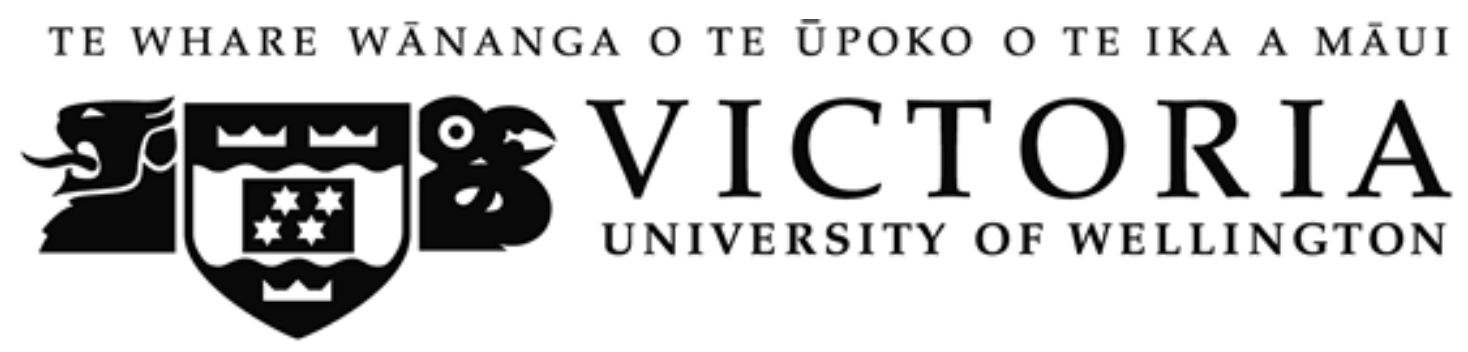

\section{Interview/Focus Group Schedule for Justice Workers}

\section{Topic: Tino Rangatiratanga for Rangatahi in the Criminal Justice System}

\section{Part 1: Introduction to the study (approx. $10 \mathrm{~min}$ )}

Introduction (state objective of the study, procedure of the interview and ground rules, questions from the participant regarding the research)

\section{Part 2: Interview (approx. 60-90min)}

\section{Context (5-10min)}

1. What is your role in the MBYC?

2. How was the MBYC started? Who started it? Why did it start?

3. Were there particular challenges faced in setting up the MBYC?

4. In your opinion, what is the difference between the MBYC and the regular youth court?

\section{Process (15-20min)}

1. How are young people offered the MBYC?

2. How would a young person's experience of the MBYC be different to the regular youth court?

3. How are the needs of the young person determined?

4. Are these needs being met?

5. Are there any process to encourage whānau support?

6. Are victims involved?

7. What role does the Marae play?

8. Are there any changes you would like to see to the process of the MBYC? 
9. What are the challenges with running a youth court on the Marae?

10. How difficult is it working with the different agencies/departments?

\section{Outcomes (15-20min)}

1. What were the outcomes that the MBYC set out to achieve?

2. Do you think that these outcomes are currently being met?

3. What are some examples that have illustrated the success of the MBYC?

4. Are there factors that limit the achievement of outcome?

5. Is the MBYC having an impact on the community?

\section{Tikanga (15-20)}

1. Which concepts of tikanga Māori are working in this programme?

2. How do you prepare young offender s, their whānau or workers, who have been disconnected from their cultural base, for this programme?

3. What challenges are you faced with when running this court on the marae?

4. What feedback have you had from the hapu and iwi of Te Tairawhiti?

\section{Other (20-30min)}

1. How transferable do you think the MBYC is to other communities?

2. What issues need to be addressed before it can be transferred?

3. Are there Gisborne specific aspects that have been critical to the success of the MBYC?

4. Are RJ concepts being consciously incorporated into the MBYC?

5. If so, are they proving affective?

Part 3: Post interview/post discussion (saying thank you, reiterating confidentiality and debriefing) (approx. 10 min) 


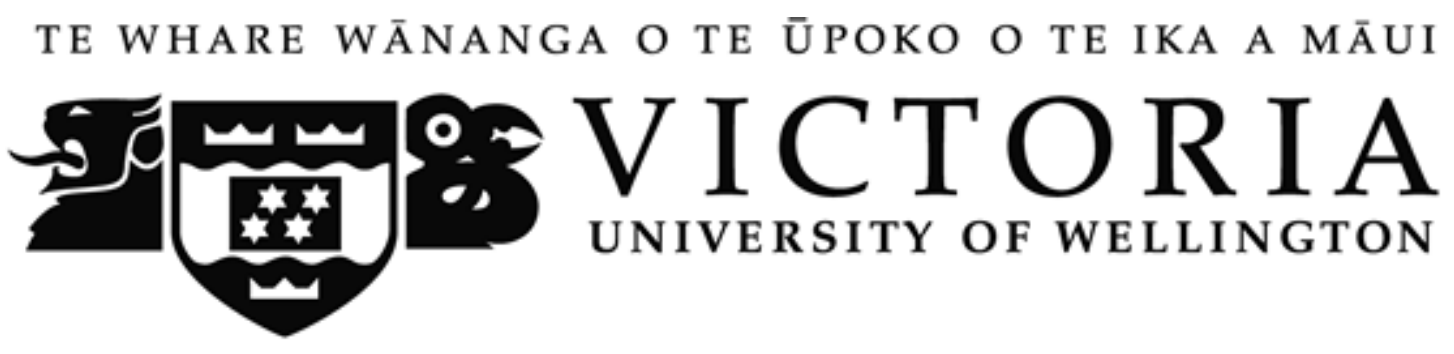

\author{
Interview/Focus Group Schedule
}

\title{
Rangatahi
}

Topic: Tino Rangatiratanga for Rangatahi in the Criminal Justice System

\section{Part 1: Introduction to the study (approx. $10 \mathrm{~min}$ )}

Introduction (state objective of the study, procedure of the interview and ground rules, questions from the participant regarding the research)

Part 2: Interview (approx. 60-90min)

\section{Demographics (3-5min)}

1. What is your age?

2. Do you identify as Māori?

\section{Experiences with the justice system (15-20min)}

5. Is this the first time you have been to a youth court?

6. Have you been to the youth court in town?

7. Did you understand what was happing during the court process?

8. Why did you and your whānau choose to come to the MBYC?

9. Did you want your whānau to come with you?

10. Who has helped you the most getting through this process?

\section{Post court (15-20min)}

11. What kind of punishment did you get? 
12. Do you think it was a fair punishment?

13. Had you been to this marae before?

14. When this is all over do you think you will come back again to other hui on this Marae?

15. When you finish your plan is there anyone who will be around to help you stay out of trouble?

16. What other things need to be happening in your life to keep you out of trouble with the police?

Part 3: Post interview/post discussion (saying thank you, reiterating confidentiality and debriefing) (approx. $10 \mathrm{~min}$ ) 


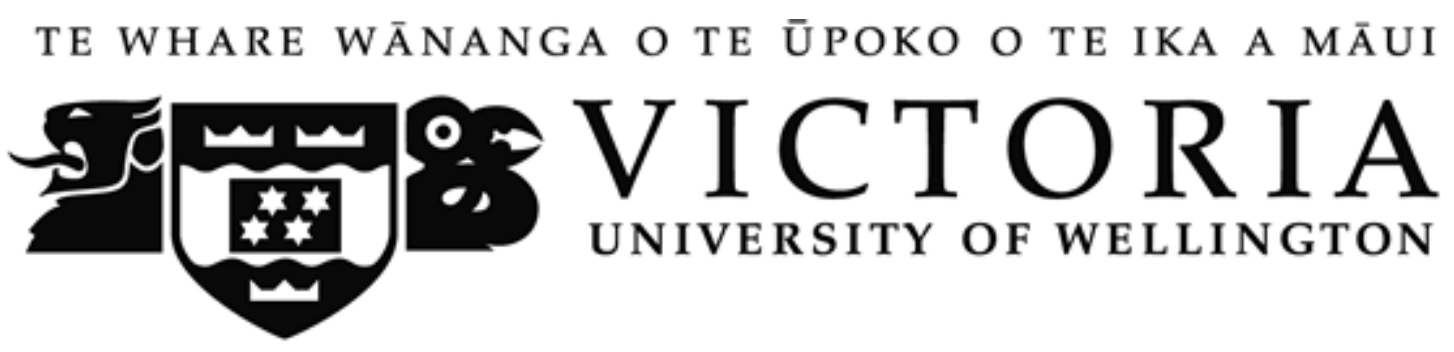

\section{Interview/Focus Group Schedule}

\section{Kaumātua}

Topic: Tino Rangatiratanga for Rangatahi in the Criminal Justice System

Part 1: Introduction to the study (approx. $10 \mathrm{~min}$ )

Introduction (state objective of the study, procedure of the interview and ground rules, questions from the participant regarding the research)

Part 2: Interview (approx. 60-90min)

\section{Demographics (3-5min)}

1. What is your age?

2. Do you identify as Māori?

3. Talk to me about the history of the Marae

Experiences with the justice system (15-20min)

4. What role do you play in the MBYC?

5. How long have you been doing it for?

6. Have you been to the standard you court?

7. What are some of the differences you have seen between the Marae and the town court?

8. What is it about this Marae that makes this work?

9. If you were the boss of this process what would you do to make it work better?

Post court (15-20min) 
10. Do you see any of the rangatahi come back to the Marae after their hearing?

11. What impression do you think the Marae leaves on the rangatahi?

12. What does the future hold for the MBYC and the marae?

13. Do you think other Marae should have courts on them?

14. What kind of impact do you think the MBYC has made on the rangatahi you supported?

15. In your opinion, what other things need to be happening to keep rangatahi out of trouble with the police?

Part 3: Post interview/post discussion (saying thank you, reiterating confidentiality and debriefing) (approx. $10 \mathrm{~min}$ ) 
